Hans-Jörg Albrecht, Maria Walsh,

Elke Wienhausen-Knezevic (eds.)

Desistance Processes Among Young Offenders Following Judicial Interventions 
Schriftenreihe des Max-Planck-Instituts für ausländisches und internationales Strafrecht

\section{Kriminologische Forschungsberichte}

Herausgegeben von Hans-Jörg Albrecht und Günther Kaiser

Band K 182 


\author{
Hans-Jörg Albrecht, \\ Maria Walsh, \\ Elke Wienhausen-Knezevic (eds.)
}

\title{
Desistance Processes Among Young Offenders Following Judicial Interventions
}

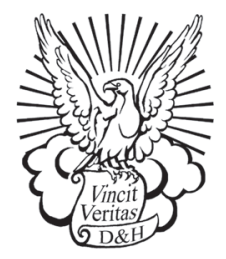

Duncker \& Humblot • Berlin 
Bibliografische Information der Deutschen Nationalbibliothek

Die Deutsche Nationalbibliothek verzeichnet diese Publikation in der Deutschen Nationalbibliografie; detaillierte bibliografische Daten sind im Internet über http://dnb.ddb.de abrufbar.

\section{Alle Rechte vorbehalten}

(C) 2019 Max-Planck-Gesellschaft zur Förderung der Wissenschaften e.V. c/o Max-Planck-Institut für ausländisches und internationales Strafrecht Günterstalstraße 73, 79100 Freiburg i.Br.

$$
\text { www.mpicc.de }
$$

Dieses Werk ist lizenziert unter einer CC-Lizenz by-nc-nd/3.0.

Vertrieb in Gemeinschaft mit Duncker \& Humblot GmbH, Berlin www.duncker-humblot.de Umschlagphoto: iStock.com/Christian Guiton Lektorat und Satz: Peter Welk (Lektorat Freiburg) Druck: Stückle Druck und Verlag, Stückle-Straße 1, 77955 Ettenheim Printed in Germany

https://doi.org/10.30709/978-3-86113-271-4 


\section{Foreword}

In recent years, desistance research has become a key topic in criminological research. Increased attention has been paid to the ways in which one could encounter the mechanisms influencing the exceedingly complex process of establishing a continuously concurrent lifestyle. The mutual theories all seek the bottom of the dynamics that are supposed to be effective during the desistance process. The applied theories reach from social learning over social control to cognitive transformation.

Every theoretical approach provides its own angle and a way of looking at phenomena in this multi-level process. Thus there are a lot of different approaches which can be divided into methodological strategies, in other words into qualitative and quantitative methodological directions. Although both research ideologies can fertilize each other, there still appears to be a large gap between those research lines. How can we overcome these apparently insurmountable differences? While this has already been taken on with research approaches combining quantitative and qualitative methods, it is a big issue in the debate on research methodologies. Our entitlement with the workshop "Desistance Processes among Young Offenders following Judicial Interventions", organized by the Max Planck Institute for Foreign and International Criminal Law in 2016, was to shed light on the different research approaches undertaken in Europe and to learn from each other as well as from different methodologies. The workshop covered three interdisciplinary topics. In each thematic area, experts addressed current issues and set the tone for in-depth discussion. This book refers to the key points and contributions of the workshop.

The first chapter addresses the relationship between structure and desistance, stressing the lack of studies on the macro-level influences on desistance. Stephen Farrall emphasizes that the qualitative nature of desistance studies and the focus on individual countries in desistance research necessitate studies which incorporate both structural and agentic factors. In the second chapter, Joanna Shapland and Anthony Bottoms pay attention to group identity as an essential part of the individual's identity, as well as on friends as one of the keys to desistance from crime. They illustrate their major points by analysing interviews from the Sheffield Desistance Study. Subsequently, Diana Willems and Jana Meier scrutinize findings from a project on criminal careers of young multiple offenders in Germany. As the authors point out, young multiple offenders are often stuck between youth services and the justice system, struggling to meet their own needs for support and the external demands placed on them.

Mechthild Bereswill refers to typical features of imprisonment in the fourth chapter. Focusing on the conflicts of young people, she stresses the operational peculiarities 
of imprisonment in connection with psychosocial dynamics from a biographical research perspective. Elke Wienhausen-Knezevic presents findings from a qualitative study of early transitions towards desistance or recidivism among a group of young formerly incarcerated violent and sexual offenders. In a multi-level process of analyses, interaction effects have been identified which may explain the dynamics of both processes. These interaction effects are subsequently outlined in the different stages of desistance and persistence respectively.

Next, Anke Neuber contributes some methodological thoughts on young women's desistance from crime. She argues that desistance research usually does not consider gender aspects in a suitable way and raises the question of how gender aspects can be addressed in desistance research without mimicking gender variances.

In the following chapter, Franz Zahradnik focuses on the interplay between generativity and desistance. His exploration is based on the experiences of male adolescents by taking a biographical approach to interview analysis. Furthermore, this chapter gives some insight into a unique Swiss sanction for young adults, the so-called Massnahmezentrum. Using two case examples, Maria Walsh examines the influence of possible turning points on desistance from crime in the following chapter. The author takes a biographical approach to the criminal careers of young multiple offenders by focusing on the influence of judicial interventions on desistance and persistence.

Jasmina Arnez presents her sth Spiegel (31.07.2011) perceptions of delinquency and parenting in Great Britain. The Spiegel (31.07.2011) ofessional perceptions of social class are based on family backgrounds. Furthermore, these perceptions and resulting labels might be crucial for delinquency as well as for desistance from crime. Finally, Astrid Hirschelmann introduces a new method to support prison release in France. The Longuenesse Quartier pour peines aménagées is an effort to engage in supporting desistance from crime with professional community work.

We want to take the opportunity to thank the authors for their contributions, patience, and productive collaboration. Furthermore, we thank the editorial office for their meticulousness.

In January 2019

Hans-Jörg Albrecht Maria Walsh Elke Wienhausen-Knezevic 


\section{Contents}

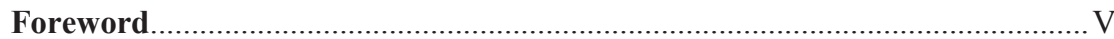

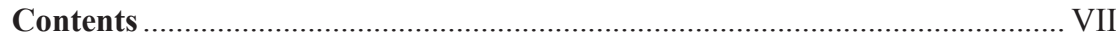

STEPHEN FARRALL

Exploring the Role of 'Structures' in Processes of Desistance ................................. 1

JOANNA SHAPLAND \& ANTHONY BOTTOMS

Disengaging from Peers in the Process of Desistance

DiANA WiLLEMS \& JANA MEIER

Closed Windows for Desistance: Young Multiple Offenders between Youth

Services and the Justice System ..... 51

MECHTHILD BERESWILL

Between Authoritarian Provocations and Promises of Development:

Imprisonment as a Profound Biographical Experience of Conflict 59

ELKE WIENHAUSEN-KNEZEVIC

Life-Course Dynamics among Young Prison Releasees. An Empirical

Interaction Model: The ZARIA Scheme 75

ANKE NEUBER

Fragile Transitions: Methodological Reflections on Young Women's

Processes of Desistance 87

FRANZ ZAHRADNIK

Generative Experiences and the Desire to Become Generative:

A Biographical Approach to the Self-Conceptualizations of a Young Former Delinquent in Switzerland 
MARIA WALSH

The Influence of Possible Turning Points on Desistance from Crime of Young Multiple Offenders: Results of a Qualitative Analysis.....

\section{JASMINA ARNEZ}

Institutional Responses to Youth Deviance and Parenting: Exploring Professional Perceptions on the Role of Social Class at the Beginnings of Offending Pathways and Desistance from Crime

\section{ASTRID HIRSCHELMANN}

Focus on New French Schemes and Methods to Support Prison Release and the Desistance Process

Epilogue 157

\section{Annex}

Index of Authors 159

Programme of the Workshop 163 


\title{
Exploring the Role of 'Structures' in Processes of Desistance
}

\author{
Stephen Farrall
}

\section{Introduction and outline}

In this paper, I will summarise and try to organise what little is known about the ways in which macro-level structures may shape routes out of crime for former offenders. This paper has four sections to it. I will start by reviewing what we know about the relationship between structures and processes of desistance from crime in general. I will conclude that whilst many accept that both agency and structures shape processes of desistance, as a community, we have tended of late to focus on agentic processes (such as choice, decision, motivation, hope, and so on) rather more than on the structural processes. This review is consciously skewed towards a consideration of those studies which have uncovered and explored the ways in which wider social, economic, cultural, or political processes (i.e. structures) can shape individual or cohort life-courses and trajectories away from crime. Following this, I briefly summarise those structural processes which are related to desistance and give an indication of the strength of the evidence base for each. I then briefly outline my own thinking on how we can explore these matters further, first at the theoretical level and second (as a fourth section) in terms of the sorts of studies which we would need to undertake in order to throw further light on this area of research. In some ways then, my paper is a 'call to arms' or a manifesto for a future research agenda on desistance.

\section{What do we know about why people desist from crime? ${ }^{1}$}

Research into desistance from crime has recognised for some time that when people cease offending this is a process, which involves the interplay of agency (decisionmaking, choice, restraint, and so on, Farrall \& Bowling 1999) and wider social, cultural, and economic processes (such as national and local economic conditions criminal justice system 'philosophy'), and opportunities for people to move away from areas where they are 'known', to mention just three such processes (Farrall et al. 2010; Bottoms et al. 2004). Whilst many researchers acknowledge the inevitable

1 Despite my focus here on the structural processes which may be associated with desistance, it is important not to overstate the role of such processes. In any social system, individuals will often remain the greatest source of variability. It is, of course, the individual who decides to give up (Halsey et al. 2016) or to persevere in the face of adversity (Farrall 2005). 
truth in these sentiments, very few have been able to demonstrate how and why these processes operate to facilitate or hinder desistance, as I will show below. This is partly because most studies of desistance have been based on one country and/or jurisdiction (preventing the thorough exploration of macro-level system effects) and have been qualitative in nature, which has tended to focus on the internal dynamics of desistance (Vaughan 2007; Maruna 2001; Gadd \& Farrall 2004; Farrall 2005). Some studies are beginning to emerge which do suggest differences at the country level (Osterman 2015 or Segev's on-going doctoral research), but these tend to be small-scale $\mathrm{PhD}$ projects and are based on two-country comparisons. Other studies (such as Finestone 1967 or, more recently, Calverley 2013) suggest variations in terms of ethnicity (but Finestone's study of New York Poles and Italians is now almost 50 years old, and Calverley's study was of non-white ethnic groups living in London, who may face additional obstacles to desistance).

Several of the more recent very good studies of desistance from crime (such as Maruna 2001; Healy 2010; Hunter 2015; Weaver 2016) have focused on the internal dynamics of desistance from crime. Maruna's goal, for example, was "to identify the common, psychosocial structure underlying ... self-stories [of desistance], and therefore to outline a phenomenology of desistance" (2001, p. 8). He described his work as being a "supplement" $(2001$, p. 8 ) to research examining the structural correlates of desistance, such as the work of Sampson and Laub. Maruna argued that in order "to desist from crime, ex-offenders need to develop a coherent, pro-social identity for themselves" (2001, p. 7) which they can use to explain to both themselves and other people how their past lives have contributed to their 'new' identities. Maruna refers to this narrative device as a redemption script. In a similar vein, Hunter (2015) used insights from existentialism to explore and elucidate the processes by which former 'white-collar' offenders try to make sense of their lives as they move on from conviction and imprisonment. Hunter's work brings to the fore the roles of values and beliefs, feelings and emotions, and the developing sense of self and search for meaning which, to varying degrees, we all must confront. Such studies, of course, are not alone in charting the 'inner-world' of desistance, for the likes of Peggy Giordano et al. (2002), Barry Vaughan (2007), David Gadd (Gadd \& Farrall 2004; Gadd 2006), as well as Ray Paternoster and Shawn Bushway (2009) have forced desistance theorists to think about hope, shifts in awareness, fears for the future, dedication, the 'self as a project', and choice. All of these studies, as ground-breaking, significant, and welcome as they are, tend to foreground 'the agent', 'agency' or 'agentic processes' in one way or another, and in so doing have, all for very good reasons, tended to 'hold constant' the issue of structural variation in processes of desistance (see also Farrall \& Bowling 1999).

As such, in recent years, the developments which we have witnessed in our understanding of why people stop offending have mainly been focused on what may be termed 'internal' processes. In part, this is to be expected; many of the landmark studies of desistance from crime in the modern era (namely, Gottfredson \& Hirschi 
1990; Sampson \& Laub 1993; Moffitt 1993; and, to a lesser extent, Graham \& Bowling 1995) tended to emphasise social structural variables and downplayed or (completely) ignored such internal processes. The flip side of this swing back towards uncovering the internal dynamics of desistance is that we may be neglecting the role played by larger social forces. Of course, what is needed are studies which attempt to build explanations which can incorporate both of these frameworks within one account - an issue I shall return to later. Having said that, many of the studies which I will rely on to demonstrate that wider structures can influence and shape desistance have been based on qualitative research designs. Below, I review some of what we know based on the few studies which, I feel, tell us something really key about desistance and structures.

\subsection{Studies which illuminate the role(s) of structures in processes of desistance}

The first publication I wish to refer to (Barclay 1990) relates to the peak age of offending and the last year of compulsory schooling in England and Wales. Barclay reports that the peak age of conviction in England and Wales used to follow a fairly simple rule; it was the age of children when their compulsory education ended minus one. So when compulsory schooling in England and Wales ended at age 14, the peak age was 13; when the age at which one could leave school was raised to 15, the peak age of conviction rose to 14. As successive generations of young people in England and Wales started to remain in the education system (studying at sixth form colleges, for example), the peak age of conviction rose and its relationship with compulsory education started to break down. What is one to take from this? First of all, if the peak age of conviction is used as a proxy measure of the start of cohort-wide processes of desistance, then it would appear that such processes are malleable by changes in social policies. Second, it could be argued that the retention of young people in education is part of a wider process by which the transition to adulthood has been lengthened in many post-industrial nations. As such, delayed ages of marriage, home-leaving, employment and the like impede the transition from dependence on parents and/or peer-group cohabitation, which may also lengthen the age at which young people are likely to become embroiled in crime and offending (Farrall et al. 2010).

Another examination which suggested that changes in social and economic structures may have an impact on the processes associated with desistance from crime is that by Farrall et al. (2010). This review explored how the macro-level changes experienced by the UK between the early 1980s and the year 2000 may have affected the abilities of people caught up in crime to make this transition 'towards the mainstream'. The authors point to the significant changes in economy (in common with several other European countries). In terms of the employment available, there has been a significant decrease in those employed in manufacturing and mining, and a 
dramatic increase in those working in banking, finance, and insurance, and in distribution, hotels, and restaurants (Farrall et al. 2010, p. 554). As such, the jobs which are predominantly available require graduate-level skills and are usually not the ones, which those with few (or no) formal skills are able to gain easily. Thus, exactly the type of employment which in the past assisted many men in making the move away from crime (manual labour) has largely disappeared, to be replaced either by posts which require formal qualifications or by lower-status white-collar jobs which, in the UK, have often had the image of 'feminised' work (and therefore might be culturally difficult for young males to consider). In addition, there has been an increasing tendency for employers to ask prospective employees to undergo criminal record checks, demonstrating no previous convictions; obviously, this potentially creates difficulties for offenders wishing to desist.

Farrall et al. (2010) also discuss those shifts in the operation of the criminal justice system. A key shift has been the increasingly punitive approaches taken to offenders. This has focused especially on violent and sexual offenders, and on repeat offenders. Its most obvious manifestation is the massive growth in the size of the prison population, which in England and Wales has risen from 49,500 in January 1995 to 82,100 in January 2009, a cumulative growth rate of 3.8\% per annum. (By contrast, in the period $1945-1995$, the average growth rate was $2.5 \%$ per annum). The recent rapid population increase results from both an increase in the courts' use of imprisonment and from a lengthening of the average prison sentences imposed. Other features of the increasing punitiveness of recent criminal justice policy include the 'tightening up' of prison regimes in various ways, and a general tendency to make community sentences more onerous. The net effect of these developments has been subtly to redefine the relationship between the offender and the state. Increasingly, the "penalty box' analogy has been eroded. In the view of the classical jurists, during a period of punishment, the state suspended various rights of the punished citizen; but on completion of the punishment, the citizen resumed those rights. More and more, however, such a view is being replaced by an ideology in which the individual being punished becomes a sort of 'non-citizen' or 'other' who is permitted to return to civil society only grudgingly or not at all.

Not unrelated to the above, the period since the mid-1970s has seen changes in the way that the concept of the rehabilitation of offenders has been understood and developed. This concept was, in the early post-war period, a cornerstone of the criminal justice system, and at that time, the welfare of offenders was usually considered to be integral to rehabilitation. That version of 'the rehabilitative ideal' was dealt a severe blow by a series of research overviews (Martinson 1974) and controlled experiments (Folkard et al. 1974; 1976) which resulted in a marked diminution of confidence in rehabilitative approaches. Among the many consequences of these events, the training of probation officers in England and Wales has been drastically reshaped so that it is no longer associated with social work training (Raynor 1996, p. 17). 'Rehabilitation', however, has not died; instead, since the 1990s, it has been reborn 
in the so-called 'What Works?' agenda, where the primary theoretical focus has been on cognitive-behavioural treatment approaches, centred upon the modification of offending behaviour and the development of improved 'thinking skills'.

Kemshall (2003) has linked the rise of interest in risk with the demise of the 'modernist' welfare-oriented penal agenda. The rise of the risk agenda means that there is increasing pressure to apply 'risk assessment' tools (for example the Offending Group Reconviction Scale) to guide key decisions. The rise of the risk management style of thinking in the probation service has been charted by Gwen Robinson (2002) who notes that approaches to risk management are not "imbued with a sense of transformative or rehabilitative optimism" (p. 10). In an era dominated by concerns with protection of the public, risk assessments can lead to a risk-aversive mind-set on the part of officials, and consequently to defensive or precautionary actions (such as refusing bail or parole). Perhaps the most worrying of outcomes arising from the "risk agenda' results from the trend towards categorising people on the basis of their level of risk, and assuming that these categorisations remain valid or invariable in the next few years. This is particularly true for late adolescence and the early twenties, when there can be major changes in lifestyle and social contexts. By categorising an individual as being 'high risk', one sends various messages. The first of these is sent to the offender. The communication to an individual that they are at 'high risk' of reoffending is equivalent to saying to them 'You can't change'. In some cases, this may motivate the individual to prove the system wrong, but in many cases, given the obstacles to desistance such individuals may already face (lack of qualifications, lack of employment record, etc.), this message may lead to a fatalistic outlook (Halsey et al. 2016).

There are very few cross-national studies of desistance from crime. One study which did explore desistance in two countries is that by Linnéa Osterman (2017). Osterman studied females in the criminal justice systems in Sweden and England, interviewing twelve women in each country who had identified themselves as desisting. Osterman's study contributes to the much-needed internationalisation of criminological knowledge about gender, offending careers, desistance, and crime through an analysis of these female ex-offenders' experiences of crime and criminal justice. Osterman focused on pathways into crime, the gendered experiences of criminal justice, and (of most interest in this context) desistance from crime. Of course, some cross-national symmetry is detected between the two countries (both are European countries with high levels of human development and gender equality). However, Osterman finds that the differing 'inclusive' and 'exclusive' penal cultures shaped the women's desistance. As such, these 'macro-level' cultures 'trickle down' and help produce different female experiences of criminal justice and desistance in Sweden and England. Osterman argues that the Swedish criminal justice system offers a context (supported by a strong welfare state) in which routes out of crime are easier, shorter, and less burdensome, meaning that former inmates are more effectively able to play a full and active part in mainstream society. Osterman puts the differences down to the 
following features of the Swedish criminal justice system when compared to that in England and Wales: (1) a more robust infrastructure which is able to support individual change (for example, Sweden has a higher-quality drugs and alcohol provision than is the case in England and Wales); (2) less conflictual relations between the prisoners navigating the criminal justice system and the authorities (which increased feelings of legitimacy and trust in individual-level criminal justice interactions, encouraging desistance); (3) the adoption and commitment to what Osterman refers to as 'normalisation ideals' and practices associated with this within the criminal justice system, which enabled smoother transitions away from the criminal justice system; finally (4), she pointed to more accessible and attractive routes into participation and inclusion in wider society, including structured and well-resourced investments in employment support.

A study which is in many ways similar to that undertaken by Osterman, is that nearing completion and undertaken by Dana Segev. Segev has interviewed 30 male probationers who are making good progress towards desistance in England and Israel, comparing their routes away from crime. What is certainly true is that whilst Israel and England share a very similar criminal code (the Israelis simply adopted most of the English criminal justice system's apparatus after Palestine ceased to exist in 1948), it appears that the ways in which the two criminal justice systems operate are very different. In Israel, only people with training in social work can legally work with offenders (in either prisons or the community). So the Israeli criminal justice system adopts a rather different approach to the English and Welsh prison system, in that the Israeli system is more focused on therapy. In addition, intra-psychic approaches are more commonly adopted in the Israeli criminal justice system than is the case in England. The ways in which the two countries' court systems operate are different, too; the English court system may delay sentencing for a couple of weeks in order for a pre-sentence report to be undertaken, but will typically sentence those found guilty within a matter of weeks at the very most. In Israel, it is not uncommon for the court system to defer sentencing to assess the progress an individual is making for many months, sometimes well over a year. In this case, the Israeli criminal justice system 'hangs over' individuals, delaying sentencing in a way in which the English system does not. Of course, the impact of this is hard to fully assess, but it may account for the older peak age of conviction in Israel (which is 34 years).

Another, absolutely fascinating study which has recently been undertaken is that by Carolina Villagra. Her study (2016) is of desistance in Chile, which in itself makes it a fascinating study, since there have been so few studies of desistance in Southern America. Villagra finds a number of different groups of desisters amongst the 62 people whom she interviewed. Of these, there was a large group which she called 'traditional desisters' because their desistance revolved around family formation, gaining work, and engagement in their local communities. However, she also found a small group of men who had been sentenced in the late 1980s under the 1973-1990 dictatorship (which she termed 'the stolen generation'). At this point in time, the 
criminal justice system in Chile was highly inquisitorial, human rights were not widely upheld; there was disproportionate use of pre-trial detention, low standards of protection for defendants, an absence of accountability, and the sentences handed out were very severe. The stolen generation desisters had all been sentenced for very long periods of time for relatively minor offences such as robbery when they were quite young men. They did not receive any form of supervision upon release from prison. Villagra observes that:

... all the Stolen Youth's accounts of prison life there were episodes of extreme violence, rape, conspiracy, threats, and so on. It was not fully clear whether they were victims or perpetrators, suggesting their masculinity and identity-building in prisons were shaped by strategies of self-defence and power relationships (Villagra 2016, p. 198).

She goes on to report the following:

The inhumane prison conditions and the extensive use of solitary confinement seem to have had a great impact on most of the Stolen Youth who spent even months in isolation for disciplinary purposes. Antonio recalled eating on the floor and next to the place for defecating, Octavio resented the minimal opportunities for interaction with others, and all of them had painful memories of physical and psychological abuse that deeply undermined their sense of control and self-worth, echoing research on solitary confinement that has demonstrated that psychological consequences can be devastating, even in the long term (Villagra 2016, p. 195).

Given their experiences, the age of the commencement of these experiences and the duration for which these lasted, it ought to come as no surprise that these men experienced quite pronounced problems resettling into the community after release (see also the work of Adrian Grounds on the release of the wrongfully convicted, 2005), who displayed an

... astonishment [at] the changes in the city and in society, reiterating expressions such as 'new world', 'new life' or 'being born again'. They strived for understanding and adapting into a society that was radically different to the one they knew, and whose social rules they barely remembered (Villagra 2016, p. 206).

As such, Villagra finds evidence that these men's offending careers were influenced by Chilean dictatorship which brutalised the criminal justice system in such a way as to alter their life courses. Villagra's study suggests per se that political regimes may influence processes away from crime.

There have been very few studies on desistance from crime which have explored matters from an historical perspective. Such studies have a great potential to throw light on the ways in which different structures influence desistance, since - if the eras studied are carefully selected - such studies allow one to compare the influences of changes in the criminal justice system, social, cultural, or economic processes. 
Godfrey et al. (2007) was one such study, however. They studied the criminal histories and careers of offenders in one small town (Crewe, Cheshire) in England from 1880 to 1940. During this period, England went from being the 'workshop of the world', empire nation, to engagement in the $1^{\text {st }}$ World War and the social upheavals and changes which went with this. Whilst they found an employment effect (in keeping with many studies of around that era, such as Sampson \& Laub's (1993) study), they did not find a 'marriage effect'. Why might they have not found a marriage effect?

As many historical studies have shown (D’Cruze 1998; Hammerton 1992), many Victorian and Edwardian marriages involved tension, violence, distrust, and dislike, rather than romantic love. Marriage in the period since the 1950s (with the increased emphasis upon romantic love) may act as a mechanism for reforming men who wish to please or win approval from their spouses. However, in the period studied by Godfrey et al., economic need played a more important role in relationship formation. As such, wives' ability to control or influence the behaviour of their husbands may have been severely weakened. Many working-class women in the period up to the $1950 \mathrm{~s}$ and 1960s were in a very weak position in society. Almost none of them had access to independent sources of income for very long periods of their lives, few had a livelihood outside of marriage; those who refrained from marriage were often dealt with suspicion, and none had the vote. When they became pregnant, women were expected to stop work and were not expected to return for many years. Families of that era were also much larger than is the case now (with families of five or more children not uncommon). It was not until 1918 that women were given the vote in the UK (and then only if they were aged over 30 years). Until the $1880 \mathrm{~s}$, women did not have the right to own property or wages and could be imprisoned for refusing sexual intercourse (Smith 1989, p. 19). Women saw their employment downgraded as a result of the industrial revolution, were prevented from working by trade unions and excluded from work more generally, saw their trades 'feminised' into low-skill, lowprestige jobs, and found themselves at the bottom of the class/gender hierarchy, coping with a culture of female subordination to males (Valenze 1995; Clark 1997; Rose 1992; Lewis 1988; Smith 1989; and Ross 1992). This position continued until the 1970 s, and even at the time of writing, women are often paid less than their male counterparts. The town studied, Crewe, was no different in this respect: although in the 1881 Census, rates of employment of females aged 15-74 outside of the house were quite high at 22 per cent (Drummond 1995, p. 28), this figure dropped to about eight per cent for women aged 25-59 (and who could be reasonably expected to be wives, mothers, and unpaid housekeepers).

During periods in which gender inequalities are less pronounced than they were in the late $19^{\text {th }}$ and early $20^{\text {th }}$ centuries, females may be able to exert (willingly or otherwise) a greater degree of 'control' over their men-folk (be these husbands, brothers, fathers, or sons). Although accounts of the UK's suffrage movement have portrayed it as essentially middle class, there is good evidence to suggest that a strong working- 
class suffrage movement also existed, especially in the north of England (Smith 1989, p. 351). Hence the marriage-desistance nexus may be as much an artefact of historical shifts in inequalities that take decades to emerge as it is about romantic love. The central argument put forward by Godfrey et al. (2007) is that emancipation (by which they mean the right to vote, increased employment rights, greater levels of education, and so on) sends a cultural-political signal about who has a legitimate voice in society and who ought to be listened to. In short, the extension of the vote is communicative; and it communicates who wider society views as having a legitimate voice. As such, female emancipation increased the power of women's voices and as such their ability (wittingly or unwittingly) to influence others, including their husbands, brothers, and sons. This suggests to us that an understanding of the role played by social institutions in the production of desistance needs to understand how those institutions are shaped by political, historical, and cultural contexts which unfold over time. Other studies, this time from the Netherlands (Bersani et al. 2009; Beijers et al. 2012), also suggest that marriage effects are stronger for those men who entered them between 1971 and 2009 than was the case for those marrying between 1930 and 1970. Beijers et al. attribute this to changes in Dutch society after the 1960s, including an improvement in the economy, changes in divorce legislation in 1971, females being given ownership rights over property, and an extension of social security to divorced in 1965, non-working females (meaning that they were no longer dependent on their former husbands), increasing educational attainment amongst females and changes in cultural norms as to what constituted a 'good marriage' (2012, p. 429).

One way of exploring the role which wider social, economic, and cultural structures may have on processes of desistance is to explore these experiences for different ethnic minority groups. The basic premise is that ethnic identity indexes social-structural position. It assumes that many members of a minority ethnic group share certain things, such as belief systems (religious faith, for example), cultural institutions (the nature of preparations for weddings, for example), levels and types of economic activities (for example, if economically active, and if so, as an employee or an employer, and if working in a large organisation or a small firm), and so on. This is exactly the approach taken by Adam Calverley (2013).

From his studies, Calverley reports that on the whole, the 'age-old' ingredients of employment, family formation, and motivations and hopes for a better future are still present in the accounts he elicited. However, the extent to which these resonated in the lives of the members of the different minority groups he interviewed varied. Calverley demonstrated that the different cultural norms, values, and structural locations of three of the UK's largest ethnic minorities (namely Black Britons, British Indians and British Bangladeshis) shape the routes away from crime for members of these communities. He found, for example, that many Black British (but not Bangladeshi or Indian) desisters felt that the only way to respond to situations in which they might meet old acquaintances (and be tempted into re-offending) was to isolate themselves physically and socially. This they did by spending time alone or at the gym. For 
British Indian men in his sample, religion placed little importance in terms of a set of values or motivations for desistance, but Indian weddings did provide an opportunity for would-be desisters to find employment via extended family networks. However, religion was much, much more important for the British Bangladeshis.

As Calverley (2013) notes, the Bangladeshi community in the UK is poorly situated with regard to access to employment, school achievement, housing, and many other indicators of general social well-being. Despite this generally poor outlook, the men Calverley interviewed for his study were still able to make the break away from involvement in crime. This was in large parts due to the roles played by their families - the vast majority of which were intact - and the development of a series of joint projects between the families and their troubled sons. Rather than socially shunning their sons (as had been the case with the British Indian sample members), Bangladeshi families appeared to re-embrace them, taking every opportunity to support them whilst they were in prison, as well as after their release. Although research into the relationship between desistance and religiosity is still embryonic, the sensible money (for the time being, at any rate) is going with the idea that religiosity supports desistance as it brings about a change in social circles with an additional set of values which, for the most part, are incompatible with offending. Calverley's respondents certainly suggest that these processes were in operation when they desisted, but unlike other accounts of religious conversion (or re-awakening) which one encounters in the desistance literature and which have been largely concerned with Christianity - the sentiments expressed by the men Calverley interviewed feel as if they go much 'deeper' into their 'souls'. As such, Islam provided a strong religious code for the would-be desisters and the goal of being 'a good Muslim'. This begs the question: are some religions better placed than others to assist in those sorts of personal, interpersonal, and social processes associated with desistance?

The variance in the styles and nature of desistance between the groups Calverley studied was not haphazard. Via a detailed examination of the socio-structural 'location' of these minority groups and key aspects of their cultural and religious belief systems, he was able to show that these factors shaped and moulded the nature of desistance from crime experienced by each of these groups. In many respects then and certainly by my reading of his work, Calverley's study contributes greatly to our understanding of the ways that structural and cultural factors can affect processes associated with desistance from crime.

\subsection{Offending careers as 'structures'?}

To talk of offending careers as representing a form of structuring itself may seem a little odd. 'Structures', after all, are macro-level processes relating to the economy, social systems, prison systems, and so on. However, if one takes seriously the idea that a person's past life (that is, the jobs they have held, the roles in life they have taken on, where they have lived, and what they have done) in some way shapes what 
one can do in the future, then past offending careers do indeed shape future lives. As a simple example, a person who has spent several years injecting heroin, stealing to pay for their habit, is well-known to the local law enforcement agencies and who has spent several years in prison is likely, in all probability, to have a different style of desistance from someone who has had a shorter offending career and who's offending has been limited to drinking heavily, using recreational 'party' drugs, fighting with people in pubs and in nightclubs and who has had little or no contact with local law enforcement. Let me quickly outline some of the differences in these two offending careers:

- Injecting drug users: a professional ex-role exists in many societies (the former user who now works as a drugs counsellor); they may have had longer careers (addiction being harder to leave behind); in all likelihood, they will have had greater contact with the criminal justice system and, as such, have spent more time in prison and appear less attractive to possible employers; they may also have done more damage to their physical self (in the form of scarring or amputation following limb infection); and their personal reputations may be more deeply and more thoroughly stained.

- Drinking and fighting: although this is becoming less the case, there are some communities in which being known as someone who can 'take a drink' and/or be 'a fighter' is seen as socially acceptable; unless they have an alcohol addiction, there is no clear professional ex-role for such offenders; these may have started at an earlier age and may accordingly cease offending earlier, too (which may mean that their offending is socially constructed as 'youthful indiscretions' rather than fully-formed 'criminal careers'); they may also have had less contact with the criminal justice system; in some cases, the drinking and fighting may serve to reinforce masculine identities.

In our review of the theories used to account for desistance (Farrall et al. 2014), my colleagues and I highlighted how different researchers have emphasised different features in their accounts of how and why people change. For example, Sampson and Laub pointed to social and economic processes such as marriage and employment, whilst others (including Maruna, Giordano and colleagues, Vaughan, and Paternoster and Brame) have emphasised the experiential dimensions of desistance (what people want and how offending feels to them). Accordingly, the image of the desister invoked by each author team varies considerably. Sampson and Laub, for example, present an image of troubled youths who are 'conventionally deviant' and whose conventionality also characterises their processes of reform, which include employment, marriage, and 'growing up'. Contrast this with Maruna's (2001) image of the ex-offender; a person with an extensive drug-injecting career living in a city which was severely economically disadvantaged. Giordano et al. (2002) provide a different image again; ex-institutional (state correctional facility) delinquent girls and boys 
with experiences of abuse; whilst Shover (1983) sampled older, male acquisitive offenders who have spent considerable periods of their lives involved with street life and/or in prison. Graham and Bowling's (1995) British school-based study emphasised processes similar to those reported by Sampson and Laub: employment, childrearing, and maturation were central in the desistance process.

As such, the debates about how and why people cease offending are, essentially, debates about different styles of desistance precipitated by different offending trajectories (which themselves are played out in diverse social, economic, geographic, and historical contexts, of course). Theoretical divergence or disagreements, coupled with a reluctance to recognise that there may be multiple routes away from crime, often reflect these contingencies. From our perspective, many different theoretical accounts are right in some instances and for some people. As soon as we acknowledge that a single theoretical model of desistance cannot possibly account for desisters' experiences, one is able to see that numerous theoretical models (to varying degrees) are 'correct'.

When first interviewed, the 199 men and women in the sample I have followed (Farrall 2002) appeared to be rather heterogenic, both personally and in terms of their offending careers. However, during the years in which they were re-interviewed, they started to coalesce into distinct and identifiable pathways of desistance. Most attempts to identify groups of offenders have focussed on the frequency, timing, or nature of offending. For example, Moffitt tried to identify groups of offenders on the basis of time of onset and duration. The goal my colleagues and I set ourselves was slightly different; rather than trying to identify types of offending careers, we tried to identify styles of desistance based on the sorts of offences each group predominantly committed. To some extent, these map onto existing theories of interest to those studying desistance - most notably those advocated by Sampson and Laub, Maruna, and Moffitt (although only with regard to her theorising about adolescent limited offenders). Other theories enter our taxonomy in places (e.g. Gadd on street offenders' investments in stereotypical male 'bread-winner' roles). Similarly, Matza's work appears to apply to those people with limited offending careers. Hints of the themes associated with 'fearing' one's future self and the 'internal conversation' (Paternoster \& Brame 2009; Vaughan 2007) did emerge for desisting drug users, who appeared to become anxious about what the future held for them and started to ruminate on this. Our interviews with desisting drug users also suggested that whilst they did (eventually) spot 'hooks for change' (Giordano et al. 2002), this often happened after they had actually ceased offending and was related to maintaining desistance rather than initiating it. What this suggests is that no single theory of desistance can ever account for all of the possible routes through and away from crime. In short, this observation reinforces the need to develop theories which are sufficiently flexible and broad as to allow for heterogeneity, and which allow as many influences as possible for some role in the processes being described, it does other things, too. First of all, it deters us from entering into 'beauty parades' in which 
different theories are compared against each other in order to see which one 'wins' (an example of this approach is that adopted by Ezell \& Cohen 2005). This in turn encourages us to strive for theoretical triangulation, taking those elements of existing theories which are most useful. However - and key in this context -, it reminds us that some existing theories may work well with some groups of former offenders, but less well with others - in other words, why people cease offending and the processes (both internal and external to them) may be shaped by the nature of the criminal career they have engaged in previously.

Turning now to the specifics of processes of desistance as explored empirically, I wish to draw a comparison between a study of former life-sentence prisoners undertaken by my colleague Catherine Appleton (2010) and my own studies of probationers. Unlike the initial sweeps of data from my own studies (Farrall 2002) - during which probationers suggested that they wanted practical help rather than 'talking therapies' -, Appleton (2010, pp. 111-112) found that most of the former inmates in her sample did not expect probation officers to "provide direct practical intervention" (2010, p. 112) and valued "being listened to" (2010, p. 113). It must be remembered, of course, that Appleton's sample of released lifers is made up of much more serious offenders (see Appleton 2010, pp. 62-68 and Farrall 2002, pp. 49-52). Almost half of Appleton's sample was sentenced for homicide, whilst only $10 \%$ of the cohort I followed was on probation for acts of violence. Appleton's sample - being by all accounts 'tougher' and 'meaner' than mine and with greater experience of the criminal justice system - may have become more self-reliant, needing less practical help. Having committed far more serious offences, they may also have been in more need of someone to talk to about what had happened both during the offence and leading up to it. In this way, the offences committed shape the nature of the process of desistance; and it is this observation to which I am referring when I argue that offending careers structure processes of desistance.

\section{Which forces may structure desistance from crime?}

Let me now summarise the key points from the above discussion:

Gender: Despite some of the excellent studies which have been undertaken, I am still unsure exactly of the role in the processes of desistance played by gender. Some studies have suggested that the same process may operate for men and women as they desist, but for different reasons or in different ways. For example, 'back to work' programmes may provide women with a supportive social network, but may equip men with resources to find a job. As such, the input is responded to and used differently by different social groups. Similarly, it may be that any observed differences between females and males are due to the fact that females tend to mature earlier than males (a point suggested by Graham \& Bowling 1995). A recent review of the literature in 
this area suggested little difference between men and women (see Rodermond et al. 2016). I remain genuinely uncertain of the degree to which the processes of desistance differ for males and females, and suspect that there are key interactions (for example drug-injecting careers) which may obliterate (or reduce) gender differences (that is to say that I suspect that leaving behind an offending career in which injecting drug use has been a big element is in many ways similar for men and for women).

Ethnicity: On the basis of the very few studies which have been undertaken, I would have to conclude that in all likelihood, ethnicity does shape processes of desistance. We must be careful not to simply reduce such processes to ethnic identity, however. Being a Pakistani male living in France is not going to be the same as being a Pakistani male living in Pakistan; so this is not simply about ethnicity. Rather it is about (given the empirical studies we have at hand) being a member of a minority ethnic group in a large (and largely 'white') culture. Very few members of ethnic minority groups in Westernised societies occupy positions of power. Many ethnic minority groups reside in the poorest sections of our towns and cities and have amongst the lowest levels of education success and employment. As such, ethnic status indexes the socio-economic structural position of some groups. However, a focus on ethnicity also opens our eyes to cultural belief systems, differing family structures (for example) and religious practices, all of which may help to shape processes of desistance (for good or bad). Looking to the future, what will be interesting will be the effects of multiple ethnic identities for those born to (for example) a 'white' mother and a Pakistani father. How will this 'blending' of ethnic identities influence criminal careers and processes of desistance?

Age: Given the now famous idea of the 'age-crime curve', age would appear to be chronically implicated in the processes associated with desistance. However, given the changes in the peak age of conviction in England and Wales (see Barclay 1990 above), this relationship appears to be one with some degree of fluidity to it. This suggests to me that the social meaning of age needs to be built into our thinking about the relationship between age and desistance from crime. In this way, even 'age', as a variable, ceases to be directly comparable in comparative research. Being 16 in England in 1946 is not the same as being 16 in England in 2018; similarly, being 16 in Germany in 2018 may not be the same as being 16 in North Africa in 2018. If cultural expectations of what is appropriate at a particular age are malleable, so research in which age may be a crucial variable that needs to explore both 'biological age' and 'social age'. Age, I am sure, is related to processes of desistance, but how and in what ways needs to be more thoroughly understood. 
Historical 'moment': The 'when' question has not frequently been raised by those studying desistance from crime. This is partly because a) desistance is a relatively recent area of research, so there are few 'old' studies undertaken during different era, and b) there have been few historical studies of desistance from crime. Nevertheless, on the basis of our knowledge that when human lives unfold, this is crucial to the nature and shape of their unfolding, I believe that the historical moment during which a person is alive and offending can serve to shape the ways in which they come to desist (and even, I would argue, the degree to which they can desist). Godfrey et al. 's study of desistance in Crewe (2007), Villagra's study of desistance in Chile (2016), and Karstedt's study of former Nazi-Party war criminals (2011) have all suggested to me that questions of 'when?' (that is, historical moment) in desistance research will come to the fore in the future.

Economic systems: By 'economic systems', some may immediately think of the very macro-level characterisations of these (such as 'capitalism', or 'communism'). Whilst a study of the influences of this level of economic systems on desistance would be fascinating, this is not what I had in mind. Rather, I am referring to the differences which Joanna Shapland, Tony Bottoms, and I discussed in our earlier paper (Farrall et al. 2010). What we argue therein is that the managing of the economy on a day-to-day basis (the result of course of wider changes in political economies) may serve to shape processes of desistance. If crime is (partly) a consequence of social and economic processes, then sudden changes in these and the consequences this has for the nature and type of employment which is available, the timing of partnership formation and family formation may well shape processes of desistance. It is very hard to assess on the basis of one review the degree to which the economy does indeed shape processes of desistance. My instinct is to assume that it ought to shape the opportunities which exist to leave crime behind (employment being one such route out of crime for some). However, until there are sustained studies of shifts in economic fortunes and processes of desistance (and which take account of changes in aging and the lagged effects of economic cycles), this has to remain 'plausible' but unproven.

The criminal justice system: Two angles can (and should) be taken. The first relates to comparative studies. Comparative studies of offending often run into definitional difficulties; what is termed 'assault' in one country may not be the same sort of behaviour in another. Similarly, when exploring processes of offending in two countries, one has to allow for the fact that formal agencies (such as the police) may respond to the same sorts of offences quite differently (informal warnings may be used more often in one country than formal charges are in another). Similarly, sentence lengths for near-identical offences may be quite different due to differing national sensitivities about some crimes. However, studying desistance from crime which (even if it isn't 
easy to operationalise) would be consistently similarly defined across countries does strike me as a useful way forward. There are currently very few studies of desistance which span countries and hence are able to explore the impacts of different criminal justice systems. Osterman's study hints that there may be criminal justice system effects, but being a small-scale study, this has to remain tentative. Of course, it may be that such system effects are only felt in for some sorts of offenders or people. Osterman had studied females; there is nothing to suggest that had she studied males, she would have found differences between England and Sweden. In summary, this is also 'plausible' but unproven. Second, there are the different disposals which any one system may meter out. This approach returns us to some of the research questions asked of prisons and probation in earlier years ("which is more effective?", Martinson 1974). However, armed with new concepts and new ways of approaching the matter in hand, I wonder if there is not some utility in exploring processes of desistance for a population of those on probation and a population of those on parole.

Criminal careers: I ended my review by discussing the possibility that offending careers structure routes out of crime for people. Although this approach has not been widely adopted by those studying desistance from crime, the recent proliferation of studies of sex offenders and the high levels of stigma which such individuals report does suggest to me that there is some mileage in exploring the ways in which different criminal careers may shape the nature, speed, and timing of desistance. This is not to open the floodgates on a series of studies comparing 'robbers' with 'burglars' since there will be little of much difference between them, I suspect (even if a pool of 'pure' robbers and 'pure' burglars could be identified), but to rather open up the possibility that certain categories of offenders may - by virtue of the sorts of offences they have committed - experience desistance differently. As well as sex offenders, other groups which may be worth exploring include whitecollar offenders (see Hunter 2015) or those involved in various forms of 'hate crime'.

What these findings hint at is the possibility that some of the variance in the frequency with which desistance is observed - or the processes, nature, and character of desistance when it occurs - is driven not by individual choice alone but by individuals operating in wider structures, some of which they may have only the vaguest awareness of. Of course, some of what I have discussed suggests the influence of processes which operate at the national level (such as different criminal justice systems) and which may only be readily explored and made visible by cross-national, comparative studies of desistance from crime. Other processes may be more readily explored 'within' the confines of one country, of course. In the next section, I will outline how I think we can best approach the study of such matters. 


\section{My current thinking on how we ought to explore structural forces and desistance from crime}

Given the above, and especially my comments regarding the recent trend towards exploring 'internal' processes of change, it ought to be apparent that I believe firmly that we need to build theoretical models and undertake research projects which enable cross-cultural and/or cross-national contexts to be made 'visible'. We must, however, avoid falling into the trap of thinking 'everything is unique', since, as noted above, those studies which have made spatial or temporal comparisons have not always found radically different processes of change. For example, Calverley still finds employment and partnership to be important in his study of ethnicity and crime, Godfrey et al. still find employment to be a key part of the process, and Villagra still found 'traditional' models of desistance in Chile. It is, of course, also important to bear in mind, however, that an identical variable may operate differently for two groups of people. For example, employment schemes may help both men and women, but for different reasons; for men, it may be about practical assistance with gaining work, whilst for women, it may be about the development of support networks which can assist more indirectly.

In this section, I wish to outline the theoretical model of desistance developed by myself and colleagues (see Farrall et al. 2014; Farrall et al. 2011). ${ }^{2}$ This theoretical model is an attempt to integrate insights from many existing theories and, in so doing, to bring together explanations which focus on agency with those which highlight structural processes. Whilst this theory is of a fairly general nature (for example, I do not specify which variables ought to be assessed), I believe that this is the correct level of specification to be working at this stage. The model has sufficient flexibility to be adapted for use in different cultures, contexts, or historical periods, meaning that the precise variables and processes to be studied can be chosen according to the nature of the societies and criminal justice systems being studied. When we were drawing up the model, we were keen to produce something which included all of the following:

- a focus on structural processes (including the criminal career itself as a form of structuring), crucial when exploring cross-national and cross-cultural research since it is often the structural processes or variables which one is most centrally interested in when comparing countries, cultures, or systems;

- theorising at such level which would enable one to retain the ability to explore what it 'feels like' to stop offending (or to continue offending) and to have once been an offender, crucial for understanding processes of stigma or guilt

2 Farrall et al. (2010, pp. 550-553) deal with some of the wider theories of structuration which can be utilised when thinking about the relationship(s) between agency and structure. 
at the individual level - but, of course, for which they may be specific culturally-mediated understandings held by desisters, their supporters, the criminal justice system, and the wider society in which they live and which shape the understandings of what these feelings 'mean';

- the retention of the role of agency as a key aspect of our explanations of desistance, but which nevertheless takes seriously the idea that there are various social, legal, cultural, and economic processes influence crime, offending, desistance, and circulating ideas and images about these - and that whilst people may make decisions which are in accordance with efforts to desist, these may be rendered null by wider processes (or supported by these);

- recognises that social actors do not possess full information about the consequences of their decisions and may be wrong in their assessments of the best course of action, and may additionally suffer from temporary or permanent set-backs which influence and shape their lives both immediately and into the future (Halsey et al. 2016);

- the incorporate changing beliefs about some inputs (such as probation) which may develop over time as those subject to these reflect on their lives - and which, as such, allow for the possibility that people may say one thing about one process at one time, and another about it sometime(s) later, after they have reflected on the changes (or lack of changes) they have experienced;

- takes seriously in a number of ways the spatial processes associated with desistance from crime. This means recognising that where one spends one's time is both reflective of processes of change and can operate to support or to undermine such efforts. It also means recognising that desistance in a small country may involve different processes from those associated with desisting in a larger country (where it may be easier to move away from places and people one was associated with and in so doing to escape some of the aspects of being labelled negatively);

- an openness to exploring other (in some cases, consequential or collateral) dimensions of desistance (such as feelings of citizenship, inclusion, social rehabilitation); and

- a move away from 'one size fits all' theoretical models of desistance, but which instead recognises that there are differing trajectories of criminal careers and hence variations in routes out of crime - and that one set of variables and processes may be at play for some groups of desisters, whilst other variables and processes are associated with another group (the precise nature 
of the groupings may vary between cultures and countries being studied; being age- or cohort-related in some studies, but related to ethnicity, cultural beliefs, or socio-demographic characteristics in other studies). 


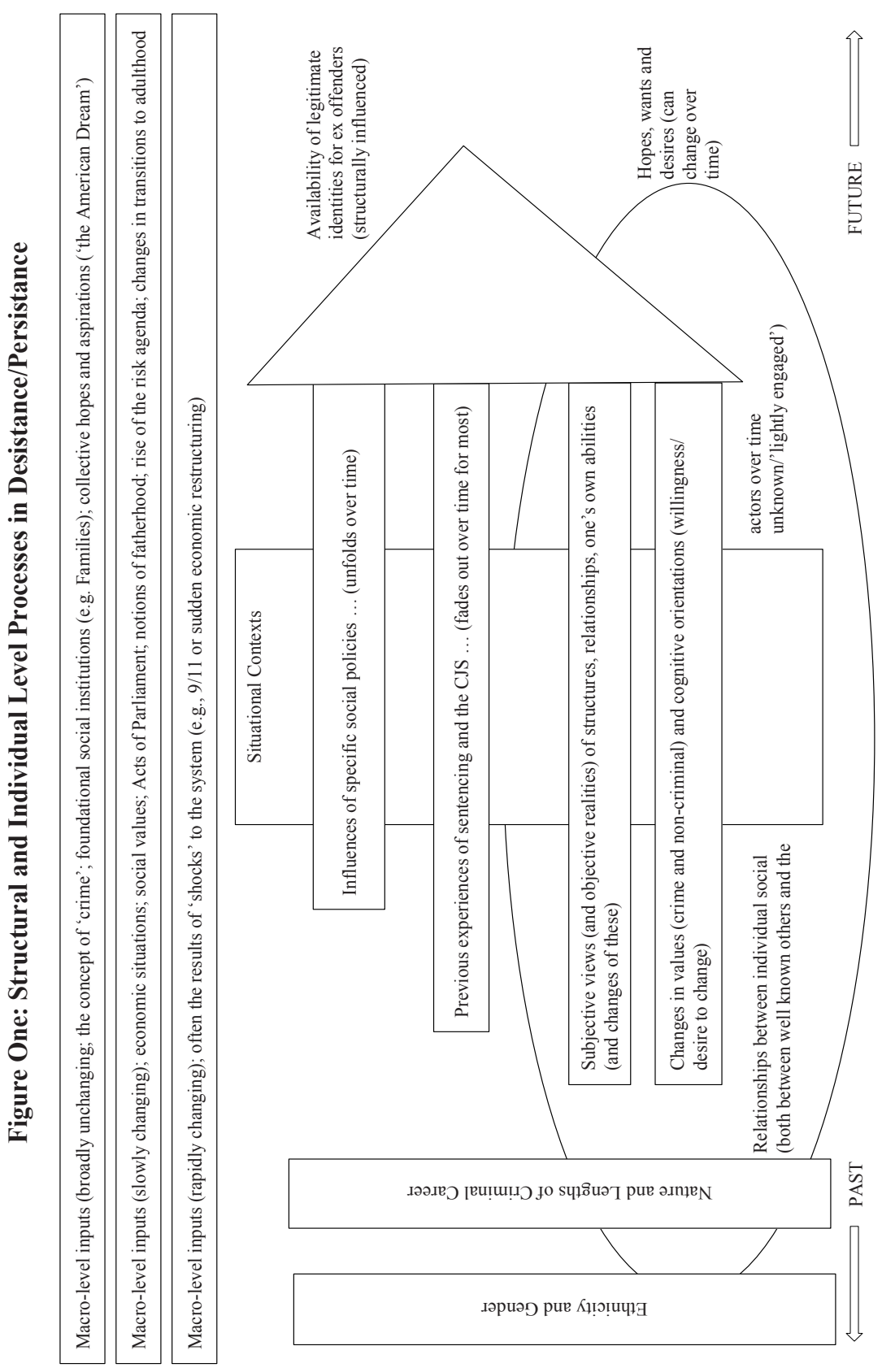


Space constraints preclude a full outlining of our approach, which can instead be found in Farrall et al. 2014; Farrall et al. 2010; Farrall et al. 2011. Our model is summarised as a diagram in Figure One. Let us start with the three bands of general influence which run across the top of the diagram and represent different macro-level influences. The influences in the top band are those which are broadly unchanging, or very slowly changing (such as social institutions such as 'the family', even if the definition of what constitutes a family may alter over time, and the idea that there are acts which are labelled as 'crimes'). Below this are macro-level influences which change less slowly (such as social values) and finally, amongst the macro-level influences, are the shocks to the system which emerge with little warning (such as sudden economic downturns). As such, nation-states have their own unique histories and in-built path dependencies which shape the social, economic, and cultural institutions they contain and are made up of. These in turn, we believe, shape both the criminal justice system and the processes of desistance for those caught up in it. On the left-most side of Figure One are individual-level influences, such as gender and ethnic identity which can shape the opportunities which are presented to them throughout their life, and of course which vary between countries (masculine identities in Spain, for example, will not be the same as in England or Sweden, although some similarities will exist). Another factor which influences the character of pathways out of crime is the nature and length of the previous criminal career. For individuals with intensive criminal careers, desistance from crime may well require a greater degree of 'rebuilding' of their core selves (and hence many turn to religion or to quasi-religious forms of belief in order to make such changes possible, intelligible, and sustainable). Again, the choice of religion which is adopted (if it is adopted) by the would-be desister will vary across countries. At the bottom of this figure is an oval which represents routine social interactions and relationships between individuals over time. It is an oval as not all relationships extend far backwards in time (some people we have only known briefly), and nor will all last for the rest of one's lifetime. This indexes the degree to which social relationships with people one has known for long periods of time and those one has known for shorter periods of time are resources upon which the would-be desister can draw. In societies with low levels of trust of strangers, there may be fewer chances for desistance involving the development of new relationships of mutual trust and support. Cutting into this is a column (labelled 'Situational Contexts') representing specific circumstances, chapters, events or processes in individual would-be desisters' lives. These may be short-lived episodes, or they might represent extended periods, such as time spent in prison or living in a particular city. Running from left to right are four further rows. The bottom two rows relate closely to ongoing social relationships and deal with subjective views of structures, of relationships and of one's own abilities, and changes in personal values and cognitive orientations to the world and the way it works, the 'habitus' (Bourdieu 1977). Relationships, of course, are dynamic and can change and develop over time and extend into the future, influencing hopes and desires. The top two rows across the centre of Figure One relate to experiences of the 
criminal justice system. Few ex-offenders, in our experience, go on to become 'professional exes' or develop a new pro-social identity based on their previous criminal identities (however, see Maruna 2001). Of course, in some cases, repeated and prolonged exposure to the criminal justice system may become so dramatically cumulative to the point that even if an individual does cease to offend, they carry with them a legacy of their earlier sentences. Similarly, we have uncovered evidence that some criminal justice workers leave imprints on offenders (see above) and this is located within this row of our model. Finally, on the righthand side of Figure One is a triangle which represents the idea that lives are lived into the future and that humans are often involved in on-going projects of the self which they project forward into the unlived future as part of their immediate day-to-day lives and as part of their concern for their own future over longer time periods. Of course, the extent to which ex-offenders can achieve their desires and goals is partly dependent on the availability of legitimate identities, and in societies which prevent ex-offenders from full engagement in social and economic life, we imagine that more would-be desisters will return to their old (criminal) behaviours.

\section{What do we need to do next?}

Studies of why people stop offending have drawn on a range of theoretical perspectives. These include theories of informal social control (Sampson \& Laub 1993), generative theories building on phenomenology (Maruna 2001), rational choice theories (Cusson \& Pinsonneault 1991), social learning (Moffitt 1993), psychosocial theories (Gadd \& Farrall 2004), existentialist thinking (Farrall 2005), and cognitive transformations (Giordano et al. 2002), amongst others. However, most of these theories are based on thinking developed in North America (such as the works of, for example, Sampson \& Laub 1993; Giordano et al. 2002; Cusson \& Pinsonneault 1991). Whilst there is much to commend in these studies, the USA have a different economic, social, and cultural history and different institutions to many other parts of the world. The US welfare regime is less well-developed than many European ones, for example, and levels of economic inequality in the US are far greater than they are in many European countries. Presently, these theories are seen as 'competing' against one another (Ezell \& Cohen's review of the main theories of desistance is an example of this approach, 2005). However, in fact, many of these theories a) share some similarities with one another (e.g. existentialism, phenomenology, psychosocial theories and theories of cognitive transformation) and b) can be integrated into one overall theory (Farrall et al. 2011;2014). What I conclude from this is that whilst we have a lot of very well-argued theoretical explanations for desistance, we are (or at least have been in the recent past) overly reliant on a small number of countries for both their development and empirical testing (these countries being the US, the UK and some other parts of Europe where good-quality longitudinal data 
sets of offending careers exist, such as the Scandinavian countries, Germany, and the Netherlands).

My first suggestion, therefore, is that in general we need more studies of other countries, cultures, and criminal justice systems. There are, for example, to my knowledge very few studies of desistance in France or Italy. ${ }^{3}$ Some other European countries have only one or two different studies (the Republic of Ireland and Spain being examples), and there are no studies (again which I am aware of) in African countries or many South American ones, aside from Villagra's study in Chile. However, simply adding to this knowledge base will not help terribly much in the longer run, as welcome as it would be: whilst such studies could be compared in terms of some of the general processes of desistance, they are not strictly comparable, since different researchers will inevitably operationalise key terms differently, highlight different mechanisms in analyses, undertake fieldwork using different methodologies from one another, design the studies and recruit the samples differently from each other. As such, the thorough theoretical and conceptual understanding of why people stop offending and the role in this played by national-level characteristics is simply unknown, although, as I have suggested above, some differences can be inferred.

I would recommend that future research which attempts to compare processes of desistance cross-nationally uses qualitative data in order to unpack the various and subtly shifting meanings of key concepts when exploring the mechanisms by which individuals stop offending. Subsequent studies can then use various modelling techniques to assess the degree to which these are associated with desistance from crime. An eye will need to be kept on the shifting meaning of concepts as societies develop over time. The jurisdictions selected for inclusion need to be selected on the basis of theoretical considerations (rather than just convenience); that is to say that some structured sampling of countries needs to be undertaken in order to tease out precisely how various structural-level processes may shape, at the national level, desistance from crime.

The problem with the above is that it takes time to secure such funding, to collect the data, and to undertake the required analyses. One solution to this is to undertake analyses of historical data. This enables us to compare Country A at time 1 and time 2 (as Godfrey et al. 2007 did), but - if the countries included are selected carefully and if sufficient data exists, to compare Country A and Country B at time 1 and then again at time 2 - it also enables a comparison of national-level characteristics and their durability over time. Another possibility lies with age-period-cohort analyses (Grasso 2014). Such analyses would enable us to explore the degree to which different cohorts are affected by much earlier structural influences which may have been present at an earlier point in their life-courses. Similarly, multi-level models may be appropriate for exploring the influence of different structural contexts (individuals 
within communities, within cities, within regions, with countries, for example). However, both age-period-cohort and multi-level modelling require data sets of a particular form and data which have been collected and structured in a particular manner. At present, such data do not exist in very many countries (although the Scandinavian total population registers may enable some analyses of this nature); it is possibly the case that it will not be for many years that such analyses can be performed in many other countries. Whatever the challenges, be they methodological, theoretical or the perennial problems of access, gate-keeping and comparability, I am sure that the next 'big step' for scholars of desistance is to embrace and grapple with the cross-national investigation of why people stop offending.

\section{References}

Appleton, C.A. (2010): Life after Life Imprisonment. Oxford.

Barclay, G. (1990): The Peak Age Of Known Offending By Males. Home Office Research Bulletin 28, pp. 20-23.

Beijers, J., Bijleved, C. \& van Poppel, F. (2012): Man's Best Possession: Period Effects in the Association Between Marriage and Offending. European Journal of Criminology 9/4, pp. 425-441.

Benazeth, $V$. (on-going): $\mathrm{PhD}$ studies on desistance from crime and probation supervision. UVSQ/CESDIP.

Bersani, B., Laub, J. \& Nieuwbeerta, P. (2009): Marriage and Desistance from Crime in the Netherlands: Do Gender and Socio-Historical Context Matter? Journal of Quantitative Criminology 25, pp. 3-24.

Bottoms, A., Shapland, J., Costello, A., Holmes, D. \& Muir, G. (2004): Towards desistance. Howard Journal of Criminal Justice 43/4, pp. 368-389.

Calverley, A. (2013): Cultures of Desistance. London.

Clark, A. (1997): The Struggle for Breeches: Gender and the Making of the British Working Class. California.

Cusson, M. \& Pinsonneault, P. (1986): The Decision To Give Up Crime, in: D.B. Cornish \& R.V. Clarke (eds.), The Reasoning Criminal. New York.

D'Cruze, S. (1998): Crimes of Outrage: Sex, violence and Victorian working women. London.

Drummond, D. (1995): Crewe: Railway Town, Company and People, 1890-1914. Aldershot.

Ezell, M.E. \& Cohen, L.E. (2005): Desisting from Crime. Oxford. 
Farrall, S. (2005): On the Existential Aspects of Desistance from Crime. Symbolic Interaction 28/3, pp. 367-386.

Farrall, S. (2002): Rethinking What Works With Offenders. Cullompton, Devon.

Farrall, S., Bottoms, A. \& Shapland, J. (2010): Social Structures and Desistance from Crime. European Journal of Criminology 7/6, pp. 546-570.

Farrall, S. \& Bowling, B. (1999): Structuration, Human Development and Desistance from Crime. British Journal of Criminology 39/2, pp. 253-268.

Farrall, S. \& Calverley, A. (2006): Understanding Desistance from Crime. Crime and Justice Series. Maidenhead.

Farrall, S., Hunter, B., Sharpe, G. \& Calverley, A. (2014): Criminal Careers in Transition: The Social Context of Desistance from Crime. Clarendon Studies in Criminology. Oxford.

Farrall, S., Sharpe, G., Hunter, B. \& Calverley, C. (2011) Theorising Structural and Individual-Level Processes in Desistance and Persistence: Outlining an Integrated Perspective. Australian and New Zealand Journal of Criminology 44/2, pp. 218 234.

Finestone, H. (1967): Reform and recidivism amongst Italian and Polish criminal offenders. American Journal of Sociology 72/6, pp. 575-588.

Folkard, S., Fowles, A.J., McWilliams, B.C., McWilliams, W., Smith, D.D., Smith, D.E. \& Walmsley, G. (1974): IMPACT: Intensive Matched Probation and AfterCare Treatment. Home Office Research Study No. 24. HMSO. London.

Folkard, S., Smith, D.E., Smith, D.D. \& Walmsley, G. (1976): IMPACT: Intensive Matched Probation and After-Care Treatment, Volume II: The Results of The Experiment. Home Office Research Study No. 36. HMSO. London.

Gadd, D. (2006): The role of recognition in the desistance process: A case analysis of a former far-right activist. Theoretical Criminology 10/2, pp. 179-202.

Gadd, D. \& Farrall, S. (2004): Criminal Careers, Desistance and Subjectivity: Interpreting Men's Narratives of Change. Theoretical Criminology 8/2, pp. 123-155.

Giordano, P.C., Cernkovich, S.A. \& Rudolph, J.L. (2002): Gender, Crime and Desistance: Toward a Theory of Cognitive Transformation. American Journal of Sociology 107, pp. 990-1064.

Godfrey, B., Cox, D. \& Farrall, S. (2007): Criminal Lives: Family Life, Employment and Offending. Clarendon Series in Criminology. Oxford.

Gottfredson, M.R. \& Hirschi, T. (1990): A General Theory of Crime. Stanford.

Graham, J. \& Bowling, B. (1995): Young People And Crime. Home Office Research Study No. 145. HMSO. London. 
Grasso, M.T. (2014): Age-period-cohort analysis in a comparative context: Political generations and political participation repertoires. Electoral Studies 33, pp. 6376.

Halsey, M., Armstrong, R. \& Wright, S. (2016/2017): 'F*ck It!': Matza and the Mood of Fatalism in the Desistance Process. British Journal of Criminology 57/5, pp. 1041-1060; DOI:10.1093/bjc/azw041.

Hammerton, A.J. (1992): Cruelty \& Companionship: Conflict in $19^{\text {th }}$ Century Married Life. London.

Healy, D. (2010): The Dynamics of Desistance. Charting Pathways Through Change. London.

Hunter, B. (2015): White-Collar Offenders and Desistance from Crime. London.

Karstedt, S. (2011): Life After Punishment for Nazi War Criminals, in: S. Farrall, M. Hough, S. Maruna \& R. Sparks (eds.), Escape Routes. London.

Kemshall, H. (2003): Understanding Risk in Criminal Justice. Buckingham.

Lewis, J. (1988): Sexual Divisions: Women's Work in Late Nineteenth Century England, in: S.J. Kleinberg (ed.), Retrieving Women's History. Oxford.

Martinson, R. (1974): What Works? Questions and Answers about Prison Reform. The Public Interest 35, pp. 22-54.

Maruna, S. (2001): Making Good: How Ex-Convicts Reform and Rebuild Their Lives. Washington, DC.

Matza, D. (1964): Delinquency and Drift. New York.

Moffitt, T. (1993): 'Life-Course Persistent' and 'Adolescent-Limited' Antisocial Behaviour: A Developmental Taxonomy. Psychological Review 100, pp. 674-701.

Mohammed, M. (ed.) (2012): Les Sorties de Delinquance: Theories, Methods, Enquêtes. Paris.

Osterman, L. (2015): Stories Across Borders: How female ex-offenders make sense of their journey through crime and criminal justice in Sweden and England. $\mathrm{PhD}$ Thesis, Dept. of Sociology, Univ. of Surrey, England.

Paternoster, R. \& Bushway, S. (2009): Desistance and the "Feared Self": Toward an Identity Theory of Criminal Desistance. Journal of Criminal Law \& Criminology 99/4, pp. 1103-1156.

Raynor, P. (1996): The Criminal Justice System, in: Drakeford, M. \& Vanstone, M. (eds.), Beyond Offending Behaviour. Ashgate.

Robinson, G. (2002): Exploring risk management in probation practice. Punishment and Society 4, pp. 5-25. 
Rodermond, E., Kruttschnitt, C., Slotboom, A.-M. \& Bijleveld, C. (2016): Female desistance: A review of the literature. European Journal of Criminology 13/1, pp. 3-28.

Rose, S. (1992): Limited Livelihoods: Gender \& Class in 19th Century England. California.

Ross, E. (1993): Love \& Toil: Motherhood in Outcast London, 1870-1918. Oxford.

Sampson, R.J. \& Laub, J.H. (1993): Crime in the Making: Pathways and Turning Points Through Life. London.

Segev, D. (on-going): Drawing the Context: Understanding Desistance Processes in Different Countries. On-going $\mathrm{PhD}$ research, Centre for Criminological Research, Univ. of Sheffield, England.

Shover, N. (1983): The Later Stages of Ordinary Property Offender Careers. Social Problems 31/2, pp. 208-218.

Smith, B.G. (1989): Changing Lives: Women in History since 1700. Lexington, Toronto.

Valenze, D. (1995): The First Industrial Woman. Oxford.

Vaughan, B. (2007): The Internal Narrative of Desistance. British Journal of Criminology 47/3, pp. 390-404.

Villagra, C. (2016): Socio-Historical Contexts, Identity and Change: A Study of Desistance from Crime in Chile. PhD Thesis, Dept. of Criminology, Univ. of Leicester, England.

Weaver, B. (2016): Offending and Desistance. The importance of social relations. London. 



\title{
Disengaging from Peers in the Process of Desistance
}

\author{
Joanna Shapland and Anthony Bottoms
}

As an adolescent, one's friends are key companions, arbiters of one's taste and habits, with group identity being a major part of self-identity. Whether one's friends offend is also highly correlated with whether the individual does. ${ }^{1}$ As Warr commented in relation to adolescent crime, "Criminal conduct is predominantly social behaviour. Most offenders are imbedded in a network of friends who also break the law, and the single strongest predictor of criminal behaviour known to criminologists is the number of delinquent friends an individual has" (Warr 2002, p. 3; see also p. 40).

But as offenders move into early adulthood and many start to desist from crime, does this correlation still hold? Do previously delinquent friends remain friends? If they do, does offending with them continue? Or do the individual and friends move out of crime together? Moreover, is offending the key connection that is shared by the individual and his/her offending friends - or are there other bonds, like support, or common places to go to and things to do?

Remarkably little has been written in the criminological literature about people's friendships as they mature from adolescence into adulthood, and how this relates to desistance. We know that in their late teens and early twenties, many individuals (including some with extensive crime involvement) reduce and then cease offending, producing the typical pattern of the age-crime curve, with its sharpest down-slope being in the early twenties (Laub \& Sampson 2003; Blokland, Nagin \& Nieuwbeerta 2005; Piquero, Farrington \& Blumstein 2007). In seeking explanations for this downturn, researchers have often focused on some of the elements that tend to change in people's lives in early adulthood, such as acquiring a stable relationship / marriage or work or, for an earlier generation, military service (Laub \& Sampson 2003; Horney et al. 2012). By comparison, little regard has been paid to changing patterns of friendship between mid-adolescence and late adolescence/the early twenties (however, see Warr 2002, p. 5).

A partial exception to this is the now extensive evidence, from several countries, that the proportion of officially recorded offences committed in groups drops sharply from age 16 to age 25 (Carrington \& van Mastright 2015, p. 14, and research cited

1 For example, in their extensive longitudinal study in Peterborough, England, Wikström et al. (2012, p. 153) found that the zero-order correlation between adolescents' self-reported crime involvement and an index measuring knowledge of peers' crime involvement was very strong $(\mathrm{r}=0.71)$. 
therein). However, the relationship in early adulthood between desistance from crime and the reduced proportion of co-offending also remains under-examined. The most important study is that by Reiss \& Farrington who, using data from the well-known Cambridge Study in Delinquent Development, found that "the decrease in co-offending with age is not caused by the persistence of solo offenders and/or the dropping out of co-offenders, but instead reflects changes within criminal careers" (1991, p. 382). An additionally complicating factor in this discussion is the offence mix at different ages, since there is now cross-national evidence that, even when one holds age and gender constant, four types of offence are most likely to be committed in groups, namely robbery, burglary, arson, and theft of or from a motor vehicle (Carrington \& van Mastrigt 2015, p. 15). ${ }^{2}$

The literature also suggests that typically, co-offending occurs with only a small number of associates (Carrington \& van Mastrigt 2015, p. 11) and that only rarely do delinquents commit more than a few offences with the same accomplice. Though offenders can have large networks of people with whom they might offend, the lifespan of a delinquent group is usually short and groups are relatively unstable (Warr 2002). There are exceptions, of course: for example, Beth Weaver (2016) studied a group of male friends that held together for many years, initially offending together, but then supporting each other into desistance.

As regards explanations of group delinquency, $\operatorname{Warr}$ (2002, p. 134) usefully reminds us that "a strong correlation between the behavior of adolescents and that of their friends (...) says nothing about the process or mechanism of influence that gave rise to" that correlation. Until recently, the dominant mechanism offered in the criminological literature has been learning theory (Akers 1998), although some have preferred a self-selection approach - 'birds of a feather flock together' (Gottfredson \& Hirschi 1990). However, recent research by Costello and Hope (2016), although based empirically on less than ideal samples, ${ }^{3}$ has suggested an additional theoretical possibility:

There is a great deal of situational peer pressure toward deviance, notwithstanding that most criminological literature has dismissed this. (...) Our research uncovered a variety of mechanisms of negative influence that seem to fit the category of "peer pressure", including coercive tactics such as ridicule [or] trying to convince a friend to deviate by minimizing the potential negative consequences of the behavior. (...) This suggests that we need to pay much more attention to the influence of "short-term,

2 These data are from official statistics in three countries. However, when self-reporting crime, 16-year-olds in Peterborough (see previous footnote) were asked to state whether they acted alone or with friend(s). The three offences for which over 90 per cent said they were with friends were burglary, arson, and vehicle theft (Wikström et al. 2012, p. 152).

3 The samples were convenience samples of college students in the US who provided written accounts of peer-influence attempts on an anonymous basis. The authors acknowledge the limitations of such samples, but reasonably claim that the information collected constitutes "a first step in learning more about the mechanisms of peer influence" (p. 4). 
situationally induced" motives for deviance in addition to (...) values, social bonds and levels of self-control (Costello \& Hope 2016, pp. 85-86).

We can add that "short-term, situationally induced" motives for deviance may include not only 'coercive tactics' but also a collective generation of excitement within a group, since breaking rules can be exciting (Katz 1988). As Costello and Hope (2016) themselves point out, we should also not assume that peer influence always leans towards deviance; in certain contexts, it can tend towards compliance with law (see also Costello \& Zozula 2016). It remains an unexamined question in the desistance literature whether negative peer influences are replaced by more positive ones as people start to move away from crime.

In light of this background, in this chapter, we shall explore the relationship between friends and offending in their early twenties, using the Sheffield Desistance Study's sample of male offenders, many of whom were persistent offenders. During the three to four years the sample was followed, many began to desist from offending, though the offending of some accelerated. We shall look at whether the sample had the same friends throughout that time period, whether their friends were offenders as well, and, crucially, whether those who were intending to desist from offending felt they needed to drop their offending friends or at least to avoid situations where crimes might be committed. What effect did any of this have on their lives, and were friends, in general, a source of temptation or a source of support?

\section{The Sheffield Desistance Study}

The sample for the Sheffield Desistance Study consists of 113 young men who were born between 1982 and 1984 and were aged between 19 and 22 years at the first interview (Bottoms \& Shapland 2016). In addition to age, the criteria for inclusion in the sample were that participants should have two or more convictions on different occasions as well as recent contact with either prison or the probation service. Because of the exigencies of how we could contact the sample, most in fact had recent prison experience and were persistent offenders, with a mean of eight convictions for standard list offences at the first interview, comprising 18 offences on average. This is therefore a highly delinquent sample who we sought to interview on up to four occasions over the following four years, with reasonably good retention rates (78 per cent at both the third and fourth interviews). ${ }^{4}$ We were also able to obtain the official conviction records for sample members. The interviews were long and included quantitative as well as qualitative questions on families, girlfriends, friends,

4 On four key variables, there was no statistically significant difference between those who completed the fourth interview and those who did not (Bottoms \& Shapland 2011, p. 50). Thus, although only three-quarters of the sample completed a final interview, these respondents are representative of the whole. 
leisure time, victimization, experiences with criminal justice and self-reported offending. Details of their offending (official and self-reported) can be found in Shapland \& Bottoms (2017). Some quotes from the qualitative questions on the respondents' friends ('mates') are included below.

When applied to this sample, the national group reconviction formula for England and Wales, known as OGRS2, predicted that 78 per cent would be reconvicted over the next two years. This was accurate: in fact, 80 per cent were reconvicted over three years. However, there was a significant reduction in the frequency of reconviction over that time, from 8.2 standard list offences per offender in the year before the first interview to 2.6 per year in the period after the third interview, around three years later. ${ }^{5}$ Moreover, the extent of self-reported offending in the group bifurcated: for the final period, most of the sample reported few or no offences, but a minority reported many, and about a third had increased their rate of offending since the beginning of the study. The situation over the whole follow-up period was therefore that most members of the sample (as would be predicted by the age-crime curve) were starting to desist, but a minority were clearly persisting. In the first interview, a majority said they had a firm intention to desist - but the accomplishment of that desistance was often a complex, rather wavering affair, with both intention to desist and amount of offending varying up and down over time, although with a general downward trend for those who expressed an intention to desist.

\section{Who were their friends: 'mates'}

For young men in England, one's friends and peers with whom one would spend time are colloquially called one's 'mates' (who might be either male or female). At each interview, we asked respondents if they could let us know who their 'three best mates' were - they were asked to provide a first name, but it could be a nickname or pseudonym to protect the mate's identity. The only restriction was that it could not be their parents or their current partner. For each person named, we asked a number of questions (on a 'mate sheet'): how long they had been known, where they had met, how they spent time together, whether the mate had been in trouble with the police (to their knowledge), whether they had ever committed an offence together, and to what extent they trusted their mates. In subsequent interviews, we also asked how often they saw that mate, whether the mate had a drug problem, and whether the mate did hard drugs. In the fourth interview, we asked whether the named people from the first interview were still their mates, and if not, why not. We aimed at obtaining a picture of how and why friendships developed or changed, as the young men navigated the period between the late teens and early twenties.

These calculations exclude times in legal custody. 
At the first interview, $13 \%$ of respondents did not name anyone as their 'best mate' - but $87 \%$ did, almost all of these mates being male and in the same age bracket or slightly older than the respondent. Over the next interviews, the predominance of having male best mates and their age did not change very much: the mates they named had grown a year older on average, like the respondents themselves (the interval between interviews was about 11-12 months). This is very similar to the results of Warr (2002) who found that his slightly younger adolescents (14-16 years) tended to spend a considerable amount of their time talking with a small group of peers (a third of their time on average, with a quarter spent talking to adults and the rest being alone). These small groups of peers tended to have around 2-4 members and to be homogeneous in age.

In the Sheffield Desistance Study, 'best mates' might have been known for just a short time (months) or alternatively for a very long time (mean for the first 'best mate' who was named was 8.13 years, median 7 years; with the second and third being very similar). There were peaks at the first interview for those known for around 4-5 years (corresponding to secondary school) and 10 years (corresponding to primary school). Mates primarily came from the local area.

We should not conclude, though, that these small groups moved through into early adulthood together unchanged. Though it was common for one person to be named across three or four interviews (i.e. one 'best mate' remained a best mate), it was very rare for the same two people to be named over that time frame (just $9 \%$ of respondents did this). The length of time that respondents had known their firstnamed best mate by the fourth interview had a lower mean of 5.68 years and a median of 2 years, though the second- and third-named best mates had medians of 8 and 9 years. Over half of the respondents at interview 4 (59\%) said they had picked up a new 'best mate' in the last three years.

So we do not see small, continuing, close-knit groups (as, for example, Weaver 2016 did). Instead, a picture unfolds of some continuity but much change in mates. Given that most members of the sample were recruited from prison and some went back there during the study, it might be concluded that these were new friends made in prison (perhaps from other cities), and this change was an artefact of the sample. However, these new best mates turned out to be predominately from the local area, too, and not from contacts stemming from criminal justice links. This may not be surprising given the extent to which respondents lived in similar local areas in Sheffield during the whole time period and the constant 'churn' in the prison population because of overcrowding, so that people might have been moved from prison to prison both between remand and sentence and during sentence.

We also asked how often they saw their best mates, with the options being 'daily', 'every other day', 'weekly', and 'less often' (the question was only asked during interviews 2, 3 and 4). At interview 2, respondents saw their best mates very often, with $67 \%$ saying they saw their first-named best mate daily (see Table 1). Though 
many best mates continued to be seen daily over the whole period, there was a definite tendency for mates to be seen less often as time went on. This was a period during which social media had not yet become a daily habit (Facebook was launched in 2004 in the US, whereas the first interviews were conducted in 2002-2003). So contact between friends needed to be face-to-face or by telephone. The trend towards seeing one's 'best mates' less often throughout the early adulthood period may be one towards having more long-term, more carefully chosen friends, less dependent on the respondent's day-to-day and routine activities.

It is of course an important question whether these changes in friendship are related to offending: either to patterns of offending or to attempts to desist. In order to explore this, we need to consider the extent to which mates were important to our respondents and their lifestyles, whether they offended with their mates and whether they saw them as being linked to their offending.

Table $1 \quad H o w$ often do you see your best mates? (percentages)

\begin{tabular}{|l|r|r|r|r|r|}
\hline & Daily & $\begin{array}{c}\text { Every other } \\
\text { day }\end{array}$ & Weekly & Less often & $\begin{array}{c}\text { N (mate } \\
\text { named) }\end{array}$ \\
\hline Mate 1 & 67 & 18 & 10 & 5 & 79 \\
Interview 2 & 46 & 13 & 25 & 14 & 71 \\
3 & 33 & 14 & 25 & 28 & 76 \\
4 & 46 & 34 & 15 & 5 & 60 \\
\hline Mate 2 & 48 & 18 & 26 & 8 & 61 \\
Interview 2 & 32 & 23 & 19 & 26 & 62 \\
3 & 45 & 30 & 13 & 13 & 47 \\
4 & 40 & 30 & 15 & 15 & 47 \\
\hline Mate 3 & 20 & 23 & 33 & 40 \\
Interview 2 & & & & \\
3 & 45 & & & \\
4 & & & & & \\
\hline
\end{tabular}

\subsection{The importance of mates}

It is known that for many men, the early twenties is a time of acquiring both a more stable girlfriend and steady employment. Laub and Sampson (2003) have posited that desistance is linked to 'turning points', which they found to be marriage, work, and serving in the armed forces (note that these were men born between 1924 and 1935). Skardhamer and Savolainen (2016) have cast some doubt on the causality of this as 
far as marriage is concerned, showing that desistance, in the sense of reducing officially known offending, preceded marriage. However, both sets of researchers essentially emphasise the 'pull factor' of a serious relationship and marriage - that the man was pulled away from criminality by wishing to be in the relationship.

Warr (2002) has commented that the desistance effect of a serious relationship may be due not just to such a pull factor, but also to the push factor causing the man to spend less time with his mates - with whom he is therefore less likely to offend. We believe that this important observation needs to be considered in terms of two different elements - the relative importance of the relationships to the man (with the girlfriend and with mates) and the effects on time spent with each person. The two are likely to be correlated - but they are not identical. Both provide tensions in relation to offending and could be spurs to desistance - and to the maintenance of desistance. In terms of desistance, the importance of a relationship with a girlfriend is likely to entail both cognitive and normative/emotional elements: that is the man wishes to desist because his girl, for whom he has genuine affection, does not approve of his offending. However, time spent together also has an effect on opportunity - if being with mates means being with those with whom one has offended, then spending less time with mates (and more with a girlfriend) reduces temptations to offend offered by mates and also the situational pull of the former offending lifestyle. With our data, we are able to tweak apart these strands, first looking at the importance of mates during the early desistance process and then at changes in lifestyles and time spent on different activities with different people.

For the sample in the Sheffield Desistance Study, at the first interview (at ages between 19 and 22), most respondents said their 'best mates' were very important to them. More precisely, $62 \%$ saw them as very important, $23 \%$ as fairly important, just $8 \%$ as not very important, and $6 \%$ as not at all important. By the fourth interview, the same question produced broadly similar responses, with a small decrease in importance: $48 \%$ said their 'best mates' were very important to them, $34 \%$ fairly important, $14 \%$ not very important, and only 5\% not at all important. Asked in the fourth interview to look back over the last three years, a majority said that their mates were either as important to them as previously (44\%) or more important $(22 \%)$. There is therefore clearly little decline in the importance of one's mates over this four-year period, with one's best mates remaining a very significant part of one's life.

In which ways were mates important? Asked during the fourth interview, respondents said that key aspects were 'they're there for me', that 'they're someone to talk over problems with', that you 'need friends', that they're 'supportive' and that they're 'someone to trust':

I've got respect for me mates, they've got respect for me. If you needed anything sorted, if you needed some help, you just have to ask. (interview 4) 
Clearly, one's mates are not just people to hang around with, but also people in whom to confide and from whom to seek support. We asked how much trust respondents put in their mates and found there was very little variation between interviews. The scale ranged from 'totally' to 'quite a lot' to 'a little' to 'not at all'. In the first interview, $58 \%$ said they trusted their first-named best mate totally and $22 \%$ said quite a lot, whilst at the second, third, and fourth interviews, the figures for 'totally' were $61 \%, 63 \%$, and $63 \%$. A few people had very few mates they did not really trust (particularly if they had still been offending and their mate had 'grassed them up' [informed on them]), but this was very rare. Over the whole period, the people named as best mates might have changed, but the role they played was similar - and they remained important. We will later return to the importance of the changes in mates.

\subsection{Mates and offending}

To what extent were mates linked to offending? Again, there are several aspects to this question. Did respondents, who generally were persistent offenders at the beginning of the study, have mates who were also offending? And had they offended, or were they offending, with these mates? In other words, were there direct links between one's mates and offending, and did these links persist throughout the three or four years while most of the sample were starting to desist?

Table $2 \quad H a d$ respondents' best mates been in trouble with the police and did they say they had offended together? (percentages and $n$ in brackets)

\begin{tabular}{|l|r|r|r|r|r|r|}
\hline & \multicolumn{3}{|c|}{ Been in trouble } & \multicolumn{3}{|c|}{ Offended together } \\
\hline & $\begin{array}{c}\text { First } \\
\text { mate }\end{array}$ & $\begin{array}{c}\text { Second } \\
\text { mate }\end{array}$ & $\begin{array}{l}\text { Third } \\
\text { mate }\end{array}$ & First mate & $\begin{array}{c}\text { Second } \\
\text { mate }\end{array}$ & $\begin{array}{l}\text { Third } \\
\text { mate }\end{array}$ \\
\hline Interview 1 & 88 & 59 & 85 & 69 & 59 & 61 \\
$(n)$ & $(96)$ & $(87)$ & $(52)$ & $(96)$ & $(87)$ & $(49)$ \\
\hline $\begin{array}{l}\text { Interview 2 } \\
\text { (n) }\end{array}$ & 90 & 79 & 80 & 70 & 69 & 61 \\
\hline $\begin{array}{l}\text { Interview 3 (in } \\
\text { last 9 months) } \\
\text { (n) }\end{array}$ & 60 & 63 & 60 & 54 & 54 & 61 \\
\hline $\begin{array}{l}\text { Interview 4 (in } \\
\text { last 9 months) } \\
\text { (n) }\end{array}$ & $(67)$ & $(57)$ & $(43)$ & $(41)$ & $(37)$ & $(31)$ \\
\hline
\end{tabular}

We asked whether the best mates had been in trouble with the police. At the first two interviews, the question was whether they had been in trouble at any time during their life, whereas for the third and fourth interviews, the question changed to 
whether they had been in trouble since the last interview. This did not necessarily mean that the mate had a conviction, because respondents in England would understand the question as also being in trouble with the police, but not being prosecuted, or being suspected by the police of having committed an offence. We also asked whether the respondent himself had been offending together with the best mate (see Table 2).

From the first interview, it became clear that most best mates had been in trouble at some point in their lives - so they, as well as the respondents themselves, were offenders. Moreover, most respondents had offended together with their best mates. The picture which Warr (2002) paints of delinquents who offend together, in a number of small groups, also seems to hold true of the Sheffield Desistance Study. Best mates were important and often co-offenders.

In later interviews, we looked at current patterns of offending. We see that the majority of best mates were still those who had recently been in trouble with the police, but the frequency had declined considerably, with 30-40\% not having been in trouble recently - and by interview 4, only a quarter of respondents were offending together with their best mates. However, we do not know yet whether our respondents and their mates were all desisting during this period or - given the changes in named mates which were very apparent (as we have seen above, only one named mate was likely to stay constant) - whether respondents were changing their mates as they desisted, towards those who were less likely to be offending (or at least less likely to be currently offending).

A linked question is whether mates were using illicit drugs, particularly 'hard drugs' (almost all of our sample were using cannabis, which they usually considered not to be a criminal activity). By 'hard drugs', they meant opioids (heroin, cocaine, crack cocaine), although those who took drugs were likely to take a considerable range including amphetamines, ecstasy, methadone, and prescription drugs (though not solvents). In the first interview, less than half of respondents $(35 \%)$ thought they had a hard drug problem themselves whilst $8 \%$ thought they had a soft drug problem. This decreased by the fourth interview (with 18\% thinking they had a hard drug problem, $7 \%$ a soft drug problem). Equally, only some thought their offending was due to drugs or alcohol (at the first interview, 32\% said they thought all their offending was due to drugs or alcohol, whilst $21 \%$ thought most of it was, $11 \%$ thought some or not much of it was, whereas $34 \%$ said none of it was). Considerable cultural differences appear to exist between countries as to the extent to which persistent offending or offending which leads to involvement with the criminal justice system is connected to drugs. Healy's $(2012 ; 2016)$ probationers in Ireland almost all had a hard drug problem, whereas one third of the Sheffield sample said none of their offending was linked to drugs.

Were their best mates doing drugs? We only asked this question in the last two interviews. In interview 3, 13\% of respondents said their first-named best mate did 
hard drugs, whilst $18 \%$ said their second-named best mate did, and $15 \%$ said their third-named best mate did. The corresponding proportions for interview 4 were $17 \%$, $21 \%$, and $23 \%$. So only for a minority of our respondents was being with one's best mates associated with doing hard drugs. Being part of a hard drug culture was linked to offending for only a small number of our sample, as they saw it.

\section{Mates and desistance}

So far, we have seen that mates were important to our men in their late adolescence and early adulthood, and that they remained important throughout this time, although they saw their best mates less frequently than they had done at the time of the first interview. Mates were important for support, and they were trusted. Moreover, their mates had often been offenders and had indeed offended with them. Yet, most of this group were also trying to desist, and their frequency of offending declined overall over the four years of the study. At the same time, best mates often did not remain the same people - there was a lot of change in who would be named best mate. Was this changing pattern of mates linked to desistance?

Measuring desistance is problematic because we can never know whether someone has finally finished offending. It is often also a process over many months or years, with some steps forward being followed by setbacks or falling for temptation. The Sheffield Desistance Study sample started with most participants being persistent offenders and their criminal records going back into adolescence and childhood (Bottoms \& Shapland 2011). We have therefore used a number of measures of desistance.

One measure taps the extent of official offending and how it has changed. We were able to obtain the official criminal records of convictions and cautions for all our sample up to 31 August 2007. This measure of desistance according to official records is therefore the extent of offending between the date of the third interview and 31 August 2007 (a period of about 18 months). This was coded into three categories: 'no recorded offences'; 'some offences but not as many as the upper quartile for the sample'; 'in the upper quartile of offending'.

Another measure of desistance is whether self-reported offending went up or down over the period between the first and the last interview. Using self-reported offending as a desistance measure removes uncertainties about whether the police caught that offender and how long the criminal justice process takes to arrive at and record a conviction; but of course, self-reported measures are subject to the respondent keeping quiet about their activities or indeed boasting about them. However, as we have discussed above, most of our measures about lifestyle and mates come from selfreports as well, so a self-reported measure of desistance is likely to be more consistent with regard to how that individual sees their life at that point, as well as more fine-grained in terms of offending. 
Finally, the results of the study have led us, like Giordano (2016), to theorise that desistance tends to be preceded by a cognitive decision (often with emotional elements) to try to desist or at least to change one's current offending lifestyle. We asked respondents at each interview to choose between whether they had 'stopped offending' (except at interview 1 when all of them were offending); or 'I have made a definite decision to try to stop'; or 'I would like to stop, but I am not sure if I can'; or 'I am unlikely to stop at least in the near future'. Given that we wished to separate those who had stopped or taken definite decisions to stop from others, we then amalgamated the last two categories so as to provide a dichotomy for interview 1 and a trichotomy for the other three interviews.

How do these three measures of offending/desistance (official and self-reported delinquency and intentions to desist) relate to mates and particularly to offending mates? First, considering officially recorded criminality, we find there is no significant difference between whether a respondent's first-named best mate at interview 1 or at interview 2 had been in trouble with the police and the extent of the respondent's official offending after interview 3. In other words, having a best mate who has been in trouble does not predict future criminality (or desistance). There was a highly significant relationship between having a first-named best mate in trouble at interviews 3 and 4 and official offending after interview 3 (chi-square $=7.455, \mathrm{df}=2, \mathrm{p}=0.024$ for interview 3; chi-square $=9.094, \mathrm{df}=2, \mathrm{p}=0.011$ for interview 4 ). However, for interviews 3 and 4, the question was whether the best mate had been in trouble in the last nine months or so. So the result is partly artefactual, particularly if the two had been offending together - we could merely be measuring the correlation between self-reported offending/co-offending and offending resulting in an official conviction during the same period.

Considering self-reported criminality (whether it went up or down between interviews 1 and 4), there was no relationship with whether someone mentioned having best mates or with how long they had kept that same best mate. The same was true in relation to making a definite decision to desist. So some of those who desisted (and some of those who increased their offending) were loners, some had mates; some changed their mates and some did not. Equally, there was no relationship with self-reported offending or decisions to desist in terms of how old respondents' best mates were. However, naming a female best mate (not one's partner) only occurred in later interviews and amongst those who were desisting. In terms of having mates who did hard drugs, there was no relationship between this and self-reported offending increasing or decreasing during interviews 1 to 3 - but there was a significant relationship at interview 4 (ANOVA F $=6.593, \mathrm{p}=0.013)$. Continuing to have a best mate who did hard drugs was by then associated with a continuation of offending.

This general lack of relationship between who one's mates are at any point in time and offending seems to be counterintuitive, given the known association between having delinquent peers and offending in adolescence (Farrington et al. 2006; Wikström et al. 2012). Is early desistance so different from the process of becoming 
delinquent and increasing delinquent involvement that it is not important who one associates with? That extent of 'asymmetric causation' (Uggen \& Piliavin 1998) seems to be very unlikely. ${ }^{6}$ Or does the answer lie in the fragile nature of being a best mate during these years? We know that though it was common to name one best mate over two or more interviews, it was very rare to name the same two or three best mates. Equally, Warr (2002) found that the offenders he was studying in the US offended in small groups of 2-4, but each offender knew a wide range of people and the small groups changed their membership frequently.

So does the answer lie in changing mates? That mates change frequently so that those who are desisting may change to different best mates, perhaps ones who are less frequently offending (or doing hard drugs)? This fits the picture of women only being named as best mates later on and for desisters, as well as the connection at interview 4 between increased offending and having a best mate who did hard drugs. We asked respondents at interviews 3 and 4 whether they had changed their mates since the previous interview, finding that $44 \%$ said they had changed their mates at interview 3 and $35 \%$ at interview 4 . Thus, changing mates was clearly common, and respondents said this was because of their own changing nature or lifestyle.

\subsection{Connections respondents made between their mates and their offending}

Did respondents themselves think there was a connection between their mates and their own offending? At interview 4, we asked whether the mates they had first named (in interview 1) were still their mates now. Answers were mixed - 40\% said yes, $25 \%$ said some of them, and $35 \%$ said no. There was no relation between whether their self-reported criminality had gone up or down and whether their mates had stayed the same. So we then asked them to tell us a bit more about why their original mates were still their friends or not.

The most frequent answer was 'I don't see them anymore' (33\% of those who gave reasons, the majority of whom had reduced their offending), followed by 'they would get me into trouble' $(22 \%)$ - with the implicit meaning that the respondent did not want to get into trouble and indeed wanted to desist. Similar results occurred when reasons were compared between those who had no recent official convictions and those who had. Other reasons included 'They moved away', 'I moved away', 'I fell out with them', and, for one or two still offending, 'They grassed me up'. Clearly, respondents themselves linked the mates they went around with - and where they went - to the potential for offending:

6 'Asymmetric causation' is a concept which postulates that the factors leading to desistance from a criminal career are not simply the reverse of the original criminogenic factors. 
I don't really fit in with what he does and that [a previously named best mate]. He just don't do nothing. He's just a dosser. Just drinks all the time. Doesn't work. I just can't be around people like that. Coz I don't want to do that. (interview 4)

Yeah, I stopped seeing all them ... I don't hang about with them no more. They only get into trouble, don't they? ... And me girlfriend as well because she didn't like them. (interview 4)

However, though desisting respondents were more likely to make the link between their former friends and the risk of them offending, some of those who were still offending, or who did so more frequently, also made this link.

At interviews 3 and 4, we asked whether people had changed their mates in the last nine months, and if so, why. The most frequent reasons given at interview 3 were 'got into trouble when with them' (27\% of those changing their mates) and 'not on drugs anymore' (16\%), with other reasons being that they had been in prison, that they had fallen out, or that they had no time (because of their partner or their job). Here we see for the first time the potential influence on desistance of girlfriends and work - and the tension between those demands and that of spending time with mates. Far more common, though, was the perceived need to spend less time with previous mates in order to start or keep on desisting - a direct perceived link between mates and offending:

If I carried on knocking about with people I used to, I wouldn't be sat here now. I'd probably be back in jail. (interview 4)

By interview 4, reasons for changing one's mates became even more desistancefocused: 'I'm not offending now' (17\%); 'just don't see them' (15\%); 'got into trouble when with them' $(12 \%)$; 'no time' $(12 \%)$; and 'been in prison' $(10 \%)$. Respondents clearly saw the links between their previous (offending) friends and their own offending. Again, however, the ones who saw those links were from both groups: the ones desisting and the ones still offending.

Why did those seeing these links still offend? In the introduction, we saw that Costello and Hope (2016) have recently drawn attention to the situational dimensions of peer pressure, and we also noted that the excitement often generated in groups can be an important situational issue. ${ }^{7}$ So it is important to recognise that offending can happen suddenly, in a particular social and environmental situation, even among those who have begun to desist - as in the case of 'Len' reported in a previous paper (Bottoms \& Shapland 2016, pp. 111-112). Len had been taking active steps towards desistance, but one evening, he met an old friend and got drunk with him, then together they committed the offence of taking and driving away a car. In other words,

7 Also note that the 'need for excitement or to relieve boredom' was the third most common obstacle to desistance identified by respondents in the interviews in the Sheffield Desistance Study (Bottoms \& Shapland 2011, p. 61, Table 2.4). 
generally, mates are one thing and the immediate situation is another, although the desistance literature is only at the start of working out the connections between mates and the situations one finds oneself in. However, we do know from a data analysis of the Sheffield Desistance Study that the majority of men in its qualitative subsample (14 out of 18) reported having adopted a tactic of 'diachronic self-control' at some stage (that is, self-control achieved by planning their daily activities in order to avoid situations where they thought they might offend) (Bottoms 2013, p. 80). These data therefore show that would-be desisters are themselves aware that in particular situations - and perhaps especially when they are with certain people - they can be tempted to do things that they would not want to do in their more rational moments. In light of this, we now need to consider issues of lifestyle and how - as far as we can tell - mates fitted into the lifestyles of our sample during the research period.

\section{Changing lifestyles}

In previous publications, we have characterised early desistance, as shown in the Sheffield Desistance Study, as an iterative process in which agency and behaviour interact, with behaviour also being constrained or facilitated by the structural aspects of individuals' lives (Bottoms \& Shapland 2016). Hence, though we think that the impulse or decision to desist does come first, behavioural change is strongly affected by the possibilities afforded by the situations in which the individual exists - or can access - and by the obstacles to desistance which stem from the individual's past offending. These obstacles include the need to find legitimate sources of income (in place of what has previously been provided by offending), difficulties in finding employment, lack of education and training, the emotional pull of the excitement of offending, and the simple fact of having criminal convictions (which are supposed to be declared to employers and others) (Bottoms \& Shapland 2011). Maintenance of the decision to desist (and continued progress down the behavioural path of desistance) will depend on how the first forays into new patterns of behaviour fare.

In terms of mates, desistance might therefore include changing mates and also potentially changing social activities, which would have the effect of changing the encountered people. In order to assess social activities, from interview 2 onwards, we started asking what respondents did on a typical Friday, both during the day and in the evening (Friday evening is usually a social going-out time for young people in England) ${ }^{8}$ 


\subsection{The daytime}

What our respondents did during the day on Fridays is shown in Table 3. We can see that at interview 2, very few were in work (or in any form of education). So their lives were dominated by hanging around with their friends and any girlfriend, mostly at their own or their friends' houses. Very few were out of the house on positive pursuits (such as shopping or playing snooker). Calverley (2013, p. 134) found that for some of his desisters of Black or dual heritage origin, the gym became a 'place of desistance' where they could go to keep off the streets and avoid their previous criminal associates. However, this was rare for our sample who seemed to be continuing a mid-adolescent lifestyle, without school or other activities - and sometimes, it felt pretty boring to our respondents. No wonder that offending, drinking, and doing drugs played a major role for several. At this point, there was no difference between those who were later to desist and those who would later continue selfreported offending in terms of whether they said they were hanging out with their mates, offending, or working. The same was true for official convictions. Indeed, those who later desisted as measured by official convictions and those who said they had taken a definite decision to desist were more likely to be spending time with mates. However, though not statistically significant, those who said they were likely to be drinking or doing drugs were later less likely to be those who desisted on the self-reported and official offending measures, as well as not having taken a definite decision to desist.

By interview 3, there had been considerable changes for some. A much higher proportion had found some form of work (concentrated among those who had taken a definite decision to desist). Time spent with family members (including partners) and children also became a dominant activity for others. The increasing influence of family linked to the fact that some of those who were desisting were beginning to be able to breathe new life into damaged family relationships with their parents and other relatives. The proportion saying they were likely to be spending time offending went down, as did the proportion of those saying they would be drinking or doing drugs. However, as in interview 2, those who were increasing their offending over the period of the study were more likely to be saying that they were drinking and, this time, offending/grafting. 
Table 3

Main activities during the day on a typical Friday (percentages)

\begin{tabular}{|l|r|r|r|}
\hline & Interview 2 & Interview 3 & Interview 4 \\
\hline Hang out with mates/girlfriend & 30 & 19 & 30 \\
\hline Watch TV/stay around house & 19 & 17 & 15 \\
\hline Grafting (offending) & 13 & 6 & 5 \\
\hline Work & 8 & 21 & 22 \\
\hline Drinking & 8 & 4 & 5 \\
\hline Do drugs & 8 & 0 & 8 \\
\hline With family members/children & 2 & 15 & 5 \\
\hline Shopping/gym/snooker & 8 & 8 & 7 \\
\hline Other & 5 & 11 & 3 \\
\hline (n) & $(63)$ & $(53)$ & $(74)$ \\
\hline
\end{tabular}

There was much less difference between the answers in interviews 3 and 4 in terms of a typical Friday daytime. On the prosocial side, work was continuing and becoming important at about the same rate (primarily among those who were desisting or had made a decision to do so). But hanging around with mates or a partner was still the dominant activity - for those desisting as well as for those offending. At interview 4 , those who said their dominant activity was drinking, doing drugs, or grafting/offending were far more likely to be continuing to offend on both the self-reported and official offending measures. ${ }^{9}$ So if we look at any one activity, we cannot say that all those adopting that daytime lifestyle were desisting or were offending, but there were trends that those desisting were either adopting a stay-at-home path either by themselves or with family - or they were working or spending time with mates (but not drinking or doing drugs).

It looks as though for some, the path to desistance can mean a time of breaking off offending (and drinking or doing drugs), without the compensation of work or family. For a few individuals, this could lead to an extreme form of diachronic selfcontrol, whereby they decided deliberately not to go to their previous haunts, but did not have any other ways to spend their time except for playing computer games and watching TV - very boring pastimes. But overall, it is clear that there was no single path to desistance in terms of spending time and lifestyles - for some it was solitary, but for others, family, children, or (perhaps less offending) mates filled the gaps left by the excitement of offending, drinking, and drugs:

9 Some of those still doing drugs completed interview 4 (but not interview 3), so there is actually no real increase in those doing drugs. 
It's changed loads. At one time, I'd be grafting [offending], now I hardly ever go out. All I've done is stay in. ... I'll either be here with our [family member] or I'll be up at our [second family member]'s. (interview 4)

\subsection{Friday night}

We can also look at how respondents said they spent a typical Friday night (Table 4). At interview 2 (and indeed throughout the study), a really popular activity named was going out drinking, as was going clubbing - both typical late adolescent/early twenties activities. At this point, there was little conjunction with desistance - as many of those saying they had taken a firm decision to desist were going out drinking as those who had not - and those who were later to continue their official offending were (if anything) more likely to stay with their families or partners than to go out drinking. When asked at interview 2 who respondents would generally be with, $62 \%$ said their mates, with just 22\% saying their partner, $11 \%$ their family, and $5 \%$ would be on their own. Going out for a meal, working, or staying in (on one's own or with mates) tended to appear only in later interviews, which mirrors social trends from late adolescence into the mid-twenties when people go out to eat rather than just to drink. Note that offending, as one would expect, was rare on Friday nights - general property crime, including domestic burglary, tends to be a daytime pursuit.

Table $4 \quad$ Main activities on a typical Friday night (percentages)

\begin{tabular}{|l|r|r|r|}
\hline & Interview 2 & Interview 3 & Interview 4 \\
\hline Go out drinking & 35 & 42 & 32 \\
\hline Stay in with family/partner & 32 & 34 & 32 \\
\hline Go clubbing & 21 & 9 & 12 \\
\hline Grafting & 5 & 2 & 5 \\
\hline Stay in on one's own & 0 & 8 & 3 \\
\hline Go out for meal/work & 0 & 0 & 4 \\
\hline Stay in with mates & 0 & 0 & 7 \\
\hline Other & 8 & 6 & 4 \\
\hline (n) & $(66)$ & $(53)$ & $(74)$ \\
\hline
\end{tabular}

To what extent were these patterns of evening activities related to offending or desistance? The answer, as with much of the social context around mates, is that there was no clear pattern which fitted the typical desister or persister. So, at interview 3 , more of those whose self-reported offending went down by the end of the study were staying in with their family or partner, or on their own, but some of those who increased their offending were doing the same. At interview 4, a hard core were still going clubbing on a Friday night (half of whom were increasing their self-reported offending), but the pattern of who respondents would be with was quite similar to 
that in interview 2, with 58\% saying they would be with their mates, $25 \%$ with their partner or girlfriend, $15 \%$ with their family, and $1 \%$ on their own. It is clear that there was no neat separation of desisters being with their partners or families, whilst those whose offending was increasing were with their mates. Mates remained important for respondents' social life - which means that it was key who one's mates were.

We also asked how much respondents would typically spend on a Friday night, though some could not estimate that. At interview 2, the mean amount was $£ 68$ ( $\mathrm{n}=$ 50), at interview $3 £ 89(\mathrm{n}=34)$, and at interview $4 £ 86(\mathrm{n}=55)$. However, there was a significant difference at interview 3 between those whose self-reported offending was decreasing and those among whom it was increasing - with the latter definitely spending more (a mean of $£ 111$ compared to $£ 67$ for those whose offending was decreasing, ANOVA F $=4.221, \mathrm{p}=0.048)$. There were similar findings at interview 4 , though they were not significant $(\mathrm{p}=0.078)$. So there does seem to be a split related to desistance in terms of spending money on a Friday night, with those offending being more able to afford considerably more.

What were respondents' own views about their social lives? Did they think they had changed their lifestyles? At interview 4, we asked them to look back over the last three years and say whether their typical Friday had changed. The most frequent response was that they now did not go out as much $(32 \%, n=71)$, but $30 \%$ said there was no change for them. A minority said they did not offend as much or at all, or that they now did not drink too much or take drugs - generally that they had settled down:

I don't go out and celebrate it's Friday ... I don't do it anymore. I don't do any crime anymore. I don't commit any crimes. I don't act like an idiot around the streets. I don't hang around on the streets. Things like that. (interview 4)

But these patterns occurred across the whole group, irrespective of offending, and seemed to be related to age and social context. How much they went out, for example, did not tally neatly with offending patterns - those going out more by interview 4 included those whose offending was increasing as well as those whose offending was decreasing. Nor was there much sign of those who were offending staying in a more youthful pattern - in relation to official offending, for example, $23 \%$ of those who had no offences after interview 3 said their Friday pattern had not changed, compared to $24 \%$ of those who had a few offences. However, more of those who were offending at a rate in the upper quartile (43\%) said they had not changed their Friday night pattern.

What we also found was that at interview 4, when we asked how many nights respondents generally spent at home, there was a subset of people who had made a definite decision to desist and who spent all or almost all their nights at home $(55 \%$ of those who said they had made a definite decision were spending six or seven nights 
at home). Just as we saw a period of solitary, rather boring living for some in interviews 2 and 3, by interview 4, girlfriends and family clearly had an effect for some. But this home-loving lifestyle did not entirely relate to offending: a few were spending all their evenings with girlfriend and family - and still went out offending in the daytime.

What were their own views? Several thought the way they spent their time had an effect on their offending $-27 \%$ thought it had a big effect, $26 \%$ thought it had some effect - but $47 \%$ thought there was no effect. Those who thought there was a connection between their lifestyles and their offending brought up some very proximal connections to offending - that offending was related to them drinking (33\%), just being around and out (30\%), or for a small minority, it was related to taking drugs (8\%). Respondents had clearly worked out (or been told so by probation staff or drug workers) that there were triggers to their offending. However, the more long-term lifestyle elements which have dominated the turning point desistance literature marriage, family, work - were not mentioned in response to this 'lifestyle' question. Perhaps that was the case because this was still early desistance for many, and they may well not have been sure that they could continue to desist.

\section{How are mates linked to desistance or continued offending?}

From the results of the Sheffield Desistance Study, if one were to draw a picture of the relationship between mates and desistance, this would not be a simple straightforward path, a linear route from mates $=$ bad $=$ offending to mates less important $=$ other relationships $=$ desistance. It would be more of a tangled skein where different individuals have followed slightly different paths and in which mates have played and continue to play significant roles for our respondents. The Sheffield study, however, is a study of men in their early twenties who, like many others of their age, were moving into more settled patterns and lifestyles. Because of the particular sample, respondents were only in the early stages of desistance. It is possible that later on, if desistance is maintained, the role of their mates will change - but we do not know this at present.

The story of desistance as shown in the literature - what we may call the 'typical desistance tale' - is one which contains many of the elements we have outlined above: the increasing importance of a partner and work, a recognition that some mates are linked to offending (as often is drinking and drugs), the temptation created by being in certain places with certain people, a gradual path towards desistance. As we have noted previously (Bottoms \& Shapland 2016, p. 113), however, the complexity of the desistance narratives of the men in our sample makes us cautious about the concept of 'turning points' (Laub \& Sampson 2003), whereby an event (marriage, obtaining a job) decisively pushes someone into a desisting path. Instead, in our study, the roles of partners and work were more gradual and might follow decisions to desist. 
The typical desistance tale has been relatively silent on the role of mates, perhaps because few studies have concentrated either on mates or on patterns of social life in relation to desistance. We found that for our sample, mates were not simply playing their typical assigned role in the criminological literature (as partners in committing offences). In contrast, mates were key for support and spending time with. Mates were equally important at this time of life for those who were desisting as well as for those who were continuing to offend. But who exactly those mates were could change quite rapidly within a few months or years. Changing mates was a matter of deliberate choice on occasions, linked to perceptions that they were bad news in terms of offending and the respondent's efforts to desist. But mates themselves were also changing their lifestyles, and the frequency of seeing them seemed to reduce over the three to four years of our study, as did preferred social activities (less clubbing, less drinking and drugs, more time at people's houses). Additionally, many respondents were very aware that in certain situations, the temptation to offend could overcome their resolve to desist, and so they frequently took steps to avoid those situations.

The desistance literature has stressed the importance of both agency and structural elements in desistance. In order to desist, one needs to decide to go down that route. But the obstacles to starting and maintaining desistance come from much broader societal elements, such as the possibilities for employment and housing, and societal/official reactions to those with criminal convictions. From studying mates, we would argue that the working out of these broader factors in the macro-context, also affects key micro-aspects of desistance. They affect both the potential for social life and the potential for offending. One cross-cultural example is the role of the car. So, for example, in England, social life for those in late adolescence tends to revolve around indoor venues (because of the weather), particularly places serving alcohol such as bars and clubs. Drinking is legal from age 18. In the United States, drinking is only legal later, but cars serve as an alternative social venue, as $\operatorname{Warr}$ (2002) has shown. In England, a typical criminal career for those born in the early 1980s, as were the members of our sample, would include offences of stealing cars (joyriding) or stealing items from cars (Shapland \& Bottoms 2017). Offenders in their early twenties would be banned from driving, and though some in our sample still drove (for example, to take their children to school), they would not spend a lot of time 'hanging around' in cars in full view of the police. Their social life could not include much time spent in cars.

In terms of early desistance, desisting is a matter not only of where one is, but of the situations and people that may provide temptation. As we have seen, desisting may be a fairly boring path, particularly without a steady girlfriend or supportive family. So sometimes, who one's mates are and where they meet can become key to the difficulty of staying on that desistance path. Our respondents were very aware of this, but given the need for social support from mates and despite often using considerable amounts of diachronic self-control, not all of them were able to continue to 
resist the temptations that came their way. The result is that there was no single formula for desistance: mates (and the changing pattern of mates), partners, family, work, and lifestyles at one point or another all contributed to the pattern of early desistance.

\section{References}

Akers, R. (1998): Social Learning and Social Structure: A General Theory of Crime and Deviance. New Brunswick, NJ.

Blokland, A., Nagin, D. \& Nieuwbeerta, P. (2005): Life Span Offending Trajectories of a Dutch Conviction Cohort. Criminology 43/4, pp. 919-954.

Bottoms, A.E. (2013): Learning from Odysseus: Self-Applied Situational Crime Prevention as an Aid to Compliance, in: P. Ugwudike \& P. Raynor (eds.), What Works in Offender Compliance: International Perspectives and Evidence-Based Practice. Basingstoke, pp. 67-89.

Bottoms, A.E. \& Shapland, J. (2011): Steps Towards Desistance Among Male Young Adult Recidivists, in: S. Farrall, M. Hough, S. Maruna \& R. Sparks (eds.), Escape Routes: Contemporary Perspectives on Life after Punishment. London, pp. 4380 .

Bottoms. A.E. \& Shapland, J. (2016): Learning to Desist in Early Adulthood, in: J. Shapland, S. Farrall \& A.E. Bottoms (eds.), Global Perspectives on Desistance. London, pp. 99-125.

Calverley, A. (2013): Cultures of Desistance: Rehabilitation, Reintegration and Ethnic Minorities. London.

Carrington, P.J. \& van Mastrigt, S.B. (2015): Co-offending in Canada, England and the United States: a Cross-National Comparison, in: M. Bouchard (ed.), Advances in Research on Illicit Networks. London, pp. 123-140.

Costello, B.J. \& Hope, T.L. (2016): Peer Pressure, Peer Prevention: The Role of Friends in Crime and Conformity. New York.

Costello, B.J. \& Zozula, C. (2016): Peer Influence: Mechanisms and Motivations, Deviant Behavior, published online 15 December 2016; http://dx.doi.org/10.10 80/01639625.2016.1260387.

Farrington, D., Coid, J., Harnett, L., Jolliffe, D., Soteriou, N., Turner, R. \& West, D. (2006): Criminal Careers up to Age 50 and Life Success up to Age 48. Home Office Research Study No. 299. London.

Giordano, P. (2016): Mechanisms Underlying the Desistance Process: Reflections on 'A Theory of Cognitive Transformation', in: J. Shapland, S. Farrall \& A.E. Bottoms (eds.), Global Perspectives on Desistance. London, pp. 11-27. 
Gottfredson, M.R. \& Hirschi, T. (1990): A General Theory of Crime. Stanford, CA.

Healy, D. (2012): The Dynamics of Desistance: Charting Pathways through Change. Abingdon.

Healy, D. (2016): 'I’ve Always Tried but I Hadn’t Got the Willpower': Understanding Pathways to Desistance in the Republic of Ireland, in: J. Shapland, S. Farrall \& A.E. Bottoms (eds.), Global Perspectives on Desistance. London, pp. 50-65.

Horney, J., Tolan, P. \& Weisburd, D. (2012): Contextual Influences, in: R. Loeber \& D.P. Farrington (eds.), From Juvenile Delinquency to Adult Crime: Criminal Careers, Justice Policy and Prevention. New York.

Katz, J. (1988): The Seductions of Crime. New York.

Laub, J. \& Sampson, R. (2003): Shared Beginnings, Divergent Lives. Cambridge, MA.

Piquero, A., Farrington, D. \& Blumstein, A. (2007): Key Issues in Criminal Career Research: New Analyses of the Cambridge Study in Delinquent Development. Cambridge.

Reiss Jr., A.J. \& Farrington, D.P. (1991): Advancing Knowledge about Co-offending: Results from a Prospective Longitudinal Survey of London Males. Journal of Criminal Law and Criminology 82/2, pp. 360-395.

Shapland, J. \& Bottoms, A.E. (2017): Offending and Offence Patterns in the Early Stages of Desistance: A Study of Young Men in England, in: A. Blokland \& V. van der Geest (eds.), The Routledge International Handbook of Life-Course Criminology. London.

Skardhamer, T. \& Savolainen, J. (2016): Timing of Change: Are Life Course Transitions Causes or Consequences of Desistance?, in: J. Shapland, S. Farrall \& A.E. Bottoms (eds.), Global Perspectives on Desistance. London, pp. 170-184.

Uggen, C. \& Piliavin, I. (1998): Asymmetrical Causation and Criminal Desistance. Journal of Criminal Law and Criminology 88/4, pp. 1399-1422.

Warr, M. (2002): Companions in Crime. The Social Aspects of Criminal Conduct. Cambridge.

Wikström, P.-O., Oberwittler, D., Treiber, K. \& Hardie, B. (2012): Breaking Rules: The Social and Situational Dynamics of Young People's Urban Crime. Oxford. 


\title{
Closed Windows for Desistance: Young Multiple Offenders between Youth Services and the Justice System
}

\author{
Diana Willems and Jana Meier
}

This paper examines the findings of an empirical project carried out by the Centre for the Prevention of Youth Crime (Arbeitsstelle Kinder- und Jugendkriminalitätsprävention) at the German Youth Institute (DJI) ${ }^{1}$ on the careers of male young multiple offenders between youth services and the justice system, paying special attention to the issue of desistance. After an introduction into the research design and a description of the qualitative interviews, the paper concentrates on the multiple problems male juveniles are facing, as well as the way they perceive and describe possible windows for desistance from their criminal careers. The analysis takes into account both the viewpoint of young male offenders and interviews with professionals from youth services and the justice system, as well as records from the justice system and the youth welfare office.

\section{Aims of the research project, theoretical reflections and methodological design}

The project on which this analysis is based looks at male adolescents who have (repeatedly) committed violent crimes, usually are in problematic (social) situations in life and have had experiences with child and youth services (cf. Meier 2015). The underlying research perspective focuses on institutions, investigating which role the justice system as well as child and youth services play in the biographical processes of young people under especially difficult circumstances. The project asks how institutions influence cognitive changes within young people or decisions to change their behaviour in response to action or inaction on the part of the institutions involved. Analysing the complex interconnections between these factors, the project aims at casting a light on the dynamics of these life courses from various perspectives - those of the young people and their parents as well as of the institutions involved

1 The project Jugendliche Gewalttäter zwischen Jugendhilfe und krimineller Karriere („Young violent offenders between long-term contact with youth services and a criminal career") was carried out by Jana Meier and Anke Petrat between 2011 and 2015 and funded by the Federal Ministry for Family Affairs, Senior Citizens, Women and Youth (BMFSFJ). The project was based at the Centre for the Prevention of Youth Crime at the German Youth Institute (DJI). 
- in order to find explanations for both the escalation and the termination of delinquent careers.

By taking into account questions that are specific to both the justice system and youth services, this study of young multiple offenders integrates two different research traditions: criminology and research into youth services. In line with the two research perspectives, one area of investigation is how delinquent careers develop and terminate, including possible risk and protective factors; another area is the difficult, unsuccessful processes influenced by child and youth services, i.e. cases where respective efforts do not reach young people. An important element of both research angles is that they mainly consider biographical developments and processes from the perspective of the young people concerned. Overall, less attention is paid to the role of institutions. This role, however, has been explicitly included in the present project so as to provide a wider view on "risk careers" (Risikokarrieren).

In order to gain new insights into the progression of especially difficult cases in Germany, a multi-perspective design was chosen. The starting point for the study were 30 qualitative, biographically oriented interviews with male juveniles aged between 15 and 18 who were in Jugendarrest (treatment at attendance centres not exceeding four weeks' duration) or Jugendstrafvollzug (custodial treatment at a young offenders' institution) at the time of the interviews. Among other things, the interviews focused on the young people's own (retrospective) evaluation of the contact they had had with the institutions and the youth services system. Based on a qualitative analysis of these interviews, recurring patterns were (re-)constructed and compared. Ten cases were analysed in-depth. Not only the aforementioned interviews were used but additional ones were conducted with the staff of child and youth services working in the cases, as well as professionals from the other involved institutions. The young people's records from youth services and the justice system were also analysed. As a further component of the analytical process, focus groups (including experts with professional experience in child and youth services) were used to discuss interpretations and preliminary findings as well as to sharpen the analytical view of the role and perspectives of youth services professionals.

\section{The situation: young people in conditions of particular risk}

The overall analysis of all interviews and records included in the study shows that the sample does in fact contain especially difficult biographies and risk careers. All male juveniles interviewed are burdened with multiple problems and risks (cf. Meier 2015, pp. 19-31). They have problems on an individual level, facing conflicts within the family and difficulties they cannot cope with, including the loss of people close to them. In several cases, family members have already spent time in prison. Many report conflicts, failures, and non-attendance at school, as well as frequent changes of schools. Consequently, those young people do not graduate but drop out from school. A large proportion of them also engage in the risky use of drugs and alcohol, 
and their circle of friends is dominated by young people in similarly problematic circumstances who also exhibit delinquent behaviours. Most of them are growing up in socially disadvantaged neighbourhoods and are affected by poverty. A subgroup of those young people interviewed who have migrant backgrounds also have a precarious residence status, with only short-term residence permits or none at all.

Most of the young people have been in contact with youth services institutions and the justice system from early in their biography. In these difficult cases, it is very clear from the records and the interviews with the professionals - but also from their own accounts - that the contact with youth services in particular is marked by numerous breaks and changes. It is often possible to reconstruct different definitions of needs and different support objectives which the involved institutions are pursuing or have pursued - differences which, in some cases, have contributed to the discontinuation or failure of support. Constant shifts between the institutions - youth services, school, police, justice system, and child and youth psychiatry - can be observed.

Experiences with child and youth services were not the only criterion for case selection; the young people had also committed one or more violent crimes. The analysis, however, shows a broad range of offences, as it is typical for this group of especially troubled multiple offenders. These range from property offences, fare evasion, and drug-related offences to serious bodily injury and attempted murder. In many cases, the number and severity of the offences committed increases with age, as do the various judicial sanctions - from non-custodial measures to custodial sentences in young offenders' institutions.

Due to the resources available (which vary between institutions), there are limitations on and very different forms of inter-institutional collaboration. The analysis of the records - especially for those cases where contact lasts over many years - further shows that even within the institutions, there are problems when cases are transferred from one professional to another, with transitional problems appearing here and elsewhere. There is also often a lack of support for reintegration into everyday life after the completion or discontinuation of support measures, or after release from a young offenders' institution or attendance centre. In some cases, the young people are unable to take up the offer due to additional acute stresses such as the loss of important people in their lives.

In retrospect, it seems to be particularly problematic that the many different phases of intervention which some of the young people have been through lead to a "blurring" of the roles of the "helpers". The young people are no longer able to accurately identify or recall which professional was responsible for what, and the way they remember the chronology of the various offered services differs from the records or accounts of the professionals. This suggests that the young people may not have been reached, or a durable connection may not have been established, or that suitable support may not have been provided at the right time. 


\section{Patterns of development between youth services and the justice system}

When it comes to criminal careers and desistance, criminology distinguishes between different types. The individual definitions of these categories are quite heterogeneous, however. A distinction, for example, is made between early and late starters, and desistance from delinquent behaviour is never regarded to be impossible (cf. Boers 2009).

In the present study, biographies were compiled - on the basis of the available data - in order to identify patterns (using timelines and other devices to make the sorting process more straightforward). In the following, a case study will serve to illustrate one of the difficult life courses in the sample (Meier 2015, pp. 33-36).

For one of the young people interviewed (referred to in the following account as Sven), his risk career within the youth services system began at a young age. After acting aggressively towards a nursery teacher at the age of three, he was diagnosed with ADHD and underwent frequent periods of residential treatment in hospital. At the same time, his parents got divorced and he began to self-harm. Youth services began when he was about seven. At the special school, he had recurring behavioural problems, got into trouble for violence, and received several disciplinary measures. When he was about nine, his mother separated from his first stepfather. At twelve, he entered his second phase of institutional care and received additional support from youth services. During this time, he repeatedly displayed behavioural problems, continued to get into trouble for violence at school, and changed schools because of this. He was involved in a violent incident in which a police officer was injured and was drinking alcohol and taking drugs on a regularly basis. He committed thefts and violent offences as well as causing damage to property - while still being under the age of 14. In this period, he no longer had any contact with his father, and his grandmother, a very important person in his life, died. At 14, he entered his third phase of institutional care, in a residential care facility from which he ran away several times. He was supported by the youth welfare office and by Youth Services in Youth Court Proceedings (Jugendhilfe im Strafverfahren). At the same age, he was excluded from school and had further conflicts with the justice system. He was frequently absent from the new school and continued to consume drugs and alcohol. In the meantime, he had problems with his second stepfather. Aged 16, he was excluded from institutional care and left school. After court proceedings, he was sentenced to an anger management programme and community service. Further offences followed, and he dropped out of the youth services system, became homeless, and ended up in custody in a young offenders' institution (at the time of the interview).

As individual and striking as Sven's biography is, commonalities with other risk careers can nonetheless be identified. After compiling individual biographical processes, it was therefore an important methodological step to identify the different processes or risk careers present in the sample. In total, five patterns of long-term 
contact with the justice system and youth services were retrospectively reconstructed by generating qualitative typologies. These made it possible to differentiate problem areas, support needs, stresses, and processes, highlighting specific challenges for successful, customized case management in child and youth services, but also for the actions of other institutional actors (Meier 2015, pp. 31-41). These patterns are briefly presented in the following paragraph.

The first pattern comprises delinquent juveniles with a long history in the child and youth services system, i.e. a classic "childhood in care", in foster families and residential facilities run by child and youth services. The second pattern involves young people who had already been supported by the youth services system before their delinquent career began, mainly because of family problems. For some, the third group, delinquency is the only reason for contact with youth services. For a fourth group, addictive behaviour has had an influence on their "career" with youth services. (N.B.: A gap in the system was identified here: in many cases, programmes offered by youth services require recipients to be free of addiction - for example, in violence prevention programmes - and first send them to addiction support services. These, on the other hand, do not accept young people with a history of addiction and violence, as they cannot help violent young people and believe they need to attend violence prevention programmes first. This gap is only gradually being addressed with specialized programmes.) The fifth pattern involves a small group whose first contact with youth services occurs very late, in the context of youth court proceedings.

\section{Windows for desistance}

At last, this section takes a more in-depth look at constellations which, from the point of view of the young people or the professionals managing their cases, open or close windows for desistance. Desistance research is concerned with processes or moments in which criminal careers are stopped; there, some of the important turning points mentioned are stable couple relationships and job prospects (Sampson \& Laub 1993; Stelly \& Thomas 2011). This is a stability which, in the difficult biographies under discussion here, is often not (yet) given. Instead, the interviews point to a multitude of breaks in the life courses of these young people. Some of these breaks were unavoidable (death, separations), but in other cases, the young people criticize the work of the institutions whose job it would actually be to protect them. From the point of view of the young people themselves (and occasionally also from that of the professionals), breaks caused by changing schools, changing caseworkers, unsuitable support, and inappropriate or poorly coordinated sanctions could (retrospectively) have been avoided, or should at least have been accompanied by better support. In one case, for example, the youth welfare office is described as a punishing, controlling authority which wants to remove the child or young person from the fam- 
ily - and therefore cannot be trusted (Meier 2015, p. 47). In this example, the professionals are also aware of the negative attitude of the family as a whole towards all authorities, so "a constructive collaboration hardly [seemed] possible" (Meier 2015, p. 47). From the parents' point of view, this negative attitude was justified by their experiences of stigmatization and discrimination by authorities in Germany.

Another young person described the frequent changes, the numerous "ladies from the youth welfare office" who were never really able to cope with him (Meier 2015, p. 56). This interviewee was placed in a home at an early age due to child endangerment in his own family, and then shifted between different residential facilities - as well as child and youth psychiatric facilities (Meier 2015, p. 56). He felt disempowered by the authorities who in turn felt overwhelmed by his difficult family situation and the problems getting through to him; according to a youth services worker entrusted with his case, they "didn't really know what they should do with him" (Meier 2015, p. 60).

The multiple problems faced by a large proportion of the young men interviewed already became apparent at school, and the transition from primary school (which can extend as far as year 6, depending on the federal state) to secondary school proves to be especially difficult (Meier 2015, p. 67). A large proportion of them had to change schools several times and eventually dropped out without any school-leaving qualifications. The reasons given for the frequent changes of school were problems at school, non-attendance and delinquency at school. The reasons the respondents themselves gave for their offences (and thus the continuation of their delinquent careers) include not only the quest for peer recognition but also personal material problems and individual worries (e.g. illnesses in the family).

When asked what could have stopped them in their criminal careers, the interviewees repeatedly mentioned prison. Yet upon closer analysis, this was not altogether clearcut. Some male juveniles did describe fears and a certain deterrent effect in the leadup to a custodial sentence, but these were often dissipated during their time in custody, so this sanction on its own cannot be expected to have had a positive impact on good conduct (Meier 2015, pp. 49-55). Retrospectively, the young men themselves saw the key explanatory factors for preventing delinquency and promoting successful desistance as individual age-related development, a stable partnership, or job stability - thus concurring with the findings of Stelly and Thomas (2011).

At least in the case of those young people interviewed in the study, the many programmes, projects, and other forms of support which youth services provide for this difficult group of especially troubled male juveniles were unable to prevent or end delinquent careers (Meier 2015, p. 77). Sometimes the windows for desistance which could be opened by child and youth services programmes are closed by the service users themselves. Thus, some of the young people blame themselves for the failure of projects or support from youth services (Meier 2015, p. 52). This one-sided allocation of blame is sometimes also found in the interviews with professionals who in 
some cases attribute full responsibility for the failure of measures to the service users themselves (Meier 2015, p. 52). In their study of the major factors determining the effectiveness of socio-educational provision, Macsenaere and Knab (2004) observe that the initial situation of the young people is a key factor in terms of the support process and its effectiveness. They also note that a high proportion of support measures end prematurely or unexpectedly, particularly in the case of young offenders, leading to a high likelihood that the support will fail. Other important factors are the suitability of the support, the participation of the young people (and their parents), and the quality of the relationship between them and the professionals (Wolf 2007; Rätz-Heinisch 2005).

The analyzed interviews presented in this paper clearly show that youth services have difficulties gaining access to this group of especially troubled young people (and their families). In some cases, it was not possible to establish a robust working relationship, and even more often, the contact was characterized by instability or by dysfunctional and distrustful working relationships. There are various reasons for this failure to establish a relationship and to build up trust: this may lie with the individual recipients, but also with the institutions and the collaboration between them. For a successful working relationship, it is important to offer stability with continuity; this cannot always be guaranteed with changing caseworkers and changing areas of responsibility. Over and again, the analyses of the records and the verbal accounts of the male juveniles show that their own involvement in the ongoing processing of their problems and their own subsequent path in life - i.e. their "participation", a key parameter of German child and youth services - is not being activated.

The analyses of the interviews also show that the young person's main problem sometimes is not dealt with, especially if it is not carefully identified at the outset. In order to detect the escalation of problems in good time, it is important to work with schools - yet this step has often been omitted in the case of the young people interviewed. Young people can only be prevented from breaking off youth services support measures if the programmes and support offered match their needs. Overall, it is clear that transitions are especially vulnerable moments and that often there is no effective follow-up support after time spent in young offenders' institutions or attendance centres, or after youth services programmes.

\section{Conclusion}

Focusing on the perspective of the young people, a retrospective approach makes it possible to identify biographical turning points and moments which the individuals themselves perceive as opportunities to stop their delinquent careers. This helps broaden our knowledge about processes of desistance. Even if classical explanations seem to predominate here (stable partnership, job prospects), there are many more points which open windows for desistance from criminal careers - or close them again very quickly. For example, personal misfortunes can suddenly cause even a 
good preparation for transitions to break down, simply because the underlying basis

- the fundamental stability - is lacking. On the other hand, opportunities for turning points can open up elsewhere. For educational work with this particularly troubled group of young people, this means that - despite numerous breaks, shifts, and gaps between youth services and the justice system - it is vital to keep up offering these young people supportive relationships and to work towards continuity and stabilization in their everyday lives.

\section{References}

Boers, K. (2009): Kontinuität und Abbruch persistenter Delinquenzverläufe, in: Bundesministerium für Justiz (ed.), Das Jugendkriminalrecht vor neuen Herausforderungen. Jenaer Symposium 9.11.2008. Mönchengladbach, pp. 101-133.

Macsenaere, M. \& Knab, E. (2004): Evaluationsstudie erzieherischer Hilfen (EVAS). Eine Einführung. Freiburg.

Meier, J. (2015): Jugendliche Gewalttäter zwischen Jugendhilfe und krimineller Karriere. Abschlussbericht. DJI. München.

Rätz-Heinisch, R. (2005): Gelingende Jugendhilfe bei „aussichtslosen Fällen“! Biographische Rekonstruktion von Lebensgeschichten junger Menschen. Würzburg.

Sampson, R.J. \&. Laub, J.H. (1993): Crime in the Making. Pathways and Turning Points through Life. Cambridge.

Stelly, W. \& Thomas, J. (2011): Entwicklungsverläufe jugendlicher Mehrfachtäter, in: Boeger, A. (ed.), Jugendliche Intensivtäter. Interdisziplinäre Perspektiven. Wiesbaden, pp. 227-254.

Wolf, K. (2007): Metaanalyse von Fallstudien erzieherischer Hilfen hinsichtlich von Wirkungen und ,wirkmächtigen“ Faktoren aus Nutzersicht. Wirkungsorientierte Jugendhilfe. Band 4; www.wirkungsorientierte-jugendhilfe.de/seiten/download.h tml [10/11/2016]. 


\title{
Between Authoritarian Provocations and Promises of Development: Imprisonment as a Profound Biographical Experience of Conflict ${ }^{1}$
}

\author{
Mechthild Bereswill
}

The article initially describes characteristic features of a case of imprisonment as related to classic research on prisons. It then discusses the structural peculiarities of imprisonment of juvenile offenders, relating those features of confinement to the psychosocial dynamics of adolescence. In this connection, it also looks at the significance of gender constructions for working through an incarceration. The article goes on to present the central findings of qualitative longitudinal studies. The interviews make it possible to reconstruct the perspective of male youth and young adults. This is done from the perspective of biographical analysis that focuses on the conflicts of youth and young adults. In the context of this study, imprisonment becomes comprehensible as an intensive intervention into biographies most of which are highly discontinuous.

Being incarcerated is a shattering experience for a person's self-perception and orientations for action. This general observation encapsulates what classic and contemporary studies have established in detail regarding the perspective of prisoners toward the prison (Sykes 1974; Goffman 1961; Kersten \& von Wolffersdorff-Ehlert 1980; Liebling \& Maruna 2005; Toch 2005; Toch et al. 1989; Crewe 2009; Bereswill 2011; 2010; 2007; 2006; Neuber 2009; Koesling 2010; Bereswill \& Hellwig 2012). The demand of having to cope with the restrictive everyday world in a robustly authoritarian institution confronts inmates with experiences of infantilization, triggering feelings of anxiety, powerlessness and rage. Dealing with those feelings is connected with stresses and strains that should not be underestimated. What Sykes aptly described in his 1958 study The Society of Captives as the "pains of imprisonment" was characterized by Johnson and Toch some 25 years later as an evident objective of incarceration often blanked out and hidden in the public sphere: "One of the striking things about prisons is that we make no bones about the fact that we intend them to be uncomfortable. This feature is implied by two of the prisons' most popular

1 This paper is the translation into English of an article that has been published in full in the Handbuch Jugendstrafvollzug (Bereswill 2015). I am grateful to the editor of the Handbuch, Marcel Schweder, and the publisher BeltzJuventa for the possibility to present the original text here in a faithful and exacting English translation. William Templer took on the translation, to whom I also wish to express my heartfelt thanks for his painstaking work and suggestions. 
goals, punishment and deterrence, and it is a fond desideratum in the public's view of prisons" (1982, p. 13).

The severities of punishment and deterrence are in constant tension with the claim of resocialization of the prisoner - an aim that is ridden with controversy and has been repeatedly deemed to hold out little promise. For that reason, the prison is vehemently rejected from the perspective of abolitionism or non-intervention (Christie 1983; 2000; Scheerer 1984; Feest \& Paul 2008). Both older and contemporary studies of relapse into crime show that linking punishment and resocialization yields only limited success (Kerner et al. 1996; 2011). In that connection, successful resocialization is often equated with legal probation and the absence of reincarceration. By contrast, there is little discussion of the degree of impact the experience of imprisonment may exert on the orientations for action and self-perception of persons after their release from a closed institution.

Such narrowed points of view centered on delinquency also dominate the perspectives of juvenile offenders on imprisonment. Thus, recidivism rates are repeatedly cited in arguing against the closed confinement of youth and young adults. However, the limited success of resocialization associated with juvenile incarceration is also utilized by those demanding greater severity in punishing juvenile offenders. While some argue that imprisonment is fundamentally harmful, others contend that imprisoning juvenile offenders is not effective because young delinquents are not dealt with in a sufficiently strict and consistent manner.

Polarized standpoints typify the evaluation of an institutional penal setting that involves a powerful intervention into the life situation of young people. Likewise, when it comes to imprisonment of juvenile offenders in Germany today, what Johnson and Toch stressed still holds true: The incarceration of youthful offenders confronts them with severe and uncomfortable conditions. This is the most intensive interventional measure that the German Juvenile Court Act (JGG) knows in dealing with youth and adolescents. With an eye to the shock and internal upheaval evoked by incarceration in the personal experience of youth and young adults, it is no exaggeration to see imprisonment as a grave existential intervention into a biography in the making. The further course of a prisoner's biography is not determined by such institutional intervention but deeply and lastingly shaped by such action. Yet inversely, the experience of imprisonment is also grappled with and processed in the context of an individual's previous biographical experiences.

It should be borne in mind that an effective imprisonment intervenes in and powerfully impacts on the biographical processes of adolescents. Taking the multilayered interplay between characteristic aspects of imprisonment and the psychosocial dynamics of adolescence in post-industrial society as an analytical point of departure directs attention towards a key question: How are typical conflicts of juveniles and young adults expressed under conditions of closed confinement? The present paper will flesh out that perspective. Initially, it seeks to better clarify the contradiction- 
ridden situation of youthful offenders behind prison walls (1). This is then discussed in the context of the typical conflicts for young offenders strung between autonomy, dependence and attachment, conflicts that are intensified under the conditions of a closed institutional environment (2). Such conflicts are interwoven with biographical experiences. Only from a biographical perspective can the attempt to grapple and cope with imprisonment (during and after incarceration) be understood in a comprehensive manner. In order to make this assessment more concrete, the findings from a biographically grounded longitudinal study are sketched (3). The paper concludes with a discussion of the central research findings (4).

\section{Relations of tension}

Current imprisonment of juvenile offenders in Germany is marked by an irresolvable tension between punishment and education (Cornel 2011). The idea of education in contexts of closed institutional confinement remains as controversial as the paradigm of resocialization that frames the educational concept here. The postulate of education in this situation is marked by a special task and responsibility of society vis-àvis the young. According to the legislator, the imprisonment of juvenile offenders is supposed to provide a positive educational environment for inmates and to robustly support their integration into society. A distinct internal differentiation of the prisoners into several groupings, the implementation of residential groups, social training sessions, measures for finishing school or an apprenticeship, well-trained prison personnel, psychological and socio-educational counseling, and the development of a transition-management program for handling discharge are testimony to the fact that the policy mandate of juvenile offenders' imprisonment in Germany is being translated into relevant, scientifically grounded concepts (see Bereswill \& Höynck 2002; Walter 2006; Goerdeler \& Walkenhorst 2007; Stelly \& Thomas 2011). At the same time, it should be stressed that there are substantial differences between institutions and that the conditions for male and female juveniles and young adults likewise manifest serious differences. The present paper focuses specifically on male prisoners (on female juveniles and young women, see Jansen 1999; Neuber et al. 2011; Neuber 2015).

The everyday round in imprisonment of young male offenders is often characterized by overcrowding, understaffing, issues of poor building structure and maintenance as well as scenarios of crisis and violence. An additional compounding factor is that the interaction between all the members of the social organization 'prison' cannot simply be oriented according to the guiding perspectives of working alliances focused on educating the inmates; rather, such interaction must to a significant degree fulfill the demand for the security of the prison system. Moreover, this tension is in direct correspondence to the size of a facility and its spatial structures.

From the perspective of the prisoners and also of the prison personnel, this generates a situation that is laden with tensions and contradictions whose authoritarian basic 
structure goes hand in hand with concomitant challenges in regard to the legally proscribed scenarios of social learning. It is thus not surprising that imprisoned juvenile offenders respond to the authoritarian provocations and the educational demands of closed institutional confinement by resistance and withdrawal into their own peer group. That is also manifest in the open interviews conducted in two qualitative longitudinal studies in various juvenile detention institutions for young male offenders, which the paper refers to in the following. ${ }^{2}$ For example, the closed institutional detention of juvenile offenders is repeatedly described as a "kindergarten", and the inmates stress that educational measures implemented by prison personnel are trivial and correspondingly ineffective. At the same time, they talk with displeasure, rage and a sense of powerlessness about everyday acts of interference in their own economy of action, both when it comes to interaction with personnel and between the prisoners themselves (Bereswill 2001; Neuber 2009; Koesling 2010). Against this backdrop, the threat and application of violence between prisoners as well as the associated victimizations and sanctions acquire their importance for everyday life in juvenile detention.

At the same time, most of the youth and young adult males place their hopes in the educational affordances on offer during detention. They expressly orient themselves towards the notion emphatically espoused in the detention system that a successful legal probation is heavily dependent on vocational training and work. This seizes upon the model of social relations of exchange and recognition (as well as social security) that is fundamental in the society of industrial capitalism. According to this conception, the capacity to work and social integration should merge in a seamless bond. Thus, integration into the labor process emerges in numerous conversations with young prisoners as a self-evident orientation for a normal male biography. This is a model that has not forfeited its normative power in society; yet in actuality, it has long since become precarious (Bereswill \& Neuber 2012; Bereswill et al. 2008).

This orientation is supported by the concrete experiences of the prisoners with the measures of education and employment in youth correctional facilities. Yet it must

This refers to research the author conducted from 1998 to 2007 at the Criminological Research Institute of Lower Saxony (KFN) in Hanover. It comprised two longitudinal studies: (1) "Gefängnis und die Folgen" (Prison and its Consequences), carried out in conjunction with an extensive quantitative study financed by the Volkswagen Foundation (Greve et al. 1997; Bereswill 1999); (2) "Labile Übergänge" (Labile Transitions), financed by the Deutsche Jugendmarke Foundation and carried out together with Almut Koesling and Anke Neuber (Bereswill et al. 2008). Here we had the possibility to speak with 43 prisoners about their detention and life stories; in the case of 30 of these offenders, regular interviews were conducted after their release (in 15 instances over a period of nine years; the interviews were conducted by the author and Almut Koesling). The strength of such an approach is that it makes it possible to reconstruct and investigate - from a comparative perspective, extending over the course of several years - both structural features of the prison comprising several cases as well as aspects of imprisonment specific to an individual case (Bereswill 2006). Publications on these research projects can be found on the KFN homepage: http://kfn.de/?s=Bereswill, http://kfn.de/?s=Koesling [19/07/2016]. 
be kept absolutely in mind that learning and working inside a closed institutional setting acquires a special significance different from that 'on the outside': Here, this comprises a structuring experience of activity in a situation of everyday monotony and a context of interaction that promises mutual recognition in the group as well as by teachers and vocational trainers. The prison assumes "the role of a temporary shaper of structure" (Bereswill et al. 2008, p. 46), yet without the possibility for this experience to be pursued without interruption after their release.

When the working conditions in juvenile detention are criticized, a frequently overlooked aspect is the binding and meaning-making dimension of learning and work. Yet that dimension has an especially strong shaping impact for adolescents ${ }^{3}$ because they have to come to grips more generally with the social expectations of coping successfully with the transitions from schooling into further occupational training and work. Many young males did not overcome this hurdle in their biographies before they were imprisoned. Male juveniles and young adults behind bars for the most part belong to a social group whose opportunities for education are limited. Their social marginalization, often also prefigured in terms of their family biography, is further intensified in post-industrial society (factors that should be kept in mind here are the devaluation of their school-leaving qualifications - often acquired later on during juvenile incarceration - and the downturn in the job market for certain kinds of labor by men with low-level or manual skills).

Despite this situation, inmates take up the educational promises on offer in prison and identify strongly with the concrete scenarios of learning and activity. Incarceration of juvenile offenders thus also offers experiences of education and attachment which for most prison inmates are new and not accessible in a comparable manner either before or after imprisonment. The fact that with release, prisoners dissolve their tie with the institution and once again have to fend for themselves and find a new structure is a burden that should not be underestimated. In this context, educational measures are terminated again and again (see, for example, the test case in Bereswill et al. 2008, pp. 93 ff.).

Some three decades ago, Kersten (1986) already pointed to the paradox that a closed institutional environment (in the framework of care homes) brings boys from socially marginal backgrounds into contact with options for education on offer that previously were rarely accessible to them. The qualitative longitudinal interviews in the studies at the Criminological Research Institute of Lower Saxony (KFN) - carried out with young offenders within juvenile detention facilities as well as after their release - clearly show that the dilemma described above is intensifying under the impact of social change: Male youth and young adults are still confronted with the

3 For criticism of the function of work in the situation of imprisonment, see Schumann et al. 1988; see also the empirical studies of the research group in Bremen around Schumann, which show that the connection between education and employment with the legal probation of youth, which is repeatedly postulated, is in fact not evident (Schumann 2003; 2007; Prein \& Seus 1999; 2000). 
expectations of a normal male biography as a good worker, yet without corresponding positions in the labor market being accessible to them. In this context, the social transformation of labor and changes in gender structures interlock, conceptions of masculinity and the social division of labor are in flux, and attitudes previously thought to be "typically male" are replaced by the needs of a society more strongly oriented towards the provision of services.

\section{Upheavals and disruptions}

Youth and young adults have to grapple with the fact that the "psychosocial realm of possibilities" of adolescence (King 2002, p. 29) offers all but narrow opportunity structures with regard to their long-term options for training in the dual system or in the measures of support for disadvantaged youth and a sustained and lasting inclusion in gainful employment (Solga 2006; Walther 2002). Nevertheless, a typical developmental trajectory for adolescents is also expected of them, namely the formation of work ability. The contradictory demands associated with this for male youth and young adults in prison lead to numerous conflicts that can also be investigated and understood as conflicts of masculinity. This specific focus on conflicts bound up with the acquisition of cultural constructions of gender difference shields research from merely reproducing clichés of masculinity that characterize the selfpresentations of young prison inmates. Instead of seeing "the demonstrating of not being a victim" (Neuber 2009) as an expression of masculine identity, the question arises as to how young men experience their own vulnerability and why they so vehemently seek to avoid this as an explicit topic. A perspective that includes an "exposure to being vulnerable" (Opitz 1992) - frequently concealed based on cultural ideals of masculinity with regard to vulnerability - allows for a wider aperture in looking at the violent struggles over self-assertion and the victim-perpetrator dynamics that shape interactions in the peer group in the context of a closed institution (Bereswill 2001; 2002; 2003).

In general, institution- and circumstance-specific constellations of social interaction, which are also particularly typical of adolescence, interlock in the context of juvenile detention. Through the prism of the adolescence concept, grounded sociologically and in terms of subject theory - as conceived here with reference to ideas developed by Vera King (2002) -, the focus of the researcher looks systematically at the dialectical interplay between the specific institutional constellation of youth behind bars and the psychosocial dynamics of maturation. King's image of the "psychosocial realm of possibilities" elucidates the complexity of the adolescent's situation. Here, subjective processes of psychic, cognitive and social separation, development and integration of youth interconnect with social possibilities, institutional requirements and cultural horizons of expectation of youth and young adults. Entailed here is a dialectical interplay between internal and external changes of the subject, his/her psychic bonds and social relations on the one hand - and the social conditions under 
which developmental processes of youth can unfold on the other. Adolescence always designates a socially pre-constructed, multilayered and particularly non-simultaneous dynamic of upheaval and transitions which are only in part capable of being consciously perceived. The inter-subjective ties and relations with adults and other youth likewise enter into flux, and the relation between autonomy, dependency and attachment is restructured anew. Viewed from the perspective of a changing subjectivity, this involves a conflict-ridden process replete with tensions and opposing impulses.

How does imprisonment intrude into this constellation? Highly apparent are the strong impulses generated by the numerous restrictions on one's own autonomy for action as well as the simultaneous strengthening of experiences of dependency through the regimentations present in everyday life. Against this backdrop - and shaped by social clichés of masculinity -, punitively tinted imagery of aggressive, threatening young men, ultimately difficult to reach by means of educational interventions, has an impact on how the detention of juvenile offenders is often viewed. Less obvious is the vulnerability of these young men and their biography-specific reactions to the ties for attachment a closed institution like a prison offers its inmates. Research has also largely factored out which ties prisoners in detention develop, both to concrete individuals and vis-à-vis social contexts within the prison setting, against the backdrop of the subject's inner world and biographical experiences - and what that means for their transition as well as social relations in their lives after punishment and detention. This subject-theoretical perspective on institutional intervention is of great importance for a more profound understanding of the impact of imprisonment, not only during detention but also after release. The following section endeavors to make that more concrete by presenting a biographical research perspective.

\section{Biographical patterns of processing}

In order to better grasp the effect of a measure like imprisonment from the perspective of the prisoners, theoretical and methodological concepts are needed that help us uncover the dialectic dynamic between institutional requirements and individual dynamics of appropriation. Here, the concept of the biography is a fruitful approach because, as Dausien (2004) and many others repeatedly stress, it can be described as "a mode of socialization". Biographies are modes of individual self-construction as well as of the production and reproduction of society. The approach of sociological biographical inquiry emphasizes the biographical constructions that interviewees present; it gives less attention to the intra-subjective dimension of biographical processes. Only via this concept does research also explore this dimension, seeking to illuminate the irresolvable tension between the unmistakable self-will of the subject and his/her simultaneous constitution in social relations. For the context investigated here, that means: Closed institutions exert an enormous influence on the actions of 
their members. Nonetheless, such a setting of authoritarian power over the individual is subject to its own chosen appropriation.

The following research questions arise from a subject-oriented, biographical research perspective looking at the experience of a closed institutional environment: How do inmates experience confinement? Which biographical processes do the measures of the correctional facility intrude into? How do individuals arrange their lives after such an institutional break? And which biographical experiences do they follow up on?

Such questions were investigated in the period 1998 to 2007 by qualitative longitudinal studies exploring the prison experiences of young men. ${ }^{4}$ The research focused on the long-term impact of incarceration on the further lives of young male offenders. The qualitative data permit us to reconstruct biographical developments; it should be noted that this reconstruction focuses on the self-interpretations of participants in the study, not on true stories. They construct their life stories in the interactive process of the interview. Their narratives are thus the result of a concrete, context-dependent interaction of research in the setting of which the narrator relates his self-representation to what he/she thinks to be the expectation of the interviewer in the specific situation. But the narratives are also simultaneously the expression of constellations of experiences in a person's life story which continue to have an effect in the narrator's interaction patterns and stories and cannot be arbitrarily reinterpreted. This becomes manifest over the years of a longitudinal study, when patterns of interaction are repeated but also change and outstanding unresolved conflicts and desires resurface again and again. From this perspective, the biographical appropriation of social reality is a dynamic, conflict-ridden process in the course of which past, present and future times are constantly repositioned in a new relation to each other. The experience of losing one's autonomy in prison encounters past experiences with autonomy, dependency and attachment that constitute the human subject in his/her ability to act and engage in conflict. These past experiences are simultaneously imported into the present and subjected to reprocessing. Seen from this vantage point, biographical patterns of action are patterns of conflict whose deep structure lies concealed but can be reconstructed with the aid of hermeneutic procedures.

Viewed from the perspective of a life story, biographies are subjectively shaped as structures of chance. The concrete chances people are afforded in society limit and open up their inward scope for transformational maneuver but also generate greater latitude for the reproduction of conflicts in one's life history. As already noted, that is especially true for adolescence, a period in which psychodynamic developmental processes clash with society's demands for integration. In the case of the group of young men whose biographical development was followed in the studies by the 
$\mathrm{KFN}$, it is evident that their unfolding biographies are marked by numerous psychosocial burdens. Their conflicts of autonomy and adolescence, which must also be viewed as conflicts over masculinity, intensify but are not resolved in the closed institution of the youth correctional facility. Such resolution is fundamentally beyond such an institution's capacity.

\subsection{Differing patterns in contrast}

The biographical longitudinal interviews with prisoners point out just how finely meshed exposure to institutional confinement and the experiential constellations of life events in a person's biography are. If the interviews with inmates are sorted into groups in respect of different ways of processing and coping with imprisonment, clear contrasts emerge, with an unequal distribution of patterns ranging across the entire study group. This will be explicated below as an illustration of three typical patterns of coping with detention. These are not clear and distinct typologies but rather different characteristics as manifested along a continuum of conflicts that are further exacerbated in the context of confinement and become visible, magnified as if placed under a convex lens.

\subsection{An internal process}

Only very rarely do young men experience their incarceration as an internal biographical turning point. This pattern is associated with a biographical concept that aims for "autonomy-in-relation". Biographical crises tend to be connected with crises in relationships. Participants provided lively descriptions of their experiences with significant others. Social integration and the many obstacles connected with it are tied here to a network of relationships. In such cases, as early as in the very first interview during incarceration, a participant speaks a great deal about his inner feelings and experiences. Imprisonment is interpreted as an impetus for changing oneself and is at the same time rendered plausible within the framework of the person's previous life history. Feelings and internal conflicts are expressed along emotional descriptions of concrete experiences before and during incarceration. Central here are the relations with others, whether in relationships of learning, with a partner, family constellations or in a group of prisoners. The perception of one's own change is thus discussed in relation to others. Autonomy is closely connected to attachment to others, and coping with the crisis of imprisonment is likewise closely intertwined with this network of relations. That also holds true for the transition after release. One's self-image as a "normal man" is oriented towards the ideal of (heterosexual) attachment to a partner and one's own motivation in the sphere of gainful work.

\subsection{An external change}

Far more often, incarceration is experienced as an external biographical turning point. The narratives focus on formal changes: Processes of achieving a qualification 
and finding a way out of delinquency are viewed as positive results of an inevitable adaptation to societal expectations. Imprisonment is evaluated as an unpleasant yet also unavoidable consequence of one's own actions, and the everyday round of life in prison is described as a tightly controlled routine strung between official regimentation, its rules and those of the group of prisoners. Emotional conflicts are avoided and rarely talked about. Power conflicts between prisoners and prison staff are dealt with on the basis of strategic savvy. Attachment to others is couched in material relationships of exchange; that also holds true for descriptions of family biography. The ideal self of the young men is that of a cool, independent, rational winner, connected with a lifestyle of hedonism. The ability to deal in a calculating way with social interactions is strengthened in the prison in two respects: On the one hand, dealing with the relations of exchange in the prison subculture demands substantial skills if one wants to put oneself in a successful position. On the other hand, the educational and penal measures of the institution invite the inmate to consider very strategically how to deal with matters at one's own risk. After release, it becomes evident that finding a way out of delinquency emerges likewise as a lengthy process of a cost-benefit analysis. The image of manliness associated with this orientation pattern is reminiscent of post-modern forms of (self-)management.

\subsection{A sustained rigid structure}

In sharp contrast to the first two patterns of a relational autonomy and rational separation, the most frequent conflict constellation found in the sample is the experience of imprisonment as an existential turning point for one's own biography. In numerous interviews, the narrators experience the rigidly closed structure of the institution as a radical intrusion into one's own self-perception. For them, the incarceration is a continuation of many institutional shifts and biographical ruptures - albeit with the difference that for the first time, they are not (and cannot be) passed on by one institution to another. The young adults experience a radical change in their own person. This can be interpreted positively, in the sense of powerful hopefulness for a better life - for example, by means of the fond hope for a better job and career. But it can also be experienced negatively and as a threat. Then the measures of incarceration are resisted and forcefully struggled against as a grave destructive intervention into one's own person, likewise by the willful resort to aggressive self-stagings of masculinity. In both constellations, the prisoner experiences his actions as being totally determined by the institution. In comparison with the first two patterns - to set in motion one's own ties together with others, or to protect oneself strategically from the internal and external abuses and encroachments of detention -, this narrative represents the experience of not being able to demarcate one's own internal experience from the influence and interventions of the institution. One's own changes are experienced as the product of changed external circumstances, autonomy and dependency overlaps. Attachment to others is likewise marked by dependency. Biographical autonomy, i.e. the capacity to shape one's own life, is in such cases a labile dimension 
constantly struggled for. This means that the rigid and simultaneously supporting structure of the closed institution deeply intrudes into the self-experience of adolescents and young adults, as imprisonment disrupts the pattern of biographical discontinuity and provides a clear and rigid framework. Only from a longitudinal view does it become understandable that at the same time, what is operative here is the intensified continuation of biographical ruptures and cleavage.

\section{Authoritarian provocations and impositions}

In sum, we can state: The more serious unresolved biographical conflicts present themselves, the more intensive is the intrusion of incarceration into the self-experience of adolescents, without any possibility for them to be resolved or for the associated tensions to be eased. Adolescent wishes for transformation are thus stimulated in the closed institution of the prison, but are immobilized in the long term. This dynamic does not become obvious from the isolated picture during incarceration. It acquires its depth of focus in the context of a long-term effect of biographical discontinuity. Biographical discontinuity refers to the external and internal dimensions of a biography whose structure is characterized by inconsistent, contradictory and (from the perspective of the young men) opaque institutional interventions. In the context of the "psychosocial realm of possibilities" of adolescence, this means that the processes of attachment and detachment in the transition from adolescent to adult are shaped by unresolved, unsettled, submerged, and frozen commitments and conflicts. In the case of young inmates and former prisoners released, this corresponds as a rule with an objectively restricted opportunity structure which cannot be fundamentally expanded by the measures taken during confinement in a juvenile correction facility. On the contrary: Although in a formal sense, their possibilities increase as a result of individual steps toward better qualifications, their actual situation 'inside-out' after release offers former prisoners only a very limited structure of options (Bereswill 2011). This is compounded by a concomitant high level of psychosocial stress derived from the transition from a closed institutional environment into an often unstructured situation on the 'outside'. At the same time, the question arises: Which specific abilities in coping with discontinuities were possibly overlooked and thus likewise not supported - as a result of the institutional fixation on a continuous educational biography? ${ }^{5}$

Confinement in a prison thus turns out to be a continuation of institutional changes and biographical ruptures. The intervention of imprisonment blends in seamlessly with such biographical developmental patterns. The prison provides "limited autonomy" while simultaneously intensifying previous conflicts involving commitment and dependency in an individual's life story. These conflicts cannot be resolved in a

5 I am grateful to Marcel Schweder for this instructive further observation on the biographical potentials of young prisoners. 
closed environment and cannot be appropriately cushioned and absorbed after release.

If the longitudinal interviews are analyzed from a gender-theoretical perspective against this backdrop, all the study participants fall back on the collective processes of negotiating masculinity in prison and orient themselves towards social expectations of a normal male biography. Thus, a case comparison shows the appropriation of gender constructions, on the one hand, via familiar images and collective patterns and paradigms. On the other hand, the subjective shaping and elaboration of these cultural constructions is shown to be a lifelong and context-specific process of intraand inter-subjective critical encounters with social attributions of masculinity (and gender differences) that closely correspond to the construction of normality and deviancy. With regard to the sphere of possibilities of adolescence, a strong nexus emerges between biographical discontinuity and social control. It is useful to further investigate which significance excessive and one-sided constructions of masculinity have for the biographical processing of this connection by socially marginalized young men.

\section{References}

Bereswill, M. (2015): Zwischen autoritärer Zumutung und Entwicklungsversprechen - der Freiheitsentzug als tiefgreifende biographische Konflikterfahrung, in: M. Schweder (ed.), Handbuch Jugendstrafvollzug. Weinheim, pp. 339-353.

Bereswill, M. (2011): Inside-out: transitions from prison to everyday life: a qualitative longitudinal approach, in: S. Farrall, R. Sparks, S. Maruna \& M. Hough (eds.), Escape Routes. Contemporary Perspectives on Life After Punishment. Abingdon, Oxon, pp. 202-220.

Bereswill, M. (2010): Strafhaft als biographischer Einschnitt. Befunde zum Jugendstrafvollzug aus der Perspektive seiner Insassen, in: B. Dollinger \& H. SchmidtSemisch (eds.), Handbuch Jugendkriminalität. Kriminologie und Sozialpädagogik im Dialog. Wiesbaden, pp. 545-556.

Bereswill, M. (2007): “Von der Welt abgeschlossen”. Die einschneidende Erfahrung einer Inhaftierung im Jugendstrafvollzug, in: J. Goerdeler \& P. Walkenhorst (eds.), Jugendstrafvollzug. Grundlagen, Konzepte, Handlungsfelder. Teil 2. Mönchengladbach, pp. 163-183.

Bereswill, M. (2006): Begrenzte Autonomie. Die biographische Erfahrung von Geschlossenheit zwischen Bindung und Bindungslosigkeit, in: DVJJ (ed.), Verantwortung für Jugend. Dokumentation des 26. Deutschen Jugendgerichtstags vom 25.-28. September 2004 in Leipzig. Mönchengladbach, pp. 240-261. 
Bereswill, M. (2003): Gewalthandeln, Männlichkeitsentwürfe und männliche Subjektivität am Beispiel inhaftierter junger Männer, in: F. Koher \& K. Pühl (eds.), Gewalt und Geschlecht. Konstruktionen, Positionen, Praxen. Opladen, pp. 189212.

Bereswill, M. (2002): Doing Violence, Concepts of Masculinity and Biographical Subjectivity - Three Case Studies. KFN-Forschungsbericht No. 85. Hanover.

Bereswill, M. (2001): “Die Schmerzen des Freiheitsentzuges" - Gefängniserfahrungen und Überlebensstrategien männlicher Jugendlicher und Heranwachsender in der Strafhaft, in: M. Bereswill \& W. Greve (eds.), Forschungsthema Strafvollzug. Baden-Baden, pp. 253-285.

Bereswill, M. (1999): Gefängnis und Jugendbiographie. Qualitative Zugänge zu Jugend, Männlichkeitsentwürfen und Delinquenz (JuSt-Bericht 4). KFN-Forschungsbericht No. 78. Hanover.

Bereswill, M. \& Hellwig, J. (2012): Hafterleben von Frauen mit Kindern. Eine qualitative Fallstudie. Soziale Probleme 23/2, pp. 182-216; www.soziale-problem e.de/2012/03_Bereswill-Hellwig_-_Hafterleben_von_Frauen_mit_Kindern.pdf [15.07.2016].

Bereswill, M. \& Höynck, T. (eds.) (2002). Jugendstrafvollzug in Deutschland Grundlagen, Konzepte, Handlungsfelder. Mönchengladbach.

Bereswill, M., Koesling, A. \& Neuber, A. (eds.) (2008): Umwege in Arbeit. Die Bedeutung von Tätigkeit in den Biographien junger Männer mit Hafterfahrungen. Baden-Baden.

Bereswill, M. \& Neuber, A. (2012): Prekäre Verhältnisse - fragile Autonomieentwürfe? Die Bedeutung von Arbeit aus der Sicht von männlichen Jugendlichen und Heranwachsenden mit Hafterfahrungen, in: J. Mansel \& K. Speck (eds.), Jugend und Arbeit. Empirische Bestandsaufnahmen und Analysen. Weinheim, pp. 99 116.

Christie, N. (2000): Crime Control as Industry. Towards Gulags, Western Style. $3^{\text {rd }}$ rev. ed. London.

Christie, N. (1983): Die versteckte Botschaft des Neo-Klassizismus. Kriminologisches Journal 15/1, pp. 14-33.

Cornel, H. (2011): Der Erziehungsgedanke im Jugendstrafrecht: Historische Entwicklungen, in: B. Dollinger \& H. Schmidt-Semisch (eds.), Handbuch Jugendkriminalität. Kriminologie und Sozialpädagogik im Dialog. Wiesbaden, pp. 455473.

Crewe, B. (2009): The Prisoner Society: Power, Adaptation and Social Life in an English Prison. Oxford.

Feest, J. \& Paul, B. (2008): Abolitionismus. Einige Antworten auf oft gestellte Fragen. Kriminologisches Journal 40/1, pp. 6-20. 
Goerdeler, J. \& Walkenhorst, P. (eds.) (2007): Jugendstrafvollzug. Grundlagen, Konzepte, Handlungsfelder. Teil 2. Mönchengladbach.

Greve, W., Hosser, D. \& Pfeiffer, C. (1997): Gefängnis und die Folgen. Identitätsentwicklung und kriminelles Handeln während und nach Verbüßung einer Jugendstrafe (JuSt-Bericht Nr. 1). KFN-Forschungsbericht No. 64. Hanover.

Jansen, I. (1999): Mädchen in Haft: Devianzpädagogische Konzepte. Opladen.

Johnson, R. \& Toch, H. (eds.) (1982): The Pains of Imprisonment. Beverly Hills, CA.

Kersten, J. (1986): Gut und (Ge)Schlecht: Zur institutionellen Verfestigung abweichenden Verhaltens bei Jungen und Mädchen. Kriminologisches Journal 13/4, pp. 241-257.

Kersten, J. \& von Wolffersdorf-Ehlert, C. (1980): Jugendstrafe. Innenansichten aus dem Knast. Frankfurt am Main.

Kerner, H.-J., Dolde, G. \& Mey, H.G. (eds.) (1996): Jugendstrafvollzug und Bewährung. Analysen zum Vollzugsverlauf und zur Rückfallentwicklung. Bonn.

Kerner, H.-J., Stellmacher, J., Coester, M. \& Wagner, U. (2011): Systematische Rückfalluntersuchung im Hessischen Jugendvollzug. Bericht über eine empirische Studie zur Legalbewährung bzw. Rückfälligkeit von jungen männlichen Gefangenen der Entlassungsjahrgänge 2003 und 2006; www.jura.uni-tuebingen.de/ einrichtungen/ifk/forschung/strafvollzug/abgeschlossen/hrp [15.07.2016].

King, $V$. (2002): Die Entstehung des Neuen in der Adoleszenz. Individuation, Generativität und Geschlecht in modernisierten Gesellschaften. Opladen.

Koesling, A. (2010): Erziehungs- und Beziehungserfahrungen jugendlicher und heranwachsender Inhaftierter. Berlin.

Liebling, A. \& Maruna, S. (2005): The Effects of Imprisonment. Cullompton, Devon.

Neuber, A. (2015): Junge Frauen im Jugendstrafvollzug - ein Sonderfall? Das Hafterleben aus Sicht inhaftierter junger Frauen, in: M. Schweder (ed.), Handbuch Jugendstrafvollzug, Weinheim, pp. 408-424.

Neuber, A. (2009): Die Demonstration, kein Opfer zu sein. Biographische Fallstudien zu Gewalt und Männlichkeitskonflikten. Baden-Baden.

Neuber, A., Apel, M. \& Zühlke, J. (2011): "Hier drinne kriegste schon irgendwann ne Krise" - das Hafterleben junger Frauen im Jugendstrafvollzug. Zeitschrift für Jugendkriminalrecht und Jugendhilfe 22/4, pp. 371-377.

Popitz, H. (1992): Phänomene der Macht. $2^{\text {nd }}$ ed. Tübingen. 
Prein, G. \& Seus, L. (2000): "The devil finds work for idle hands to do". The relationship between unemployment and delinquency, in: N. Fielding, A. Clarke \& R. Witt (eds.), The Economic Dimensions of Crime. Houndmills, Basingstoke, pp. 193-210.

Prein, G. \& Seus, L. (1999): "Müßiggang ist aller Laster Anfang?" - Beziehungen zwischen Erwerbslosigkeit und Delinquenz bei Jugendlichen und jungen Erwachsenen. Zeitschrift für Soziale Probleme und soziale Kontrolle 10/1, pp. 43-74.

Scheerer, S. (1984): Die abolitionistische Perspektive. Kriminologisches Journal 16/2, pp. 90-111.

Schumann, K.F. (2007): Berufsbildung, Arbeit und Delinquenz: empirische Erkenntnisse und praktische Folgerungen aus einer Bremer Längsschnittstudie, in: A. Dessecker (ed.), Jugendarbeitslosigkeit und Kriminalität. $2^{\text {nd }}$ rev. ed. Wiesbaden, pp. 43-86.

Schumann, K.F. (2003): Arbeitsbiographie und Delinquenz - Bilanz der Ergebnisse, in: K.F. Schumann (ed.), Berufsbildung, Arbeit und Delinquenz. Bremer Längsschnittstudie zum Übergang von der Schule in den Beruf bei ehemaligen Hauptschülern. Weinheim, pp. 241-254.

Schumann, K.F., Steinert, H. \& Voß, M. (eds.) (1988): Vom Ende des Strafvollzugs. Ein Leitfaden für Abolitionisten. Bielefeld.

Solga, H. (2006): Ausbildungslose und die Radikalisierung ihrer sozialen Ausgrenzung, in: H. Bude \& A. Willich (eds.), Das Problem der Exklusion. Ausgegrenzte, Entbehrliche, Überflüssige. Hamburg, pp. 121-146.

Stelly, W. \& Thomas, J. (eds.) (2011): Erziehung und Strafe. Symposium zum 35jährigen Bestehen der JVA Adelsheim. Mönchengladbach.

Sykes, G.M. (1958): The Society of Captives. A Study of a Maximum Security Prison. Princeton, NJ.

Toch, H., Adams, K. \& Grant, J.D. (1989): Coping: Maladaptation in Prisons. New Brunswick.

Walter, J. (2006): Bedingungen bestmöglicher Förderung im Jugendstrafvollzug. Teil 1. Zeitschrift für Jugendkriminalrecht und Jugendhilfe 16/3, pp. 236-244.

Walther, A. (2002): "Benachteiligte Jugendliche": Widersprüche eines sozialpolitischen Deutungsmusters. Anmerkungen aus einer europäisch-vergleichenden Perspektive. Soziale Welt. Zeitschrift für sozialwissenschaftliche Forschung und Praxis $53 / 1$, pp. $87-106$. 



\title{
Life-Course Dynamics among Young Prison Releasees. An Empirical Interaction Model: The ZARIA Scheme
}

\author{
Elke Wienhausen-Knezevic
}

\section{Desistance processes in the light of life-course theory}

Over the last few years, desistance research has become a key topic in criminology. However, to date, it has been unable to fully understand the explicit mechanisms of action that may lead to the cessation of criminal life courses. Instead of following classical criminological approaches of reoffending, the present contribution will not focus on official data that refers to recidivism, but on behavioural desistance. According to the understanding of life-course theory, processes of change must be interpreted on a behavioural as well as an attitudinal level. Given the intertwined role of socio-structural and individual-psychological factors, it is useful to look at these processes from an interactional theoretical viewpoint.

On that account, the focus of research simultaneously needs to be on the processes of desisting and persisting in order to obtain some insight into the life-course dynamics after prison release. In particular, it is necessary to shed light on the course of action of the young persons and the patterns of their individual pathways towards a crime-free life. What is missing in most studies is the question which effect imprisonment has on the adolescents' individual actions in the transformation process and on their feelings in the transitional phase from "inside" to "outside". ${ }^{1}$ Given the lifecourse-oriented understanding, these objectives require an appreciation of individual-psychological and socio-structural factors from a processual point of view. Therefore, the methodological framework of this study is based on a combination of elements from the Grounded Theory and Agency Analysis approaches.

This paper presents findings from a qualitative study of early transitions towards desistance and persistence among a group of formerly incarcerated young males. It is based on semi-structured interviews with a sample of young men $(\mathrm{N}=24)$ who were in the process of either desisting from or persisting in crime. These findings demonstrate that the reintegration process includes a complex and dynamic interplay of five key categories which are combined into an interaction model: the so-called ZARIA scheme.

1 For a further elaboration on how ex-convicts experience the period after prison release, see also Wößner, Wienhausen-Knezevic \& Gauder 2016. 


\section{Desistance as a psycho-social process}

This approach is based on the theoretical assumption that individual-psychological and socio-structural factors are equally important for the process of rehabilitation or re-entry. Conceptualising ex-offenders neither as rational agents nor as solely being determined by external forces is sufficient for understanding the complexity of the reintegration process. Additionally, it is widely believed that desistance requires a strong motivation for change coupled with a firm self-belief and a repertoire of effective coping strategies, a combination of "the will and the ways" (see Burnett 2004, pp. 663 ff.; LeBel et al. 2008, pp. 136); this means that the effects of socio-structural and individual-psychological processes are closely intertwined in the desistance process (cf. LeBel et al. 2008).

In the wider, mainly sociological debate on structure and agency, desistance is also described as an inner process. Within this debate, it is furthermore well-known that agency plays an important role in the transition from an identity of "offender" to that of "ex-offender". In contrast to the growing body of literature on agency and its pivotal role in the desistance process, there is little knowledge about "how offenders utilize their agentic resources to achieve a meaningful and crime-free life" (Healy 2013, p. 566). Desistance is often described as an inner (cognitive) process that is accompanied by a change in one's life scripts in which the would-be desister is led to a non-defending identity. The meaning of the "agency" concept is similar to Albert Bandura's socio-psychological concept of perceived self-efficacy. In his clearest terms, self-efficacy can be understood as "the belief in one's capabilities to organize and execute the courses of action required to manage prospective situations" (Bandura 1995, p. 2).

Against this backdrop, an interaction model of desistance is promising for understanding the complexity of the desistance process. To this end, the so-called "at-risk trajectories" are contrasted with courses of opportunity to identify the mechanisms which are crucial for initiating the desistance process. ${ }^{2}$ It is argued that identity reconstruction or a cognitive transformation process begin during the so-called "early phases of desistance" (cf. King 2013; Healy 2013). In my opinion, this process already starts during the period of incarceration.

2 According to Fritz Schütze's (1981) elaboration on trajectories, who in turn draws upon Strauss \& Glaser's (1971) theory of upward and downward trajectories. 


\section{Sample overview}

The interviews were conducted within the qualitative part of the project "Juvenile Sexual Offenders in the Correctional Treatment Facilities of the Free State of Saxony". ${ }^{3}$ In total, 24 adolescent sexual and violent offenders were interviewed one year after prison release by using a semi-narrative guideline. Half of the subjects took part in the so-called "social therapy"4 of the juvenile penitentiaries, while the other half were accommodated in the regular juvenile penitentiary system.

Figure $1 \quad$ Study design of the broader evaluation project "Juvenile Sexual and Violent Offenders in the Social Therapeutic Institutions in the Free State of Saxony"

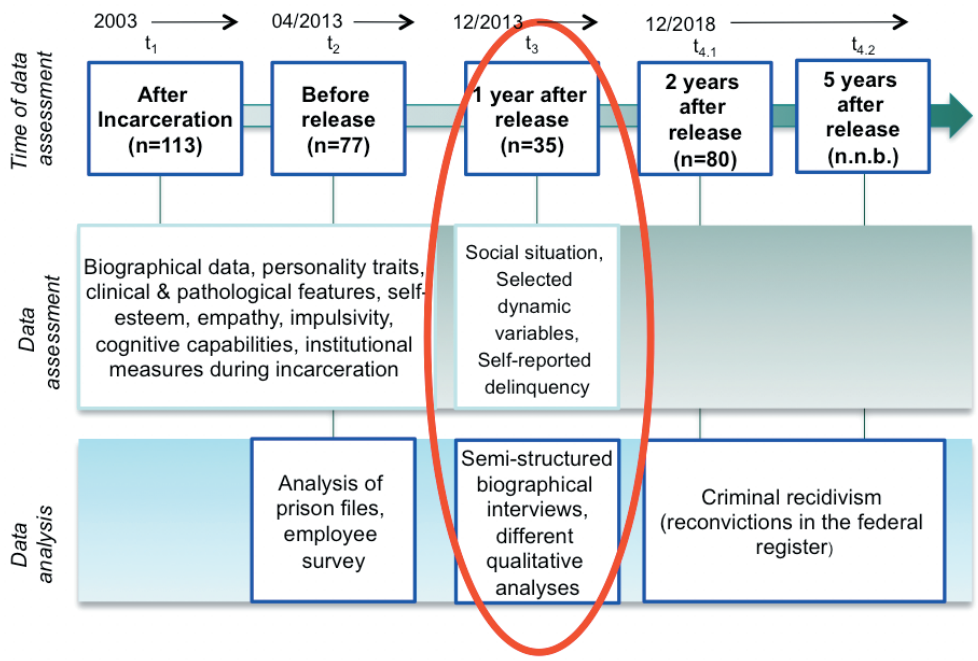

The participants were interrogated in a semi-structured biographical interview one year after their release from prison with regard to their individual living conditions, financial and working situation, their relationship status, a meaningful relationship to other people, and leisure behaviour (see also Figure 1 for information on how the project is embedded within the main study). The interviewees were encouraged by means of a suggested open narrative at the beginning of the interview to talk about

3 For further information on the overall project, see: https://www.mpicc.de/en/forschung/for schungsarbeit/kriminologie/sexualstraftaeter_sozial.html or Wößner, Albrecht \& Hefendehl 2013. For more detailed information on the implementation of interventions in the German juvenile penal system, see Albrecht 2003.

4 In Germany, correctional treatment facilities offer a range of treatment measures for the inmates. The social therapeutic treatment is an integrative correctional treatment approach with the modules psychotherapy, social work, therapeutic community, vocational, and educational training or work, but also leisure-time training. 
meaningful situations or critical moments after prison release. This approach ensured a substantive individual focus within their own "post-release story"; in other words, this facilitated realisation of an exploratory approach.

The interviewees were convicted under the Juvenile Court Act, whereas at the time of the interview, they were 23 years old on average. ${ }^{5}$ Most of the young men were first-time prisoners with an average incarceration period of three years. Half of them had been convicted for a sexual, the other half for violent offence(s). Seven interviews were conducted in total after re-incarceration in a youth penitentiary.

\section{Analytical procedure}

The qualitative study consisted of a two-stage procedure. The first step comprised a systematic analysis of data according to Grounded Theory qualitative coding, and phenomena relevant for the desistance process were categorised by contrasting sequences in a maximum variation procedure. ${ }^{6}$ The second step involved an Agency Analysis where sequences were analysed which hint at seeing oneself as an active individual within the reintegration process - hence as someone who has the ability to shape his further life course; at the same time, sequences of embracing one's own victim role were also analysed. This approach revealed narratives containing descriptions of losing control over one's life, which were contrasted with each other. A central feature of this analytical approach is the (constant) comparative analysis (cf. Glaser \& Strauss 1967, p. vii) of sequences from the interviews. ${ }^{7}$ The main objective of this analytical procedure was to shed light on the different dynamics that unfold after prison release and to find out in which way the relevant factors interact within desistance and persistence.

\section{Empirical results: life-course dynamics and the ZARIA scheme}

The results of the multilevel analytical approach suggested that the ability to build up a non-deviant identity (or to imagine a credible future self) as well as the continuation of the deviant lifestyle are connected to the dynamic interplay of five core categories:

5 Legal regulations about the age are codified in the German Juvenile Court Act in $\S 105$ JGG. It states that adolescents (aged 18-21) can be punished according to youth or adult law, depending on the individual's state of maturation.

6 For a further explication on the principles of maximum variation comparison, see Kruse 2015; Merkens 2013.

7 The categorisation has been carried out on the basis of micro-linguistic expressions, for example: "from now on everything went right ...", "there was no energy anymore ...", "I thought the whole crap restarts again ...", "then it just reversed again ...". 
1) Goals/Ziele ${ }^{8}(\mathrm{Z})$ (positioned in the middle of the other four core categories in order to symbolise that goals influence the dimension of all other categories),

2) $\operatorname{Agency}(\mathrm{A})$,

3) Resources (R),

4) Identity (I), and

5) Recognition/Acknowledgement (A).

These five core categories are combined into an interaction model (see Figure 2) in which the different interaction effects between the categories are visualised. Life goals are particularly evident throughout all categories; therefore, they build the key category for analysing these mechanisms.

\section{Figure $2 \quad$ The interaction model - ZARIA scheme}

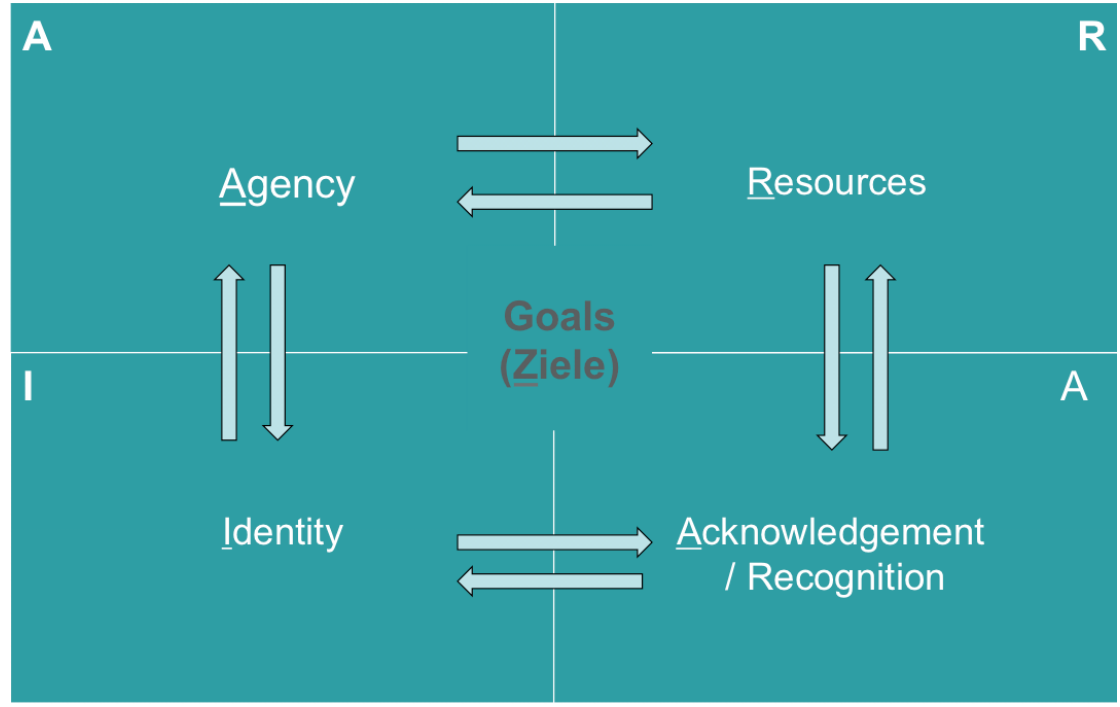

These categories contain the two poles of a continuum and can furthermore be divided into an internal and an external manifestation. All categories together constitute the ZARIA scheme. During the analytical procedures, it has been shown that these five categories of the ZARIA scheme can be embedded into life-course dynamics or stages of desistance and persistence.

8 The German word for goals, „Ziele”, constitutes the first letter of the model's acronym (ZARIA). The other categories correspondingly build the other letters of the acronym (A stands for Agency, R for Resources, I for Identity and A for Acknowledgement); altogether, they constitute the interaction model, the ZARIA scheme. 


\subsection{Life-course dynamics and stages of desistance or persistence}

The empirical results demonstrate that the development of the different dynamics either into a crime-free life or into the continuation of the criminal career - is dependent on the differential interplay of the core categories mentioned above. Subsequently, three narrative patterns have been identified.

\subsubsection{Pattern A: meaning in life and responsibility - upward trajectory}

This narrative pattern is characterised by the opening of opportunities and autonomy of action. In this pattern, the participants described themselves as being reflective regarding their criminal past and pro-active in shaping their future life courses by themselves. They seemed to have achieved developmental tasks such as becoming independent and autonomous. More characteristics of this group of participants are, for instance, the strong desire to attain future goals which had already been set up while in incarceration; a high level of agency, a pro-social attitude and actions that may lead to a crime-free life; resources in the form of social support and in many cases also internal coping strategies such as frustration tolerance; cognitive transformation regarding a pro-social self-concept, taking on adult social roles like fatherhood or being a family man. ${ }^{9}$ These parameters interact in a way that enables the individuals to generate self-acknowledgement, which once more generates recognition by significant others.

The narrative's starting point is characterised by emphasising the motivation and willpower to become an ex-offender. This explanation is followed by a detailed narration about how a successful assumption of new structures in everyday life accompanied the process of leaving the deviant lifestyle behind. Throughout the integration of the past criminal identity into the present crime-free self, an identity turn becomes visible in the narratives. The lesson learned in prison was a challenging struggle entailing hard work on oneself and bound up with the fact that they have overcome difficulties after prison release by their own endeavour. These processes generate self-recognition; the end point of the present narrative is usually linked to the observation that one's priorities and lifestyle have completely changed in comparison to the period before incarceration and that the person has reached a new pro-social identity.

The interviewees who could break the vicious cycle of their criminal acting either had a supportive and confirming social environment (family, girlfriend or a former boss on whom they could rely), or they had inner resources like self-discipline and described a process of working on their weak points and their self. They were more active regarding reintegration efforts (because they had life goals), such as searching for a job, and could overcome barriers which they mainly regarded as challenges and

9 In this sense, Helfferich et al. (2005) describe the transformation process from masculinity to fatherhood in the context of adopting the role of being a father. For further elaboration on this topic, see also Hill 1971. 
not as excessive demands. Additionally, the individuals who have adapted successfully to a new, non-deviant lifestyle were integrated within an everyday structure such as work or family life. For them, the subsequent life course is presumed to be a range of opportunities.

Furthermore, coping with painful experiences, such as the incarceration in particular, is associated with a positive outcome and is seen as a "lesson learned". The incarceration experience serves as a turning point for an individual and his pro-active behaviour in a positive way, as these individuals have succeeded in re-framing their criminal past into something positive in their life course. In other words, the dynamics of desistance and the behavioural change are related to the influence or effects that imprisonment had on the inmate's personal sense of agency and their individual capacities. In conclusion, this pattern symbolises the case of temporary desistance.

\subsubsection{Pattern B: acknowledgement deficits and boredom - between stabilisation and de-stabilisation}

In this pattern, the group of individuals shifted between the attempt to adopt new structures of everyday life and slipping back into old deviant habits. They lingered between the stabilisation and de-stabilisation of a pro-social lifestyle. Central to this narrative is the inability to avoid or resist temptation (see also Shapland \& Bottoms in this volume). When confronted with an opportunity to quickly earn money illegally or to misuse drugs again, the earlier decision of staying away from crime gradually becomes brittle. This phenomenon, which is also referred to as the "weakness of will", has been described by Shapland \& Bottoms (2011, pp. 272 ff.) and occurs when a person behaves in a way that is inconsistent with his or her long-term goals. Social ties are still existent in these cases and can even be caring and meaningful for the individuals, but they lose significance over time. On the other hand, financial and/or status pressures become overwhelming.

A core issue of this narrative pattern is the attainment of the developmental milestones normally associated with the transition to adulthood. This transition is predominantly chronically delayed; in the narratives of the young men, this delay is often bound up with the individual's drug or alcohol misuse in the past. The incarceration experience is often characterised as being a barrier for adequately acting in the "outside" world and the community. In this pattern, there is a predominant changeable course of feeling as an agentic actor in one's life on the one hand and as a victim of social circumstances on the other. It shifts between relapses into formerly deviant behaviour to overcoming difficulties and gaining autonomy of action. This phase is often followed by a total collapse in the pursuit of pro-social goals and thus a crime-free life. The self-concept is connected with changing from being a caring 
and loving family man into a hypermasculine ${ }^{10}$, macho individual, and in some cases falling back again to being a strong leader of a deviant peer-group.

In contrast to Pattern A, the incarceration experience is seen as a waste of time. The same holds true for the therapeutic interventions and the one-on-one conversations with the psychologists in the social-therapeutic institutions.

These dynamics are characterised by the lack of non-deviant relationships and therefore of acknowledgement in a pro-social surrounding. In some cases, the feeling of boredom becomes overwhelming and provides a perfect breeding ground for criminality. A major proportion of these narratives comes from participants who were neither employed nor in a caring partnership; in other words, they had no resources of acknowledgement. In the end, this pattern symbolises the trajectory of "liminal desistance" as described by Deirdre Healy (2014) in a previous contribution and can also be understood as an "at-risk trajectory".

\subsubsection{Pattern C: actualisation of negative life experiences - downward trajectory}

The last identified pattern is associated with a downward trajectory. The interviewees predominantly refer to difficulties and barriers within their post-release period, focusing on the problematic interaction with public authorities and probation officers. As they describe it, they had a much easier life 'on the inside' than beyond the prison walls. The problems they had before being incarcerated returned, becoming even more intensive and momentous than before. This can be explained in a psychological way as the actualisation of negative life experiences. Moreover, the subjects classifiable in terms of this pattern do not talk about their incarceration experience; even less do they talk about their criminal careers of the past. An interpretation of this phenomenon might be that their criminal past and the time spent in prison were so painful that they have deleted these periods from their life story.

In contrast to Patterns $\mathrm{A}$ and $\mathrm{B}$, the will and the commitment to change are nonexistent. They engage only superficially in actions that are supposed to be essential for living a crime-free life. Instead, behaviour that comes close to macho hypermasculinity predominate, combined here with incidents of over-reaction in normal social situations. Furthermore, they show no self-mastery and have less meaningful or even broken social ties that could provide positive influences; this goes hand in hand with low social capital. The pattern symbolises an at-risk trajectory (or re-incarceration cases), and most of these interviews were conducted with recidivists already back in prison.

10 For more elaboration on this concept, cf. Beesley \& Mc Guire 2009. 


\section{Conclusion}

As the aforementioned empirical results suggest, breaking the vicious cycle of a criminal lifestyle is bound up with relationships (partnership/employment) and their intermediary role of being a resource of acknowledgment. This process is accompanied by other developmental processes in identity formation and in the adoption of new adult roles which are fostered mainly by supportive and non-criminal social contacts. However, as mentioned, the influence of social therapeutic treatment is highly significant. The therapeutic staff may provide stimuli for establishing a reflexive identity. Consequently, they may trigger the process of strengthening the individual's will for change.

As the results demonstrate, the social therapeutic treatment in prison should concentrate on enabling the young ex-prisoners to initiate sustainable relationships with significant others. Therapeutic interventions within prison and other institutions involved with the reintegration of young prison releasees should focus even more on fostering positive attachment and encouraging social contacts outside the prison.

In order to return to the initial question regarding the mechanisms crucial within the desistance and/or persistence process: the five core categories identified seem to interact in a multilevel and highly complex way. The fragile transition process and coping with these difficulties after prison release can be understood as a complex interaction of the five core categories. This depends on the individual manifestation in the individual action by the young men; in other words, the direction of the activity orientation is crucial for embarking either upon a crime-free path or returning to the path of criminality. Furthermore, it has been demonstrated that a lack or low level of one parameter can be compensated by a high level in another. Aspiring life goals is thus crucial for behavioural change; it is through such goals that the individuals were able to compensate for non-existent resources, e.g. on an emotional or financial basis. Since (life) goals serve as a catalyst for generating agency, self-recognition and recognition from others, a low level of social capital can be compensated. This may well constitute the starting point of an upward trajectory, which again may trigger stimuli for establishing resources of acknowledgement, therefore providing the requisite building blocks for a new and crime-free life.

\section{References}

Albrecht, H.-J. (2003): Forschungen zur Implementation und Evaluation jugendstrafrechtlicher Sanktionen. Zeitschrift für Jugendkriminalrecht und Jugendhilfe 14/3, pp. 224-233.

Bandura, A. (1995): Self-efficacy in Changing Societies. Cambridge.

Beesley, F. \& McGuire, J. (2009): Gender-role identity and hypermasculinity in violent offending. Psychology, Crime \& Law 15/2 \& 3, pp. 251-268. 
Burnett, R. (2010): The will and the ways to becoming an ex-offender. International Journal of Offender Therapy and Comparative Criminology 54/5, pp. 663-666.

Glaser, B.G. \& Strauss, A.L. (1971): Status Passage. London/New York.

Healy, D. (2014): Becoming a desister: Exploring the role of agency, coping and imagination in the construction of a new self. British Journal of Criminology 54/5, pp. 873-891.

Healy, D. (2013): Changing fate? Agency and the desistance process. Theoretical Criminology $17 / 4$, pp. 557-574.

Helfferich, C. (2012): Agency-Analyse und Biografieforschung. Rekonstruktion von Viktimisierungsprozessen in biografischen Erzählungen, in: S. Bethmann, C. Helfferich, H. Hoffmann \& D. Niermann (eds.), Agency. Qualitative Rekonstruktionen und gesellschaftstheoretische Bezüge von Handlungsmächtigkeit. Weinheim, pp. 210-237.

Helfferich, C., Klindworth, H., Krumm, S. \& Walter, W. (2005): Familienentwicklung als Transformation von Männlichkeit, in: A. Tölke \& K. Hank (eds.), Männer - Das ,vernachlässigte“ Geschlecht in der Familienforschung. Zeitschrift für Familienforschung, Sonderheft 4. Wiesbaden, pp. 71-97.

Hill, T.W. (1971): From hell-raiser to family man, in: J.P. Spradley \& D.W. McCurdy (eds.), Conformity and Conflict: Readings in Cultural Anthropology. Boston, pp. 186-200.

Kruse, J. (2015): Qualitative Interviewforschung. Ein integrativer Ansatz. Weinheim.

LeBel, Th.P., Maruna, S., Burnett, R. \& Bushway, S. (2008): The 'chicken and egg' of subjective and social factors in desistance from crime. European Journal of Criminology 5/2, pp. 131-159.

Merkens, H. (2013): Auswahlverfahren, Sampling, Fallkonstruktion, in: U. Flick, E. von Kardoff \& I. Steinke (eds.), Qualitative Forschung. Ein Handbuch. Reinbek, pp. 286-299.

Schütze, F. (1981): Prozessstrukturen des Lebensablaufs, in: J. Matthes, A. Pfeifenberger \& M. Stosberg (eds.), Biographie in handlungswissenschaftlicher Perspektive. Kolloquium am Sozialwissenschaftlichen Forschungszentrum der Universität Erlangen-Nürnberg. Nürnberg: Verlag der Nürnberger Forschungsvereinigung e.V., pp. 67-156.

Shapland, J. \& Bottoms, A. (2011): Reflections on social values, offending and desistance among young adult recidivists. Punishment \& Society 13/3, pp. 256-282.

Wößner, G., Albrecht, H.-J. \& Hefendehl, R. (2013): Sexuelle Gewalt und Sozialtherapie: Bisherige Daten und Analysen zur Längsschnittstudie: Sexualstraftäter in den sozialtherapeutischen Anstalten des Freistaates Sachsen. Berlin. 
Wößner, G., Wienhausen-Knezevic, E. \& Gauder, K.-S. (2016): "I was thrown in at the deep end ..." Prisoner Rentry: Patterns of transition from prison to community among sexual and violent offenders. forschung aktuell - research in brief 48; https://www.mpicc.de/files/pdf3/rib_48_woessner_et_al_2016.pdf [16/02/2018]. 



\title{
Fragile Transitions: Methodological Reflections on Young Women's Processes of Desistance
}

\author{
Anke Neuber
}

Desistance research on (young) women is characterized by a remarkable contradiction: on the one hand, research has paid little attention to desistance processes of young women. Whenever women are considered at all, this is usually done without taking into account relevant gender-theoretical perspectives and the complex meaning of gender as a category. On the other hand, gender-related conclusions are drawn which presuppose differences between men and women. In this constellation, gender is either attributed too much or too little significance, which leads to a continuous (re-)production of gender differences.

In the following, the question is pursued of how women's desistance processes can be examined without reproducing gender differences, but rather by critically challenging and reflecting them. Connected to this are fundamental questions of how desistance processes can be examined theoretically and methodically.

Initially, desistance processes of women are briefly discussed and gender-theoretical questions are raised (1). Then gender is presented as a complex category, adopting an approach that is subject- and conflict-theoretical, which conceptualizes desistance as a conflictual process (2). A final section (3) develops a conflict-theoretical perspective, formulating theses on methodological and methodical considerations for desistance research.

\section{Women's desistance processes}

Women's pathways into delinquency and offending have important implications for their reentry and desistance experiences (Leverentz 2014). In both cases, the experiences are shaped by gender. The studies that deal with the "gendered pathways into crime" seek to explain female delinquency, stressing the difficult material circumstances and biographical background factors of the women. ${ }^{1}$ Studies on the imprisonment of (youth) offenders involving young women (Dembo et al. 1993; Jansen 1999; Greer 2000; Belknap 2001) proceed from the assumption that they have experienced maltreatment and abuse more frequently than young men and that their trajectories of delinquency differ. It is argued that young male delinquency mirrors their

For a theoretical overview, see Belknap 2001, pp. 61-71. 
involvement in delinquent life styles, while young female delinquency is connected with experiences of maltreatment, abuse and traumatization within the family. In summary, the findings indicate that the pathway for young women into the juvenile justice system is characterized by a high frequency of victimization and turbulence within the family. The women appear as "victims" of their circumstances, and their deviance is often explained along this line of argumentation. In this manner, both in research and in practice, conclusions are drawn from the phenomenon for an explanation. As a result, the (young) women are denied any ability to take action on the one hand. On the other, there is an overemphasis on their experience of victimization, which goes hand in hand with less emphasis on the victim experiences of (young) men. Conversely, the opposite holds true in the case of perpetratorship. It is underemphasized in the case of young women and overstressed in connection with young men. This leads to a constant reproduction of gender differences which culturally links victimhood with femininity and being an offender with masculinity. Research dealing with female desistance processes also makes use of such explanatory options (Leverentz 2014). It emphasizes that the experiences of men and women in desistance processes are "strikingly different" (Leverentz 2014, p. 177): "Even when experiencing reentry and attempting desistance in the same social context, men and women also negotiate gender roles and expectations that shape their lives, their relationships, and how others respond to them" (Leverentz 2014, p. 177). Cultural ascriptions of gender as well as gender difference and the different social positionings of women and men also have an impact on processes of desistance and are an important perspective in their analysis. However, gender is a complex category, and the dimensions of gender significance in desistance processes "cannot be reduced either to homogeneous social groups such as 'women' and 'men'. Nor can they be reduced to uniform gender identities, unambiguous gender roles or binary encodings of difference" (Bereswill 2014, p. 189). Yet to date, a differential view of the complex category of gender has remained a striking gap in research on desistance.

That is evident from a recent review (Rodermond et al. 2016) on female desistance processes based on 44 quantitative and qualitative studies. ${ }^{2}$ Various factors which are considered to be central influences on desistance processes are systematically taken into account there. ${ }^{3}$ This includes family factors (such as marriage, partners, children, family), social factors (such as employment, education, friends), individual factors (such as punishment, religiosity), as well as mental health, drugs and financial resources. The results provide an overview of factors related to female desistance and examine differences between factors related to female and male desistance. This

2 The studies stem mainly from the US but also from Scotland, the Netherlands, Norway, Australia, and New Zealand.

3 The authors are oriented towards existing theories of desistance, such as the theory of informal control (Laub \& Sampson 2001; 2003), the theory of cognitive transformation (Giordano et al. 2002) and the identity theory (Maruna 2001). Rodermond et al. (2016) come to the conclusion that these theories are applicable likewise to female offenders. 
means that there is no gender-theoretical perspective, but rather an "analysis by sex" and not gender - or that a differentiating perspective is pursued which presupposes differences "between male and female desistance".

In general, the authors arrive at a conclusion that "all in all, women appeared to benefit more from family factors, while men were influenced more by employment and peer factors" (Rodermond et al. 2016, p. 22).

Looking at the results of the different studies in detail, it becomes evident that they are very heterogeneous. This can be illustrated by the example of the significance of a marriage for desistance processes or for a termination of offending, which is described here in very condensed form: ${ }^{4}$ marriage reduced offending even when the partner had previously been convicted. Being married reduced the odds of a property arrest, whereas the odds of a drug arrest were increased. Three studies failed to find significant effects. One study found that cohabitating with a spouse led to increased offending. Some quantitative studies found that marriage can contribute to termination. In contrast, other studies found no effects of marriage or attachment to a spouse on a termination of offending. Looking at gender differences regarding the influence of marriage, ${ }^{5}$ six studies found that marriage was more likely to increase the odds of crime reduction and termination in males than in females. One study found the effect to be greater for females. The findings of yet another study suggested that marriage reduced offending only for males with low propensities to marry and for females with medium propensities to marry. And one study found that entry into a high-quality marriage had an effect only on males.

This review is only an exemplary overview which in a similar way looks for other factors such as partnership or work. A provocative question is: what do the findings tell us about the importance of marriage for the desistance processes of women? But most importantly: what is gender-related about it?

The authors of the review (Rodermond et al. 2016, p. 22) conclude that variables such as marriage, family, motherhood, work, or peers do not automatically lead to reductions in crime and offending, but that it was, for example, rather the quality of relationships, the ability to take care of children or to form new friendships which played a significant role. This makes clear that we have to take into account the quality of relationships as well as the ability to care and commit. However, this is not something specifically female but rather raises questions about the interconnection of autonomy, dependency and attachment, largely aspects still poorly understood from a gender-theoretical standpoint.

4 For a detailed overview, see Rodermond et al. 2016, pp. 6 ff.

5 The results are only based on quantitative studies. 
But how can gender be examined if it is both apparent and yet blurred at the same time? Which dimensions of gender are considered? How can phenomena be examined from a gender-theoretical perspective without continuously reproducing gender differences?

In the following, gender is first considered as a complex category in order to then sketch the methodological and methodical challenges for the analysis of desistance processes of women (and men) in the final section of the paper.

\section{Gender as a complex category}

The aforementioned results on desistance processes of women demonstrate that gender - as in knowledge about differences within everyday life worlds - is understood through bodily features and that a clear differentiation is made between men and women. Additionally, a differentiation perspective is employed that presupposes gender differences between men and women. This positing of difference is interrogated and examined from sociological, gender-theoretical perspectives and the "social category of gender" (Gümen 1998; see also Bereswill 2008).

Figure $1 \quad$ Dimensions of the gender category

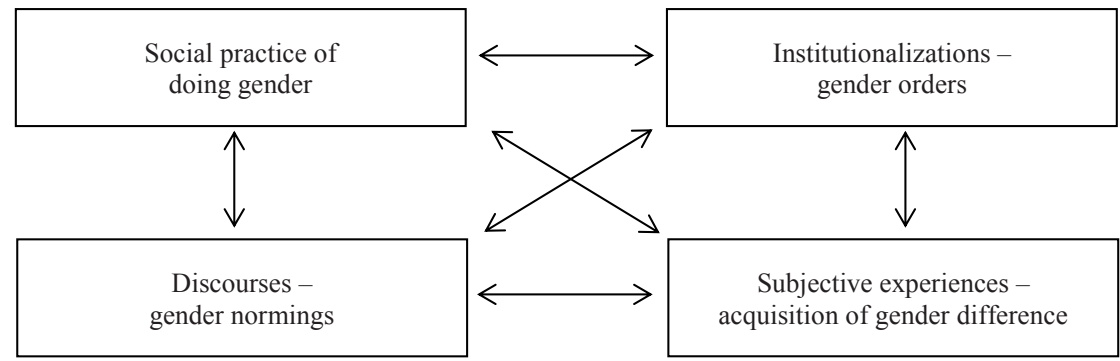

Source: Figure modified based on Groenemeyer 2014, p. 155

Gender is a complex phenomenon that can be looked at and investigated in various dimensions which can be separated out analytically and pragmatically. In this approach, the focus is not on explaining what gender really is or should be; "rather, phenomena are to be analysed in connection with how they are utilized socially" (Groenemeyer 2014, p. 154-155): as interpretive patterns of specific social practice, as institutionalizations, as discourses, and as forms of subjective and biographical experience. These ideas relate to the model Axel Groenemeyer has developed (see 
Figure 1) in order to "explicate social processes of problematization at various different levels" (Groenemeyer 2014, p. 150). ${ }^{6}$

The following observations and reflections are based on Groenemeyer's ideas in a strongly condensed and modified form in an attempt to better clarify the complexity of the gender category.

\subsection{Social practice of gender - doing gender}

From this perspective, the interactive and interpretive processes through which gender is constructed are reconstructed (known as 'doing gender'). It is assumed that gender is not a personal attribute but rather the result of ascriptions which are negotiated in complex processes of interaction. Thereby, it is not something biological and pre-social, nor something people have or are, but rather what they do (and are doing). Gender is seen as fundamental for the structure of interactions. Individuals present themselves as women and men and are perceived as such. In Groenemeyer's view, this principally entails "the work of categorization within interpretive practice [...] for which visible signs and general stores of knowledge are utilized" (2014, p. 156) - in this case with regard to gender. He stresses the bodily expressive form of social practice "in which a practical social knowledge in a self-evident form is expressed by all those involved" (Groenemeyer 2014, p. 156). However, this is an implicit body knowledge which becomes relevant in every social situation incorporated or habitualized - and thus is not consciously perceived or constantly reflected upon. Normative expectations and concepts of normality play a key role in the construction of the order of interaction and the processes of categorization. In the research field of desistance processes, societal constructions of gender and gender differences are closely intertwined with constructions of deviance and normality.

A look at the interaction processes of gender reveals that gender is not the property of the person but "rather a relational category constructed in the interaction of social practice, but then as a consequence comprises a powerfully effective reality and in this sense a social fact to which the further social practice of all those involved is related" (Groenemeyer 2014, p. 158). Gender difference is thus also culturally constructed. In social constructivist research, it is not presupposed, as opposed to many studies on desistance processes of women and men. Instead, the process of gender differentiation itself as well as the construction processes of gender are scrutinized (Seus 2002, p. 95; Meißner 2008, p. 16). The interaction-theoretical perspective serves to focus attention on processes through which conceptions of gender become operative and gender difference is repeatedly reconstructed (Meißner 2008, p. 16).

6 The levels in the analysis of problematization processes that Groenemeyer (2014) names are made concrete by him in the article as illustrated by disability. But they can be applied to various different categories. 
The analysis looks at the processes underlying the genesis and construction of the gender order as individuals interact.

\subsection{Institutionalizations - gender orders}

Individuals construct gender as well as social order and systems of dominance and subordination while they act genderly (see Lorber 1987, p. 3). That is to say, gender is not only generated in interactions; rather, as Erving Goffman (1994, pp. 105-158) makes clear in his concept of "institutional reflexitivity", 7 it is also simultaneously regulated in institutions (see Knobloch 1994, p. 41; Wetterer 2003, p. 293).

Groenemeyer sees institutions as social formations "that - via fixed, normative structures of expectations and roles that are mutually interrelated - regulate, limit and make possible social action" (Groenemeyer 2014, 158). Thus, for him, along lines similar to Goffman's conceptualization, institutions are institutionalized orders of interaction that are constructed and consolidated via interiorized norms (and sanctions), but also the "materialization or crystallization of specific cultural knowledge orders of discourses" (Groenemeyer 2014, 159). Institutions symbolize unquestioned knowledge and cultural matters of fact and thus constitute an order of knowledge (Groenemeyer 2014, p. 158).

Angelika Wetterer (2003) also refers to these self-evident matters of course when she argues that a "context of masking" is constitutive for institutional reflexivity: "what remains systematically concealed to the actors is that they are significantly involved in constructing the difference between the genders, which they consider to be the natural specification and demand of social action" (Wetterer 2003, p. 294). For practical work, this means that in institutional contexts, the character of cultural ascriptions, symbols, norms, and values as social constructions disappears within the matter-of-fact routines of practical work. They are "but rarely the object of explicit decisions by professionals, and rather are a component of the institutional setting" (Groenemeyer 2014, p. 161).

Gender orders are institutionalized via legal orders, organizations or the routinization and habitualization of knowledge. But in the processes of institutionalization, discourses and "the patterns of interpretation and basic attitudes grounded on values expressed in those discourses become efficacious, they become an objectified reality, social facts" (Groenemeyer 2014, p. 159). Thus, discourses also find their expression in institutions and social practices.

7 Institutional reflexivity means that the social gender - the arrangements of the genders - is institutionalized in such a way that the construction of „natural differences” between the genders are constructed and maintained - differences that underpin and account for the supposedly different institutionalization (see Kotthoff 1994, p. 162). That is to say, the institutionalizations are understood as the result of a "natural gender" difference, yet actually first generate that difference. 


\subsection{Discourses - gender normings}

Groenemeyer proceeds from an understanding of discourse based on the sociology of knowledge. In his view, discourses are "public debates about interpretations, definitions, categorizations and valorizations of phenomena" (Groenemeyer 2014, p. 162). Yet these mainly textual negotiations also find their expression in institutions and social practices which are "legitimated or delegitimated, imbued with sense and meaning via discourses" (Groenemeyer 2014, p. 162).

Thus, discourses generate what they apparently only designate - they are productive. Seen from this Foucauldian conception of discourse, discursive configurations are also always a form of power. They are repressive because alternative definitions or orders are excluded. "Discourses thus demarcate the realm of what is thinkable or liveable, while other options do not appear to be thinkable or liveable" (Villa 2004).

Judith Butler $(1990 ; 1995)$ builds on these ideas in her gender-theoretical approach. For her, the locus and mode of the construction of gender is the realm of language, of discourse, of the symbolically discursive orders (Villa 2004, pp. 141 f.). Seen from this concept-analytical, theory-immanent perspective, theories and categories are an object of analysis that "problematize and influence the conceptions of subject, the relation between nature and culture and gender difference in our culture" (Knapp 2000). Gender is thus understood as being discursively constructed and interrogated. Attention is directed to the efficacy and scope of discursive meaning production, which does not mean that a reality external to language is negated. From a perspective shaped by the sociology of knowledge, discourses are expressed in social practices and institutions, they take shape via positionings as well as through subjects.

\subsection{Subjective experiences - acquisition of gender difference}

The previous dimensions of social practice, institutions and discourses form the background to what condenses as the experience from and with gender, "what comprises the object and condition of adaptations, coping strategies, and suffering or resistance in interactional situations of institutional impositions and excessive demands" (Groenemeyer 2014, p. 154).

In this context, (subjective) experiences can be conceptualized in theoretically different ways. Groenemeyer names the positioning of the subject by means of discourses. He then develops this discourse-theoretical perspective along interactionaltheoretical lines by proceeding from the assumption that (problem) discourses contain possibilities for an identification of the Other and the Self which constitute individual biographies via habitualizations. He sees an excellent option in this for linking up with Goffman's investigation of identity construction within the framework of processes of stigmatization. Decisive for him is that subjective experiences "are not 
conceived as stable features of identification but rather as flexible and changing forms of the interpretation of the Self and the Other" (Groenemeyer 2014, p. 166). ${ }^{8}$

In contrast to Groenemeyer's model, the present essay does not conceive of the subjective experiences in discourse- or interaction-theoretical terms, but rather within the theory of conflict. The concept of conflict points to tensions, contradictions and ambivalences. The societal horizons of expectation and the (biographical) Eigensinn ${ }^{9}$ of the subject incur tension. This perspective is closely bound up with a dialectical tradition in thought which assumes that social relations are contradictionridden and that subjects do not simply accommodate to or turn away from these contradictory relations. Societal expectations and excessive impositions, rather, are experienced as conflictual and ambivalent and are coped with by the individual. Building on social-scientific readings in psychoanalysis, it is hypothesized that human beings not only perceive "conflicts between their interior world and external world, but also between various psychological realities, those consciously experienced and those repressed into the subconscious" (Becker-Schmidt 2006, p. 289). That also holds true for the category of gender.

Processes of genderization [can] be grasped in subject-theoretical terms as a continual tension-laden dialectic between external and internal realties, in the course of which non-simultaneous societal constellations interact with the internal conflicts of the subject (Bereswill 2014, p. 194).

In the biographical process, gender is investigated from a conflict-theoretical perspective. Attention is directed to the subjective acquisition of gender as a complex and contradiction-ridden process which by no means is always conscious for the subjects (Neuber 2009; 2011; Bereswill 2014). Cultural constructions of gender and gender difference are not simply accepted or rejected by subjects; they are rather adopted and internalized in a life-long process. Gender is thus not understood as a uniform identity or role but rather as a "conflict category" (Bereswill 2014; Becker-Schmidt \& Knapp 1987). If these reflections are linked back to the above-cited quote by Leverentz on the "strikingly different" experiences of men and women in desistance processes, then "men and women also negotiate gender roles and expectations that shape their lives, their relationships, and how others respond to them" (Leverentz 2014, p. 177). This is an important argument which focuses its attention on the reproduction of a social order and the simultaneous construction of gender difference. Not focused on is the eigensinnige $e^{10}$ acquisition and processing of the social construction of gender in the biographical context (Bereswill 2014, p. 194). The conflict-ridden confrontation with societal identity constraints - which are also pointed up in the quote

8 From this perspective, gender is constructed situationally and dependent on context within specific situations; it thus builds on the interaction-theoretical perspective of doing gender.

9 “Eigensinn” could basically be translated as obstinacy, but in German, „Eigensinn” furthermore captures a mixture of stubbornness and empowerment.

10 See previous footnote. 
from Leverentz - is characterized by ruptures and ambivalences (Bereswill 2014, p. 194).

This brief look at the complexity of the gender category makes clear that desistance processes of (young) women and likewise (young) men can be investigated against the backdrop of gender orders that are socially and culturally engendered and shaped, as well as the institutionalization of gender difference - within social practices, in discourses and in the biographical acquisition and processing of gender difference.

If the example of marriage cited above as a factor for desistance processes is revisited, then the importance of marriage for desistance processes on the level of social order can, as an institutionalized form anchored in law, investigate how gender relations are socially regulated and which asymmetries in power this creates. But the construction processes of gender and gender difference can also be examined: in interview narratives as processes of doing gender or in the gender-related ascriptions in the field, for example, when women (in contrast to men) are described as "good marriage partners" and as a stabilizing factor in the processes of desistance for men. The importance of a marriage can be analyzed in the context of gender discourses in the area of deviation and social control. These are public options for interpretation and the struggle over interpretation that determine just how a marriage, as related to gender, can be conceptualized and interpreted as a factor for processes of exiting from delinquency, but also of how a marriage should be assessed and which practices should be connected to that. In conflict-theoretical terms - and research findings also point to this with a focus on the quality of the relations -, attention is drawn to the importance of experiences of bonding and dependency. From this perspective, there are no clear and unambiguous "female" or "male" patterns of coping in dealing with conflicts over autonomy.

The four described levels comprise differing dimensions of the category gender whose separation is analytical in nature. Thus, discourses are also expressed in social practices, and in institutional rules, social practices produce discourses and influence individual experiences. However, the various theoretical perspectives have differing scopes and limits; in each case, they function in accordance with their own logic and require different methods and concepts for empirical analysis (see Groenemeyer 2014, p. 154). However, in numerous studies on gendered pathways into, but also out of crime, the dimensions for the main part are not viewed differentially, and direct conclusions are drawn from one dimension to the other. For example, frequently, direct conclusions about the subject are drawn from structural conditioning factors and social practices, or vice versa. This leads to systematic reductions and to a consolidation of ascriptions of femininity.

While Groenemeyer stresses that the levels are interconnected and not clear-cut, Wetterer puts emphasis on a different aspect: she points to the "contradictions between the various levels and media of the construction and institutionalization of gendered 
differentiation and hierarchization" (Wetterer 2003, p. 288). She describes two constellations of contradiction. The first one is between the changed everyday world knowledge about gender - which, due to discourses on gender equality, had gone through a process of modernization - and the change of social structures and institutions that are more robust in their processes of transformation. Thus, non-simultaneities exist between individuals and social conditions (Wetterer 2003, p. 302). The second contradiction constellation comprises the contrast between discursive knowledge - in which the discourse about equality is manifested - and the social practice that follows an incorporated knowledge - which determines the action of individuals by latent gender norms (see Wolde 2006). For Wetterer, what we see here is that the non-simultaneities also lie in the individuals themselves. Her stimulating diagnosis of "rhetorical modernizing" is applicable only with limitations to the desistance processes of women, because here, the discourse on quality is not manifested in such an unbroken manner, neither in the scientific and popular scholarly discourses reflecting everyday world knowledge nor in the everyday knowledge reflected in everyday discourse. We rather have to look at the contradictions on the level of discursive knowledge itself (see Wolde 2006). However, instructive for the approach of gender-theoretical analysis is that there are non-simultaneities between individuals and social conditions, but also among the individuals themselves. The non-simultaneities among the individuals can be grasped as ambivalences from the conflict-theoretical perspective. Ambivalence designates the subjective attempt to cope with and process social contradictions and non-simultaneities. This is what constitutes the strength of a conflict-theoretical perspective whose potential for a deeper understanding of desistance processes and their methodical and methodological demands will be briefly sketched in the concluding section below.

\section{Outlook}

Taking into account the current state of research on desistance processes of women, there is agreement on what Stephen Farrall and his fellow authors formulate as follows: "existing theory and research on women's pathways out of crime has emphasized the importance of both structural and psychological factors" (Farrall et al. 2011, p. 221). Elaine Rodermond et al. (2016, p. 23) also arrive at this conclusion in their review and consider it to be the task of future research to determine "whether social factors influence individual factors, or vice versa". A glance at the complexity of the gender category has made clear that it is meaningful to view these categories in a differentiated manner so as to separate them analytically and to refrain from drawing direct conclusions from one dimension to another (Neuber 2016; 2015; 2011). It is more important to reflect on the non-simultaneities and contradictions between the dimensions as well as within them. It is thus a question not of "whether ... or" but of "how". How can we best and most appropriately grasp the nexus between social and individual factors? 
Herein lies the strength of a perspective geared to conflict-theoretical aspects which also contains a potential for analysing desistance processes. From this subject-theoretical perspective, desistance is understood as a conflict-laden process. The selfinterpretations of those who desist (or persist) in regard to distancing themselves from delinquency are understood in the context of biographical conflict experiences. ${ }^{11}$ Desistance is understood here as a dialectical movement "between processes of integrating the individual into societal contexts and the conflict-laden processing of experiences within the subject" (Bereswill et al. 2008, p. 31). For a gender-theoretical analysis of desistance processes, a conflict-theoretical approach directs attention to the conflict-ridden nature inherent in the acquisition of constructions of gender difference. In this context, dichotomous mental figures of gender difference can be critically questioned and reflection can be spurred on the reproduction of gender clichés.

However, this approach entails methodical and methodological challenges for the study of the desistance processes of young women and men. These will be addressed in closing as theses in conjunction with three points.

\subsection{Strengthening biographical perspectives in desistance research}

Biography- and career-oriented approaches continue to dominate criminological research in Germany. These approaches argue "on the basis of normative models of (for instance, pathological) development, which have to be questioned when dealing with the individual biographies of people in particular" (Bereswill 2015b). The approaches of biographical research within desistance research have the potential to reconstruct action processes and process structures and thereby to comprehend the process of going straight, along with its detours.

\subsection{Desistance processes are not exclusively cognitive}

The various approaches of desistance research emphasize the cognitive changes of the desisters in the form of externally initiated turning points, as in John Laub and Robert J. Sampson (2003) but also in Shadd Maruna who looks at their subjective stances. He emphasizes the great significance of narratives for desistance research and assumes that internal cognitive transformation processes are necessary to permanently terminate a criminal career. Peggy C. Giordano et al. (2002) also focus on cognitive transformation processes. In the approaches of desistance research, going straight emerges "as a conflict-free process of consciously changing attitudes and behavior, without making clear how social conditions and individual coping mechanisms intertwine or drift apart" (Bereswill et al. 2008, p. 31). However, the ap-

11 For an empirical case study on the desistance processes of women from a conflict-theoretical perspective, see Neuber 2016. 
proaches in cognitive transformation and related turning points are closely intertwined as seen from a vantage of the theory of action. Actions are not only carried out on a conscious level, but are also subject to unconscious influences. From a subject-theoretical perspective, desistance processes include the conflict-laden processing of experiences within the subject and are not considered to be purely cognitive transformation processes. Rather, the biographical processes and deep structures of distancing are considered in order to "open up moments of mediation between institutional requirements and individual dynamics of acquisition" (Bereswill 2015a, p. 346).

\subsection{Methodical consequences}

Methodically, this means that desistance processes cannot be reconstructed comprehensively enough by means of analysing the manifest content of narrations (Maruna 2001, p. 169). Conflicts and potentials of integration that become apparent in interviews are not only tangible on the level of the manifest text; they rather have to be reconstructed from self-interpretations which also latently emerge in an interview. This requires reconstructive-hermeneutic approaches in order to identify implicit and latent meanings of desistance processes. Only by examining latent meanings does the conflict-laden nature of desistance processes and the interaction between societal conditions and individual experiences become comprehensible. ${ }^{12}$ This holds true in particular for a gender-theoretical perspective due to gender being more than what people say or do. It is a matter of reconstructing latent gender norms and subjective processing of gender difference.

In conclusion, it should be noted that a conflict-theoretical research perspective can challenge perspectives on desistance that are narrowed due to the constraints of the theory of action, since it permits a differentiation between patterns of action, cultural patterns of interpretation and the biographical Eigensinn ${ }^{13}$ of human beings. In this way, understanding is broadened concerning the often circuitous processes of desistance. The above differentiation also contains a potential for gender-theoretical perspectives. That is because in this way, a better avenue of access is opened up to the conditions for the construction and constitution of supposedly unambiguous difference, and dichotomous mental figures of gender difference can be reflected upon.

It is important to avoid attributing in haste the self-representations of young women in the processes of desistance to gender-stereotypical ascriptions. But in a reverse conclusion, this does not mean that the category of gender does not play a role for

12 The latency concept of this contribution is a psychodynamic one which focuses on the "inwardness of subjective life plans" (Belgrad et al. 1987, p. 17) as well as on subjective meaning, which is viewed as consequences of objective contradictions. See Neuber 2009 for an engagement with the latency concept as well as for a comprehensive depiction of the methodical procedure.

13 See footnote 9. 
processes of desistance. The self-representations of young women (and young men) are integrated within a web of gender relations, orders of interaction, discourses, and social practices that impact on the spaces of possibility and structures of chance and which can be subjectively acquired and processed.

\section{References}

Becker-Schmidt, R. (2006): Theoretische und methodische Anmerkungen zu "Sozialisation und Geschlecht", in: H. Bilden \& B. Dausien (eds.), Sozialisation und Geschlecht. Theoretische und methodologische Aspekte. Opladen, pp. 289-305.

Becker-Schmidt, R. \& Knapp, G.-A. (1987): Geschlechtertrennung - Geschlechterdifferenz. Suchbewegungen sozialen Lernens. Bonn.

Belgrad, J., Görlich, B., König, H.-D. \& Schmid Noerr, G. (1987): Alfred Lorenzer und die Idee einer psychoanalytischen Sozialforschung - Eine Einleitung, in: J. Belgrad, B. Görlich, H.-D. König \& G. Schmid Noerr (eds.), Zur Idee einer psychoanalytischen Sozialforschung. Dimensionen szenischen Verstehens. Alfred Lorenzer zum 65. Geburtstag. Frankfurt am Main, pp. 9-26.

Belknap, J. (2001): The Invisible Women. Gender, Crime, and Justice. $2^{\text {nd }}$ ed. Belmont.

Bereswill, M. (2015a): Zwischen autoritärer Zumutung und Entwicklungsversprechen. Der Freiheitsentzug als tief greifende biographische Konflikterfahrung, in: M. Schweder (ed.), Handbuch Jugendstrafvollzug. Weinheim, pp. 339-353.

Bereswill, M. (2015b): Review, March 2015 of Eduard Matt: Übergangsmanagement und der Ausstieg aus Straffälligkeit. Centaurus 2014. socialnet Rezensionen; www.socialnet.de/rezensionen/17209.php [30/09/2016].

Bereswill, M. (2014): Geschlecht als Konfliktkategorie, in: C. Behnke, D. Lengersdorf \& S. Scholz (eds.), Wissen - Methode - Geschlecht: Erfassen des fraglos Gegebenen. Wiesbaden, pp. 189-199.

Bereswill, M. (2008): Geschlecht, in: N. Baur, H. Korte, M. Löw \& M. Schroer (eds.), Handbuch Soziologie. Wiesbaden, pp. 97-116.

Bereswill, M., Koesling, A. \& Neuber, A. (2008): Umwege in Arbeit. Die Bedeutung von Tätigkeit in den Biographien junger Männer mit Hafterfahrung. Baden-Baden.

Butler, J. (1995): Körper von Gewicht. Die diskursiven Grenzen des Geschlechts. Berlin.

Butler, J. (1990): Das Unbehagen der Geschlechter. Frankfurt am Main. 
Dembo, R., Williams, L. \& Schmeidler, J. (1993): Gender differences in mental health service needs among youths entering a juvenile detention centre. Journal of Prison and Jail Health 12/1, pp. 73-101.

Farrall, S., Sharpe, G., Hunter, B. \& Calverley, A. (2011): Theorizing structural and individual-level processes in desistance and persistence: Outlining an integrated perspective. Australian \& New Zealand Journal of Criminology 44, pp. 218-234.

Giordano, P.C., Cernkovich, S.A. \& Rudolph, J.L. (2002): Gender, Crime, and Desistance: Towards a Theory of Cognitive Transformation. American Journal of Sociology 107/4, pp. 990-1064.

Goffman, E. (1994): Das Arrangement der Geschlechter, in: E. Goffman (ed.), Interaktion und Geschlecht. Frankfurt am Main, pp. 105-158.

Greer, $K$. (2000): The Changing Nature of Interpersonal Relationships in a Women's Prison. The Prison Journal 80/4, pp. 442-468.

Groenemeyer, A. (2014): Soziale Praxis - Institutionen - Diskurse - Erfahrung. Behinderung im Problematisierungsprozess. Soziale Probleme 25/2, pp. 150-172.

Gümen, S. (1998): Das Soziale des Geschlechts: Frauenforschung und die Kategorie „Ethnizität”. Das Argument 40/1/2, pp. 187-202.

Jansen, I. (1999): Mädchen in Haft. Devianzpädagogische Konzepte. Opladen.

Knapp, G.-A. (2000): Konstruktion und Dekonstruktion von Geschlecht, in: R. Becker-Schmidt \& G.-A. Knapp (eds.), Feministische Theorien. Zur Einführung. Hamburg, pp. 63-102.

Knobloch. H.A. (1994): Ervin Goffmans Reich der Interaktion, in: E. Goffman (ed.), Interaktion und Geschlecht. Frankfurt am Main, pp. 7-49.

Kotthoff, H. (1994): Geschlecht als Interaktionsritual?, in: E. Goffman (ed.), Interaktion und Geschlecht. Frankfurt am Main, pp. 159-194.

Laub, J. \& Sampson, R. (2003): Shared Beginnings, Divergent Lives. Delinquent boys to age 70 . Cambridge.

Laub, J. \& Sampson, R. (2001): Understanding Desistance from Crime. Crime and Justice 28, pp. 1-69.

Leverentz, A.M. (2014): The Ex-Prisoner's Dilemma. How Women Negotiate Competing Narratives of Reentry and Desistance. New Brunswick, New Jersey.

Lorber, J. (1987): From the editor. Gender \& Society 1, pp. 3-5.

Maruna, S. (2001): Making Good. How Ex-Convicts Reform and Rebuild Their Lives. Washington D.C. 
Meißner, H. (2008): Die soziale Konstruktion von Geschlecht - Erkenntnisperspektiven und gesellschaftstheoretische Fragen, in: gender...politik...online, InternetPortal des Fachbereichs Politik- und Sozialwissenschaften der Freien Universität Berlin; www.fu-berlin.de/sites/gpo/soz_eth/Geschlecht_als_Kategorie/Die_sozia le_Konstruktion_von_Geschlecht_Erkenntnisperspektiven_und_gesellschaf tstheoretische_Fragen/hanna_meissner.pdf [25.09.2016].

Neuber, A. (2016): Desistance-Prozesse junger Frauen - eine geschlechter- und adoleszenztheoretische Betrachtung. Soziale Probleme 27/2, pp. 221-235.

Neuber, A. (2015): Junge Frauen im (Jugend-)Strafvollzug - ein Sonderfall? Das Hafterleben aus Sicht inhaftierter junger Frauen, in: M. Schweder (ed.), Handbuch Jugendstrafvollzug. Weinheim, pp. 408-424.

Neuber, A. (2011): Same, same but different? Methodologische Überlegungen zum Verhältnis von Gewalt und Geschlecht. Sozialer Sinn 12, pp. 3-27.

Neuber, A. (2009): Die Demonstration kein Opfer zu sein. Biographische Fallstudien zu Gewalt und Männlichkeitskonflikten. Baden-Baden.

Rodermond, E., Kruttschnitt, C., Slotboom, A.-M. \& Bijleveld, C.C.J.H. (2016): Female desistance: A review of the literature. European Journal of Criminology 13, pp. 3-28.

Seus, L. (2002): "Irgendwas ist schiefgegangen im Prozess der Emanzipation". Abweichung und Geschlecht, in: R. Anhorn \& F. Bettinger (eds.), Kritische Kriminologie und Soziale Arbeit. Impulse für professionelles Selbstverständnis und kritisch-reflexive Handlungskompetenz. Weinheim, pp. 87-109.

Villa, P.-I. (2004): (De)Konstruktion und Diskurs-Genealogie: Zur Position und Rezeption von Judith Butler, in: R. Becker \& B. Kortendiek (eds.), Handbuch Frauen- und Geschlechterforschung. Theorie, Methoden, Empirie. Wiesbaden, pp. 141-152.

Wetterer, A. (2003): Rhetorische Modernisierung: Das Verschwinden der Ungleichheit aus dem zeitgenössischen Differenzwissen, in: G.-A. Knapp \& A. Wetterer (eds.), Achsen der Differenz. Gesellschaftstheorie \& feministische Kritik II. Münster, pp. 286-319.

Wolde, A. (2006): Väter in Väterinitiativen als ambivalente Akteure der Modernisierung, in: M. Bereswill, K. Scheiwe \& A. Wolde (eds.), Vaterschaft im Wandel. Multidisziplinäre Analysen und Perspektiven aus geschlechtertheoretischer Sicht. Weinheim, pp. 95-115. 



\title{
Generative Experiences and the Desire to Become Generative: A Biographical Approach to the Self-Conceptualizations of a Young Former Delinquent in Switzerland ${ }^{1}$
}

\author{
Franz Zahradnik
}

\section{Introduction}

The interplay of desistance and generativity has been introduced as a vital component in the analysis of reintegration processes of ex-offenders (Maruna 2001; McNeill \& Maruna 2008; Healy \& O’Donnell 2008). As a factor promoting desistance, generativity has often been bound to the wider context of maturation or the birth of a child and the changing perspective through becoming a caring partner and parent (Walker 2010). With references to Erik H. Erikson's developmental theory, the origins of establishing a generative stance in childhood and adolescence through the self-experience of intergenerational assistance and guidance also gained some attention ( Halsey \& Deegan 2015, pp. 6-7; Halsey \& Harris 2011, pp. 74-76; McNeill \& Maruna 2008 , pp. 225, 231). These connections can be worked out in more detail and should be embedded in a biographical perspective.

In this article, I focus on the experiences of male adolescents who have been placed in a so-called Massnahmezentrum for young adults in Switzerland. In the eyes of the law, these young men are neither juveniles nor full adults. For those who are eighteen but not yet twenty-five years old, there are special measures they can be assigned to instead of imprisonment. These institutions aim at providing educational and vocational support so as to enable those young men to an autonomous and self-responsible lifestyle. Therefore, the duration of their stay is not determined by the offence committed but by the ascertained educational needs (Aebersold 2011, p. 87; Baechtold 2009, pp. 275-277).

Compared with prison, those measures could be described as semi-closed community homes that are not enclosed by walls and fences but have a deeply structured overall concept and strict daily routines. One of the main goals is to accomplish a professional qualification, which is also the reason for the duration of the stay to last for up to four years (Baechtold 2009, p. 255). Complementarily, the young men must be actively involved in social work and psychotherapeutic treatment. As they prove

1 I have to thank Daniel Werner for his helpful comments and redactional work. His engagement was essential for completing this text. 
themselves during the measure, control mechanisms are reduced and the transition into the outside world is initialized (Studer 2013, pp. 203-209; see also Müller \& Rossi 2009).

Recent studies scrutinize the adolescent strife for an autonomous and self-responsible lifestyle under the conditions of juvenile correctional facilities (Cox 2011; Reich 2010). It is argued that there are conflicts between the pedagogical intentions of the institution and the young men's subjective interpretations as well as coping strategies that transform or hinder processes of self-realization: "There were pains that lay in the 'split' between what the programme dictated as appropriate for progress, and how the process of change and growth were actually experienced" (Cox 2011, p. 593). These "paradoxes of treatment" (Abrams et al. 2005, p. 19) help broaden the perspective and take the psycho-social dynamics into account that are intertwined with the wider integration conflicts of socially marginalized adolescents (Bereswill 2004, p. 316). This opens the view for the conflict-ridden processes of evolving a generative stance that is hardly being achieved by changing short-term interventions but more likely through the offering of intergenerational relationships with a certain quality and continuity. Exploring the long-term consequences of the described institutional intervention requires an integrated perspective that allows the contextualization of the contradictory and tense situation in a semi-closed "environment into the biographical processes before, during and after" (Bereswill 2011, p. 216, emphasis in original) confinement.

In the following sections, I will first outline the theoretical framework that guides my analysis as a sensitizing concept (2). After presenting an overview of our qualitative longitudinal study (3), I analyze the biographical experiences of one young man who was placed in a Massnahmezentrum for four years (4). In the concluding section, I summarize my results and give an outlook of the upcoming challenges by further analyzing the biographical processes of becoming generative and overcoming delinquent behavior.

\section{The Triad of Generativity - Adolescence - Desistance}

Desistance research provides some instructive insights when conceptualizing the thematic complex of adolescence, generativity, and the emergence of a transformed self-image that is marked by the rejection of former criminal attitudes:

[D]esistance is a process associated with maturation but often characterised by ambivalence and vacillation; that it may be provoked by life events, depending on the meaning of these events for the offenders; that it may be 'sponsored' by someone involved in a significant relationship with the offender who 'believes in' the offender; that it probably involves more than the development of cognitive skills - it involves the re-storying of narrative identities; and that it requires the development of social as well as human capital (McNeill \& Maruna 2008, p. 231). 
A limitation of this view can be seen in the circumstance that it only allows access to the wider developmental process at a relatively late point in time analytically, namely when the progression towards desistance has started. The emphasis here is on what must be added to the offender's prevailing conditions - meaningful life events, significant relationships, the development of cognitive and narrative skills plus social and human capital. These are important insights, but the focus is apparently on the coping strategies and efforts concerning current and future identity management. This gives rise to the question what the biographical origins and developmental dynamics of generative pursuits could be. To put it another way: Are the chances and capabilities for becoming generative distributed equally?

It seems that the perspective needs to be broadened through a biographical approach to disentangle the life-course dynamics of evolving individual resources, because this gives access to the predecessors of the ability to become generative by oneself. This does not mean to conceptualize the biographical process as a linear chronology of subsequent developmental steps, but to take the hint of Fergus McNeill and Shadd Maruna (2008, p. 231) seriously that maturation is interspersed by "ambivalence and vacillation". It is therefore necessary to present a theoretical framework that pays attention to the conflict-ridden psychodynamics of adolescent individuation.

The theory of adolescence presented by Vera King (2013) provides the conceptual framework for approaching these challenges on the way to adulthood. The phase of adolescence can then be seen as a "psychosocial realm of possibilities" (King 2013, p. 39) that is marked by various types of tensions and conflicts. A special emphasis is put on the ambivalences between autonomy and dependence, closeness and distance, attachment and separation, desires and normative adjustments - processes of individuation are conceived as dialectically bound to generativity (see also Lüscher 2011, pp. 193-194). In this sense, young people can benefit from a generative attitude of the adult generation and a moratorium provided by them potentially. This quality is characterized by different combinations of generational support and restraint, distinction, and availability. This applies to both the private sphere and institutional social work contexts (King 2012, p. 70). The psychosocial realm of possibilities is not an unlimited sphere to gain autonomy; instead, it is marked by specific scopes and restrictions for development. Thus, chances are not distributed equally; they rather depend on the objective "structure of opportunities" (King 2013, p. 43; Bereswill 2004, p. 318).

In the remarkable study of Mark Halsey and Simone Deegan about the struggles of young offenders for desistance, generativity is set as the central category of analysis. Following Erik H. Erikson, they state that he conceives generativity as a particular developmental stage that entails "a widening commitment to take care of the persons, the products, and the ideas one has learned to care for" (Erikson 1982, p. 67; cited in: Halsey \& Deegan 2015, p. 6, emphasis added). The reference to learning is important for thinking about becoming generative because it clarifies that the offenders' generative history should be considered more systematically. 
One specialty of adolescence is that it contains the potential of a "second chance" (Erdheim 1982). This means that young people can gain a new perspective on their childhood experiences and bring out something new. The course of this process is related to the above-mentioned quality of the adolescent realm of possibilities that is essentially shaped by the older generation. Becoming generative by oneself is part of this long-standing psychosocial reworking and also relies on stable as well as reliable relationships. When regarding pedagogical work in juvenile correctional facilities, this means that a learning environment has to be offered which to a certain degree also allows for stumbling and erring without immediate punishment and exclusion (Cornel 2011, p. 470). Moreover, the pivotal challenge of establishing a working bond in enforcement contexts already requires an appropriate amount of generative patience, especially in terms of holding an offer of support and assistance open, although the juvenile inmate is not yet capable or willing to join in (Wigger 2013, p. 158). Pedagogical generativity must bring together the tasks "to create transitional concepts and practices between being held tight and moving into more open spaces within institutions of social control" (Bereswill 2004, p. 332, emphasis in original) so as to give adolescents a sphere of action for working through their psychosocial conflicts.

Against the backdrop of this brief excursion concerning theoretical conceptualizations, I will follow Halsey and Deegan in asking whether "incarceration can be generative" (2015, p. 23) - but I will extend the question with the supplement: "and how this could be entangled within the wider biographical context."

\section{Study Design}

The qualitative-longitudinal study "Ways out of Delinquency - Reintegration of Convicted Offenders in Switzerland" is led by Peter Rieker and financially supported by the Swiss National Science Foundation. In the first survey wave in 2013 and 2014, fifty in-depth interviews were conducted with male offenders aged between 16 and 61. The offences committed ranged from petty to capital crime, so the men faced different forms and lengths of penal interventions. Most of the interviews were conducted at the end of an institutional placement, i.e. at the end of a prison sentence or placement in a juvenile facility. Up to now, we were able to interview forty of the men again about one and a half years later, and we are now conducting the third interview wave - the young man in the case example named Noah Wyss is one of those who have been interviewed consistently.

Our focus lies on understanding and working out biographical patterns of self-interpretation and coping strategies with a special interest in transition phases (Walther \& Stauber 2013). In order to get subject-oriented access to those transitional challenges, we chose semi-structured interviews that are open to both wider problem constellations and individual biographical concerns (Witzel 2000; Rosenthal 2008). 
We organized the analysis of our data in several steps; in order to categorize all interviews, we drew on the coding procedures referring to Grounded Theory (Strauss $\&$ Corbin 1990). We found indications that generativity has the character of a dialectical process structure, which means that there is a connective link between the desire for becoming generative and having experienced generative care and companionship on one's own (Zahradnik \& Humm 2016, p. 187). The case reconstruction presented in the next chapter is based on the sequential analysis of three subsequent interviews with a young man and aims at exploring deeper layers of sense-making (Wernet 2009) as well as the understanding (Verstehen) of "the latent meanings of subjective self-representations and social action" (Bereswill 2004, p. 319).

\section{Case Example: Noah Wyss}

Noah Wyss was 22 years old when interviewed for the first time in the summer of 2013. At that time, he had almost completed his vocational training and a four-year measure at a Massnahmezentrum. In the following, most parts of his narration have to be summarized, but at some point, his personal quotes will be fully included.

\section{1 "I want to pass this on to guys like I was or like I am" - The Desire to Build on Generative Experiences}

Before Noah was arrested for the first time and then placed in two custodial institutions, he had finished school and started job training. When he was 16, he became more interested in girls and parties and neglected his job training. After he was laid off, he got into conflicts with his father. The situation heated up and Noah moved out; he describes the situation as follows:

And then my father said: "If you don't want your job training, then you shouldn't wanna live here." Actually, he wanted to say: "Search for something new quickly. You shouldn't sit on your parents' thing." And I wanted to understand it the way that he wanted to throw me out, so I left. (I)

There are two things evident in this text passage. First, Noah expresses a lack of understanding for his juvenile perspective by his father whom he describes as a kind of authoritarian character, which could also be interpreted as a lack of generative stance. The second point is that he reframes his initial interpretation and provides it with a misunderstanding on his part. Being aware that this quote was made several years after the actual situation, it clarifies that his perspective has changed and that he tries to establish a more mature perspective concerning the conflict.

But in those days, he moved out and lived with a girl he had met through a friend. They became a couple, and while she was working, he was unemployed and did the housework. When she had to go to the hospital for a longer time, he felt lonely and began to drink more and more. He started stealing cars when drunk and got arrested. 
He had to undergo a time-out for two months and was placed in a farmer family up in the mountains. This was a difficult experience for him because the farmer was like a "dictator" and mistreated not only the young inmates but still more his own family. Noah's description of this time also indicates that he developed an idea of inacceptable limits in the constitution of social contact.

After eight more months in another juvenile institution, he got into trouble with his girlfriend. She left him, and he fell into a deep hole, repeating the old patterns of drinking a lot and stealing cars. At the same time, he did an internship as an early childhood educator - something he describes as fulfilling and making him "proud". Finally, he was arrested again, and this time, he received a prison sentence which was later transformed into a four-year measure.

He describes the initial period in this measurement as restrictive and difficult to fit in. This changed when he began vocational training as a carpenter. In the opening passage of the first interview, he tells about his pleasure to work with wood enthusiastically. This personal connection to practical work is embedded in a wider intersubjective context in which he gains confidence and self-efficacy. His work-oriented narratives transport an abundance of passion which is accompanied by ambivalent experiences in his social-therapeutic treatment.

The relation with his main personal advisor is conflict-laden because Noah feels misunderstood when he has to talk about his former deviant behavior. He tries to give insights into his inner life, but the advisor always recurs to his own experiences, which Noah does not recognize as comparable and appropriate and therefore as not authentic. From his point of view, the advisor can only refer to books he has read but not to real life. In light of this conflicting experience in the spheres of work and social therapy, Noah describes work as a refuge that protects him from the awkward situations with his personal advisor. Later, he also got in touch with other advisors who better fitted his realm of biographical experiences:

One of the social workers was there as an inmate himself. And then, ehm, six years later, he came back and completed training and is a social worker now. And for me, I just want that people can take me seriously, and I know a lot of people here who say: "Why should I talk to a social worker who has no clue what's going on with me?" [...] Having gone through something like this by yourself and then somebody tells you: "I have a bad crisis", then I know exactly how to handle that. (I)

This is a key passage for the interpretation because both directions of generativity join hands. The experience of feeling understood by an authentic generative other sets in motion a transition into the active realization of the desire to become generative by oneself. This desire for being generative also extends into the sphere of work where Noah "fought" for the permission to teach younger trainees. He describes his motivation as follows: 
On average, I work seven hours a day and they are my people there and I get along well with them. I can talk about every problem with them. And I'm grateful for what I got there, especially from them. And at some point, I want to pass this on to guys like I was or like I am. I want to put them on track through work because I learned carpenting by myself. (I)

Now a legitimate question is whether this development - that to a large part comes out of an institutionalized setting - can overcome the transition into the outside world.

\section{2 "And now, for the first time, I am in the situation that I must find myself" - Unselfish Self-Care}

As we can see in the second interview at the end of 2014, Noah did not go through a transition without disruptions and crises, but he made his way. Finding work with his training qualification and motivation was not a problem; he also changed his occupation twice before finding an employer he felt satisfied with. In addition, the desire to achieve further qualifications and to become a training instructor within the measure institution does still exist, even though the passion is slightly overshadowed by the realities of wage labor.

In the spheres of parents and romantic relationships, he underwent some tasks that point to the adolescence developmental process. Simultaneously, he actively worked on detaching himself from his parents. On the one side, he rejected their offer to move back in with them after being released because from his point of view, the current spatial distance brought a new kind of emotional closeness with it. On the other side, he burdened himself with a new set of dependencies when he moved in with his girlfriend and her mother. After some months, he felt constrained and broke off the relationship. He moved into another flat with a guy his age. He supports this step with the following reasons:

She begins to talk about family and kids and I say: Sorry, I was in an extreme situation before, then brought into another extreme in the Massnahmezentrum, and from that extreme to a further extreme to her and her mother. And now, for a start, I'm just me. And now, for the first time, I am in the situation that I must find myself. What do I want, how do I want to proceed? And the pressure I always was under, the kind of: "I must be a good boyfriend", finally, everything I did was for her and not for me. For her and her mother. (II)

This passage shows that the extensive pressures of the measure and the subsequent dependencies Noah got entangled with activated his resources for increasing selfcare. The separation from his partner is his chosen exit route that bears some potential for conflict. Although the above passage sounds a bit selfish, Noah represents himself in his ongoing narration as carefully considering keeping sight of his expartner's feelings. Instead of just breaking up, he tries to preserve a kind of friendship with her. In his effort to shape a balanced transition, he shows his ability to care for 
himself and strives for autonomy while not losing touch with the feelings of others at the same time.

\section{3 "I believe a little in karma" - Changed Structures of Intergenerational Reciprocity}

In the third interview in the summer of 2016, Noah provides deeper insights into his familial constellations during childhood. His parents separated early when he was three years old, and his grandmother was his continuous caregiver:

For me as a little boy, it was clearly recognizable that my grandma, despite everything that had happened, remained impartial and was always around. When I lived at my father's place, I always saw my grandma. When I lived with my mother, I also saw my grandma. She was always around. (III)

It is quite obvious that the grandmother gave Noah an early feeling of stable security in turbulent times. Later, when Noah had gone astray, she did not reproach him as his father did, but he felt her worries and anxieties. Meanwhile, she lives in a retirement home because she could not live on her own any more. Noah now cares to her needs, provides her with the things she requires, and manages her personal finances. Although he does this with love and pleasure, the circumstances that got him into this responsibility were not of his own choosing. Shortly after his grandmother had moved to the retirement home, his father and stepmother (who had been living in a house with her) decided to emigrate to southern Europe because life in Switzerland became too expensive for them. All this had happened over the last one and a half years and changed the structures of intergenerational reciprocity in the family recognizably. One main point is Noah's detachment process from his parents that has been advanced further by their geographical distance. Another point is that their financial situation remained the same, despite having moved to another country. Noah once had to lend them money in an urgent situation, and he still sends them necessities from time to time. He now is in a situation where he is the addressee for support in the family, and he has arranged himself with that responsibility. With respect to the previously often conflict-laden dynamics of familial working on relationships, he has gained the needful orientation framework to steer this development into a proper lane. On the question how he evaluates this change of roles, he answers:

Perhaps it's a bit unconscious and is linked to kind of guilt feelings that I have a guilty conscience: I have to help them. [...] I believe a little in karma: They've done good to me, I do good to them, and so, there will be something good in return from the other side. (III)

In this sequence, Noah presents his thoughts on the origins of family solidarity and the respective resulting duties for him. In his idea of the intergenerational linkage, he builds upon the spiritual concept of karma that emphasizes the direct connection between action and reaction. Regarding his early biographical experiences, he can 
set up a coherent order of mutual responsibilities, which gains an obligatory character. Creating this closed loop serves as a source of sense-making which has the potential to further stabilize his self-concept as a caring generative other - a process accompanied and traversed by ambivalences and conflicts that must be brought into balance by the subject time and again. The former delinquent behavior sorts ill with this development, as Noah shows when talking about his motives to move out from the flat he shared with a friend:

He began screwing things up, did drugs and stuff, and so I said straight out: "Look, leave me alone with this, and most of all leave our housing situation in peace." I didn't want to lose control because of this - so rather sooner before it's too late. (III)

Noah does not want to risk the life he established over the last years. Now he has his own flat and a stable relationship with his new girlfriend whom he met about a year ago. He still likes his job and keeps searching for an acceptable extra occupational arrangement so as to achieve his goal to become a trainee teacher in a measure like the one he has been in.

\section{Conclusion: Biographical Analysis of Generative Development}

Taken together, the biographical accounts of Noah Wyss provide insights into a lengthy development of one's own generative stance. When working on this topic by just using content analysis, there would have been the risk to restrict the focus on the part where Noah talks about his desire to become an instructor himself. In combination with a longitudinal study design, the biographical analysis seems to be more adequate to get to the origins and ambivalent dynamics of this process.

In the time before Noah had been committed to the Massnahmezentrum, one can see the initial formation of the desire to become generative. Starting from the conflicts with his father and during his first partnership, the time in youth custody was marked by negative experiences with a generational other. These negative experiences served as a background through which he could dissociate himself from certain behaviors that do not fit his generative self-concept and through which he could work on further positioning himself.

It comes into view that this process is far from a linear pathway when the relationship with his girlfriend breaks up. But he refrains from letting go of his generative desire by caring for children in an internship during this intermediary phase. The point is that when he is committed to the Massnahmezentrum, he goes there with a certain amount of generative resources that also arose out of the continuous caring relationship he was provided with by his grandmother in childhood. There, he not only finds structures that allow him to build on his desire, but his proactive attitude also becomes visible, which seems to be a necessary condition. Not only do the structures 
just work on him, but he also works on the structures. As he states himself, he had "to fight" for his generative desires, which points to the potential of this process for conflicts. The "second chance" of adolescence allows for obtaining a reflexive perspective to rework and reinforce his identification as a generative person.

With the longitudinal study design, we can see that Noah's generative desires were weakened temporarily but did not disappear. Moreover, the changed familial constellation due to the emigration of his parents and his care-dependent grandmother urged him to handle the associated ambivalences and to bring about a new balance. Therefore, the overall process seems to be sustainable instead of just being the manifestation of a coping strategy for getting through the measure.

A biographical perspective can shed light on the difference between the desire of becoming generative and the challenging realization of that task. Other participants in our study also delivered narrative accounts that entail concrete desires to become generative, but they did not succeed in implementing and stabilizing this intention. Therefore, the isolated glance on a narrative account at one time may be misleading. In the ongoing analysis of our data, we will further work out those differences.

\section{References}

Abrams, L.S., Kim, K. \& Anderson-Nathe, B. (2005): Paradoxes of Treatment in Juvenile Corrections. Child \& Youth Care Forum 34/1, pp. 7-25.

Aebersold, P. (2011): Schweizerisches Jugendstrafrecht. $2^{\text {nd }}$ ed. Bern.

Baechtold, A. (2009): Strafvollzug. Straf- und Massnahmevollzug an Erwachsenen in der Schweiz. $2^{\text {nd }}$ ed. Bern.

Bereswill, M. (2011): Inside-out: Transitions from Prison to Everyday Life. A Qualitative Longitudinal Approach, in: S. Farrall, M. Hough, S. Maruna \& R. Sparks (eds.), Escape Routes: Contemporary Perspectives on Life after Punishment. New York, pp. 202-220.

Bereswill, M. (2004): Inside-out: Resocialisation from Prison as a Biographical Process. A Longitudinal Approach to the Psychodynamics of Imprisonment. Journal of Social Work Practice 18/3, pp. 315-336.

Cornel, H. (2011): Der Erziehungsgedanke im Jugendstrafrecht: Historische Entwicklungen, in: B. Dollinger \& H. Schmidt-Semisch (eds.), Handbuch Jugendkriminalität. Kriminologie und Sozialpädagogik im Dialog. $2^{\text {nd }}$ ed. Wiesbaden, pp. $455-473$.

Cox, A. (2011): Doing the Programme or Doing Me? The Pains of Youth Imprisonment. Punishment \& Society 13/5, pp. 592-610.

Erdheim, M. (1982): Die gesellschaftliche Produktion von Unbewußtheit. Eine Einführung in den ethnopsychoanalytischen Prozeß. Frankfurt am Main. 
Erikson, E.H. (1982): The Life Cycle Completed - A Review. New York.

Halsey, M. \& Deegan, S. (2015): Young Offenders. Crime, Prison and Struggles for Desistance. Basingstoke.

Halsey, M. \& Harris, V. (2011): Prisoner Futures: Sensing the Signs of Generativity. Australian \& New Zealand Journal of Criminology 44/1, pp. 74-93.

Healy, D. \& O'Donnell, I. (2008): Calling Time on Crime: Motivation, Generativity and Agency in Irish Probationers. Probation Journal 55/1, pp. 25-38.

King, V. (2013): Die Entstehung des Neuen in der Adoleszenz - Individuation, Generativität und Geschlecht in modernisierten Gesellschaften. $2^{\text {nd }}$ ed. Wiesbaden.

King, V. (2012): Pädagogische Generativität: Nähe, Distanz und Ambivalenz in professionellen Generationenbeziehungen, in: M. Dörr \& B. Müller (eds.), Nähe und Distanz - Ein Spannungsfeld pädagogischer Professionalität. $3^{\text {rd }}$ ed. Weinheim, pp. $62-75$.

Maruna, S. (2001): Making Good: How Ex-Convicts Reform and Rebuild Their Lives. Washington.

McNeill, F. \& Maruna, S. (2008): Giving Up and Giving Back: Desistance, Generativity and Social Work with Offenders, in: G. McIvor \& P. Raynor (eds.), Developments in Social Work with Offenders. London, pp. 224-239.

Müller, D. \& Rossi, D. (2009): Rückfall nach Massnahmevollzug. Eine Studie zur Rückfälligkeit von jungen Erwachsenen aus den Massnahmezentren Arxhof und Uitikon; www.ub.unibas.ch/digi/a125/sachdok/2015/BAU_1_6471360.pdf [31/ 01/2017].

Reich, A. (2010): Hidden Truth: Young Men Navigating Lives in and out of Juvenile Prison. Berkeley.

Rieker, P., Humm, J. \& Zahradnik, F. (2016): Einleitung: Desistance als konzeptioneller Rahmen für die Untersuchung von Reintegrationsprozessen. Soziale Probleme 27/2, pp. 147-154.

Rosenthal, G. (2008): Interpretative Sozialforschung - Eine Einführung. Weinheim.

Strauss, A.L. \& Corbin, J. (1990): Basics of Qualitative Research: Grounded Theory Procedures and Techniques. Thousand Oaks.

Studer, M. (2013): Jugendliche Intensivtäter in der Schweiz. Zürich.

Walker, L. (2010): "My Son Gave Birth to Me": Offending Fathers - Generative, Reflexive and Risky? British Journal of Social Work 40, pp. 1402-1418.

Walther, A. \& Stauber, B. (2013): Übergänge im Lebenslauf, in: W. Schröer, B. Stauber, A. Walther, L. Böhnisch \& K. Lenz (eds.), Handbuch Übergänge. Weinheim, pp. 23-43. 
Wigger, A. (2013): Der Aufbau eines Arbeitsbündnisses in Zwangskontexten - professionstheoretische Überlegungen im Licht verschiedener Fallstudien, in: R. Becker-Lenz, S. Busse, G. Ehlert \& S. Müller-Hermann (eds.), Professionalität in der Sozialen Arbeit. Standpunkte, Kontroversen, Perspektiven. $3^{\text {rd }}$ ed. Wiesbaden, pp. 149-165.

Witzel, A. (2000): Das problemzentrierte Interview. Forum Qualitative Sozialforschung $1 / 1$.

Zahradnik, F. \& Humm, J. (2016): Zwischen Aufarbeitung und Befähigung - Integrationskonflikte von Straftätern während und nach einer Vollzugsmaßnahme für junge Erwachsene in der Schweiz. Soziale Probleme 27/2, pp. 179-202. 


\title{
The Influence of Possible Turning Points on Desistance from Crime of Young Multiple Offenders: Results of a Qualitative Analysis
}

\author{
Maria Walsh
}

\section{Desistance from crime}

Various approaches have been taken in desistance research. They are grouped into three different models by LeBel, Burnett, Maruna and Bushway (2008). The authors divided the desistance theories between the strong subjective model, the strong social model and the subjective social model. Under the strong subjective model, they summarise theories that place the drive for desistance solely within the individual. Here the individual's will and motivation are the crucial factors for changes in various areas of life. It is assumed that with the right mind-set, changes can be made. The strong social model, however, covers the theoretical concepts that consider the desistance process to be socially triggered. In this model, there are extrinsic factors that cause the desistance process. In contrast, the subjective social model considers a combination of social and subjective factors as crucial for desistance. Here both intrinsic and extrinsic factors have an influence on the behaviour, independent of one another, and may also cause changes through interaction effects (LeBel et al. 2008).

\section{The Age-Graded Social Control Theory by Sampson and Laub}

Sampson and Laub assume that in individual phases of life, criminality results from the lack of integration in social structures. These vary throughout life. While as children and adolescents, integration within the family and at school has an effect in terms of reducing criminality, as adults, the integration within a relationship and through employment is essential. Accordingly, with the creation of new ties or the breaking of previous ones, turning points can occur in later phases of life (Sampson \&Laub 1993).

The term turning point, according to Sampson and Laub, refers to an event that initiates the process of ending a criminal career. Such turning points result, for example, from commencing or changing employment, entering into a relationship, the completion of military service or relocation (Sampson \& Laub 1993; Kirk 2009; 2012; Sampson et al. 2006). Here it is not only the ties as such but the associated informal social controls, alterations to the daily routine and changes in self-perception that are of importance (Sampson \& Laub 1993; 2003; Laub \& Sampson 2003). 
This investigation is concerned with the question of whether - in the narratives of young multiple offenders - possible turning points can be identified that may have initiated the process of desistance. Thus, it deals with the strong social model of desistance from crime. The interviewees were juvenile (jugendliche) and adolescent (heranwachsende) multiple offenders who took part in a pilot project on intensive probation and parole supervision. The participants considered here were questioned for a qualitative longitudinal data survey on three occasions (at the beginning of their participation in the project, at the end, and about half a year after the project).

\section{The influence of possible turning points on desistance from crime}

\subsection{Case studies}

In this section, the stages of the desistance process will be illustrated by using two case studies. For these purposes, two participants ${ }^{1}$ were chosen according to the sampling strategy of maximum comparison (Kruse 2014; Seipel \& Rieker 2003; Akrem 2014; Hering \& Schmidt 2014). These two subjects are similar in terms of their age and the offences they committed. In addition, both were in a stable relationship during the majority of the study period and became fathers. Despite these similarities, one of them was able to end his criminal career, while the other one was handed a juvenile prison sentence.

\subsubsection{Step progression in a positive direction}

Thomas was born in Germany in 1991 and was raised by his parents with one sibling. His time at kindergarten and primary school was uneventful. His behavioural problems began at secondary school. ${ }^{2}$ Thomas had to repeat the fifth grade due to poor performance and was ultimately expelled from the school due to his behaviour. At the age of 12 , he was housed at a remedial education facility for one year and subsequently attended a school with a focus on emotional and social development. In 2007, Thomas left this school without graduating, not having been granted an extension for compulsory school attendance. In the same year, he was first officially recorded with criminal behaviour, which, in April 2010, led to a suspended sentence and placement at a juvenile psychiatric rehabilitation facility. In September 2010, Thomas was put on probation again due to other charges, but it was revoked a short time after. Following this, he found himself in youth prison until April 2011. After the suspension of the remainder of his sentence, charges were again pressed against Thomas, which, in October 2011, led to a youth sentence of three years and six months. In August

\footnotetext{
1 Names have been changed.

2 German Hauptschule. Secondary school in Germany is divided into three different levels. Hauptschule is the most basic level of education.
} 
2012, the remainder of this sentence was again suspended, and he took part in the pilot project until the beginning of 2013. By the time he commenced participation, Thomas had been officially recorded with 17 offences, including assault, coercion, narcotics, theft and criminal damage. He identified the second prison term as an individual key experience ${ }^{3}$ and as triggering his process of change. Through this imprisonment, Thomas was inspired to rethink, and hence, a cognitive change was instigated. The following interview quote from the non-recidivist Thomas illustrates the positive steps in his process of desisting from crime:

Thomas: Yes, at some point, the penny does have to drop, one can't go on like that. [...] I see a lot of them coming out of jail and still hanging out, smoking dope, causing trouble, (..) but I want to do my training. [...]

I: And when did the penny drop for you?

Thomas: [...] To be completely honest, only the second time [that I was in jail (author's note)]. And only 100 per cent when I met her [my girlfriend (author's note)], and then everything got into gear, yeah. Only then.

I: What changed then?

Thomas: Yeah well, everything. I had another way of thinking. Now and then, I was still mildly recidivist. Well, what do I mean by that? I had thoughts 'bout that, "bout that. Yeah, and then, when I heard that I'd gotten her pregnant, when we found out, I don't want to be a loser, I don't want my son to have to visit me in jail and my gi-, girlfriend. Because she definitely won't stay with me if I end up in jail again. And I really don't want this rubbish that then tears apart my family and messes up my whole life, so to speak. I don't want that. I want to be there, I want to take care of them, have a nice life and family. [...] and not go down the other path anymore, the other rubbish.

Here it becomes clear that Thomas started his rethinking process in jail. In the interviews, he mentioned it began with seeing the example of his fellow prisoners, which acted as a deterrent, along with his wish not to have to waste any more time incarcerated. When he was free, there were more situations when he toyed with the idea of offending again. However, the relationship with his girlfriend held him back from this and continued to encourage his positive development. Taking on the role of father ultimately led to a definitive stabilisation of the decision made in jail to live his life conforming to social norms. The change in self-image associated with the new role as family provider, from loser to provider, is also clear here. Due to his plans to

3 Not every life event that could serve as a turning point necessarily initiates a process of desistance. In fact, there are a number of events in the course of a person's life that could lead to a change in direction but do not actually change the course of development. In contrast tot he study by Sampson and Laub, this study pursues a prospective approach. However, identifying a turning point naturally requires a retrospective study. Due to this, the term "key experience" will be used subsequently for the possible turning points subjectively identified by the participants. 
care for his family, Thomas began to work and to look for a place in vocational training. Furthermore, from the narrative, it emerged that Thomas did not want to risk his new life with a new period of imprisonment. He did not want to risk his family, something that was of very high importance to him.

Thus, it was clear that imprisonment incited Thomas to change, but this still had to be strengthened by numerous other life events and changes once he had regained his freedom. In particular, the transition from incarceration to freedom is for many, especially young prisoners, difficult and involves diverse - and institutional - problems (Bereswill et al. 2007; Bereswill 2010; Hosser et al. 2007; Walsh 2014). In Thomas' example, the relationship with his girlfriend had a very consolidating influence which held him back from relapsing to his previous behavioural patterns. In addition, the relationship and taking on the father role made a fundamental contribution to his newly formed self-image.

It can be confirmed that from Thomas' point of view, his desistance process began during his second period in jail. An essential contribution to this success was made by his girlfriend. However, at this point, it can also be speculated that only the cognitive process of change Thomas began while in jail enabled him to enter into a serious and lasting relationship with his girlfriend. If this is the case, it means that the rethinking process that began in jail served as a preceding mechanism that first enabled changes in other areas of life (LeBel et al. 2008).

\subsubsection{Step progression in a negative direction}

Gabriel was born in 1991 and came to Germany with his mother when he was six. His time at primary school was uneventful. Due to repeatedly moving within Germany, he changed secondary school three times in the first three years. From seventh grade, there was a major drop in Gabriel's performance at school and behavioural problems arose which, in the eighth grade, led to his expulsion. After moving again, he started the ninth grade at yet another school but did not sit his final exams due to lengthy absences that school year and left the school in 2008 without graduating. Gabriel was first recorded with a criminal offence in 2006, which was met with light sanctions. In 2008, he was given a suspended sentence and was ordered to stay at a juvenile psychiatric rehabilitation facility where he could complete vocational training in an artisan craft. Gabriel served two months of detention at the beginning of 2012 and, in October 2012, was sentenced to two years in a juvenile prison, which was suspended with three years on probation. From the beginning of his probation period to June 2013, he took part in the pilot project. By the time he began participation, Gabriel had been recorded with 28 offences in the areas of assault, coercion, fraud, narcotics, theft, criminal damage and offences against public order. 
At the time of the interview, Gabriel was living in a two-man room of a boarding house ${ }^{4}$ and was unemployed. As he stated, through the negative influence of his housemate, he recommenced using light drugs. In addition, he found himself in financial difficulties which he attempted to mitigate through criminal behaviour. During much of the study period, Gabriel was in a steady relationship with an unemployed and unqualified young woman who - according to his information - was dependent on him for financial security and subsistence. Gabriel had a child from a previous relationship who he regularly saw and took care of, although the relationship with his former partner was difficult and problematic.

Gabriel identified his new job as a key experience of his subsequent positive development. With the help of his parole officer, he succeeded in finding another job and thus in improving his negative living arrangement and financial situation.

Gabriel: At that point, I had lost my job and was still living in the boarding house. Since then, I've got my own apartment and yeah. I was unemployed for three, four months and wasn't doing anything, I was at home all day. Actually, things were going really downhill the entire time. Then I got given a phone number from [my parole officer] from a temp agency where I am now, and since then, it's been continually getting better.

Thus, at the time of the second interview, Gabriel was living in his own apartment with his girlfriend, along with another friend and his partner. This friend was very important to Gabriel - he described him in the first two interviews as a great support: "I'm glad that I've got him." At reference time 2, Gabriel drew a very positive picture of where he was at and was very pleased with his professional and private situation. Even the relationship with his former partner had relaxed, meaning that it was easier for him to maintain contact with his child. Because the relationship to his child was very important to Gabriel, he had been burdened by the previously tense situation. Now he was only troubled by his girlfriend's unemployment and her expectations regarding financial support. However, by the time of the third interview, the situation had worsened massively and Gabriel was again greatly destabilised. By then, he had been sentenced to a term of youth imprisonment again, due to a theft offence which, according to his version of events, had been committed by his girlfriend. He had just been there at the same time. Due to this, his imprisonment was imminent and he had given up his job. In addition, at the time of the interview, he was no longer in a relationship with his girlfriend, who was expecting a child. $G a-$ briel stated that his negative development was instigated by falling out with his best friend and housemate, which affected him very deeply.

Gabriel: He also said a lot of things that I wouldn't have expected from him. Even racist remarks and so on. Yeah, it's full on when you think I've been kind of getting along with him here for five years and saw him as my best friend, and then he was

This refers to state-funded accommodation for the homeless. 
drunk there and then somehow said those things, like he doesn't like me at all or doesn't like those sorts of people at all.

In this quote, Gabriel describes a dispute he and his friend had and in the course of which there was also a physical confrontation between the two. However, the break between them actually took place at an earlier time. In addition to his upcoming detention, the ruined relationship with his friend troubled him the most, especially since they were still living together. However, due to his financial situation and lacking family support, no alternative was open to him. Gabriel's case highlights that the start of positive development is not sufficient to lead to lasting desistance. Initially in the study period, Gabriel succeeded in dramatically improving his situation with the support of the parole officer and in taking some steps towards living in a way that conformed with social standards. However, his situation then deteriorated rapidly. A destabilising event - namely, the rift with his main figure of attachment was sufficient to set in motion another series of negative steps. At the end of this, Gabriel's situation was even worse than at the beginning of the study.

\subsubsection{Comparison of the case examples}

Now the cases of Gabriel and Thomas will be compared in order to identify differences that might have influenced the process of desistance. The first thing to consider here is the difference in the relationships with the partners. Thomas' girlfriend had completed vocational training and hence had a higher level of education than he did. Furthermore, she held down a regular job, and had been doing so since the two met, thus for the entire length of their relationship. In addition, she viewed his entire previous way of life and his former acquaintances very critically. She encouraged him to continue and to strengthen the reflection towards his previous behaviour and social dealings that he had begun in jail. In so doing, she made a significant contribution to his process of "knifing off" and promoted his inner change. Furthermore, from Thomas' narrative, it could be seen that his girlfriend made clear to him that the continuation of the relationship was requisite upon a move away from his previous life. She not only promoted the changes to his behaviours but also demanded them.

In contrast, Gabriel's girlfriend had a lower education, as she had not completed any formal training. Throughout the course of the relationship, his girlfriend was not involved in any work or training and made barely any efforts in that regard, as noted by Gabriel. Rather, through her delinquent behaviour, she increased the probability of him reoffending (Laub et al. 1998; Sampson et al. 2006).

Furthermore, Thomas repeatedly referred to his cognitive change in the narrative. His attitude began to change in prison, and this rethinking process continued throughout the entire study period, initiating, accompanying and reinforcing the positive progress he made. Along with his relationship with his girlfriend, this change enabled him to break off contact with his former peers. Doing so had been a crucial step in his positive growth. Thomas made the decision to break contact with these 
friends when it became clear to him that it always ended with trouble. In the course of this inner change, Thomas' self-image also changed, which in his opinion had begun during his second period in jail. The change in self-image - in this case instigated by the comparison to fellow prisoners and the possibility of turning into his "feared self" (Paternoster \& Bushway 2009) - appeared to be complete at the time of the third interview:

Thomas: Some people have criminal blood, if you know what I mean. They think in a criminal way, no matter what they're doing. For me, this is just gone. I wasn't any better back then, but now that part of me is just completely gone.

His previous self-image had been replaced by the new one of a father and family provider. His new self-image provided an impulse for positive development in his performance. His vision at the time of the last interview required him to successfully complete his vocational training and to gain a stable job in order to care for his family. Unlike Thomas, in Gabriel's narrative, there is no indication of any rethinking process or cognitive changes. In addition, there were no signs of Gabriel's self-image changing. There were also major differences in Thomas' and Gabriel's narratives regarding their own roles as fathers. While Thomas also emphasised his child's financial security and happy childhood, Gabriel spoke continually about joint activities with his child. Thomas' thoughts were future-oriented, while Gabriel rather thought about the present. This could be an indication of the maturation process that Thomas had put into effect and the associated greater sense of responsibility. $G a-$ briel, on the other hand, did not seem to have undergone any maturity development in this way. The example of Thomas highlights the numerous mechanisms that seem to accompany the desistance process and could be connected to a turning point. In Gabriel's development, these mechanisms were seemingly not triggered, although his probation period initially took a positive course and he was able to gain a foothold with his new job. However, because this positive development was not accompanied by inner change or did not put this change in motion, Gabriel did not succeed in continuing on this path. For him, destabilising factors once again instigated negative developments.

\section{Relevance of possible turning points for the initiation of the termination process}

It has been shown that a subjectively perceived key experience does not guarantee success in the desistance process. Such a key experience may serve as an instigator to begin the process, but many other factors come into play and are important if the process is to continue. In particular, the occurrence of inner change seems crucial for the success of the process. Here, the key experiences and the internal change - that can enable an individual to distance himself from his previous way of life - seem to 
be mutually dependent. These results speak for the "subjective-social model" of desistance and against the "strong-social" and "strong-subjective" models (LeBel et al. 2008, pp. 137-140). As Boers and Herlth put it: desistance from crime requires both internal and external changes. However, the question of which comes first is not decisive and might vary from one individual to another (Boers \& Herlth 2016).

Especially considering the background of judicial influences on offenders, the question of whether inner transformation or a rethinking process can be initiated by outside interventions is particularly relevant. As Healy's results indicate, the results of the interview analyses indicate that this possibility exists (Healy 2010). Accordingly, these results point in the direction of the thesis of MacLeod, Grove and Farrington (2012) that the interaction with the justice system is of great importance in the desistance process.

\section{References}

Bereswill, M. (2010): Strafhaft als biographischer Einschnitt. Befunde zum Jugendstrafvollzug aus der Perspektive der Insassen, in: B. Dollinger (ed.), Handbuch Jugendkriminalität. Wiesbaden, pp. 545-557.

Bereswill, M., Koesling, A. \& Neuber, A. (2007): Brüchige Erfolge - Biographische Diskontinuität, Inhaftierung und Integration, in: J. Goerdeler \& P. Walkenhorst (eds.), Jugendstrafvollzug in Deutschland. Neue Gesetze, neue Strukturen, neue Praxis? Mönchengladbach, pp. 294-313.

Boers, K. \& Herlth, A.M. (2016): Delinquenzabbruch. Hauptaspekte des gegenwärtigen Forschungsstands. Monatsschrift für Kriminologie und Strafrechtsreform 99/2, pp. 101-122.

Healy, D. (2010): The Dynamics of Desistance. Charting Pathways Through Change. Cullompton.

Hering, L. \& Schmidt, R.J. (2014): Einzelfallanalyse, in: N. Baur (ed.), Handbuch Methoden der empirischen Sozialforschung. Wiesbaden, pp. 529-542.

Hosser, D., Lauterbach, O. \& Höynck, T. (2007): Und was kommt danach? Entlassungsvorbereitung und Nachentlassungssituation junger Strafentlassener, in: J. Goerdeler \& P. Walkenhorst (eds.), Schriftenreihe der Deutschen Vereinigung für Jugendgerichte und Jugendgerichtshilfen e.V., Bd. 40: Jugendstrafvollzug in Deutschland. Neue Gesetze, neue Strukturen, neue Praxis? Mönchengladbach, pp. 396-413.

Kirk, D.S. (2012): Residential Chance as a Turning Point in the Life Course of Crime: Desistance or Temporary Cessation? Criminology 50/2, pp. 329-358.

Kirk, D.S. (2009): A Natural Experiment on Residential Change and Recidivism: Lessons from Hurricane Katrina. American Sociological Review 74/3, pp. 484 505 . 
Kruse, J. (2014): Qualitative Interviewforschung. Ein integrativer Ansatz. Weinheim.

Laub, J.H., Nagin, D.S. \& Sampson, R.J. (1998): Trajectories of Chance in Criminal Offending: Good Marriages and the Desistance Process. American Sociological Review 63/2, pp. 225-238.

Laub, J.H. \& Sampson, R.J. (2003): Shared Beginnings, Divergent Lives. Delinquent Boys to Age 70. Cambridge, Mass.

LeBel, T.P., Burnett, R., Maruna, S. \& Bushway, S.D. (2008): The 'Chicken and Egg' of Subjective and Social Factors in Desistance from Crime. European Journal of Criminology 5/2, pp. 131-159.

MacLeod, J.F., Grove, P.G. \& Farrington, D.P. (2012): Explaining Criminal Careers. Implications for Justice Policy. Oxford.

Paternoster, R. \& Bushway, S. (2009): Desistance and the "Feared Self": Toward an Identity Theory of Criminal Desistance. The Journal of Criminal Law \& Criminology 99/04, pp. 1103-1156.

Sampson, R.J. \& Laub, J.H. (2003): Life-Course Desisters? Trajectories of Crime among Delinquent Boys Followed to Age 70. Criminology 41/3, pp. 555-592.

Sampson, R.J. \& Laub, J.H. (1993): Crime in the Making. Pathways and Turning Points Through Life. Cambridge, Mass.

Sampson, R.J., Laub, J.H. \& Wimer, C. (2006): Does Marriage Reduce Crime? A Counterfactual Approach to Within-Individual Causal Effects. Criminology 44/3, pp. 465-508.

Seipel, C. \& Rieker, P. (2003): Integrative Sozialforschung. Konzepte und Methoden der qualitativen und quantitativen empirischen Forschung. Weinheim.

Walsh, M. (2014): Der Umgang mit jungen Intensivtätern im Deutschen Justizsystem. Recht der Jugend und des Bildungswesens 62/3, pp. 347-362. 



\title{
Institutional Responses to Youth Deviance and Parenting: Exploring Professional Perceptions on the Role of Social Class at the Beginnings of Offending Pathways and Desistance from Crime
}

\author{
Jasmina Arnez
}

\section{Introduction}

Since criminology is a multi-disciplinary field that explores crime from theoretically different viewpoints, criminologists rarely agree upon how, why, and when people become criminals or desist from crime. However, the relationship between age and antisocial behaviour has been one of the most robust observations since 1831, when Quetelet first presented his "age-crime curve" (McAra \& McVie 2012a, p. 540; see also Morgan \& Newburn 2012, pp. 512-513). Although it is still generally accepted that most adolescents "grow out of crime" in their late teens or early twenties (Rutherford 1992), the relationship between aging and desistance remains one of the most poorly understood criminological findings.

Moffitt, for example, has argued that the understanding of the relationship between age and deviant behaviour is inadequate because the onset of offending is defined according to first police arrest - or court appearance - statistics, while data on troubling behaviour is sparse in children that have not yet reached the age of criminal liability (Moffitt 1993, p. 675). According to Moffitt, law enforcement officials record only the tip of the "deviance iceberg", while there could be distinct types of juvenile offenders with different pathways to desistance, depending on their childhood conduct - and its social and neuropsychological triggers (Moffitt 1993, pp. 679693 ) - prior to entering the youth justice system (Moffitt 1993, p. 675).

Drawing on Moffitt, Maruna has also exposed that the relationship between getting older and desisting from crime is insufficiently understood (Maruna 2001, p. 10). He has argued that criminological research has mainly been exploring biological maturation and particular life events as reasons for desistance, but has neglected an individual's self-narration of their decision to "make good", which amounts to more than half of their change (Maruna 2001, p. 10). Despite acknowledging that most offenders are of disadvantaged backgrounds (Maruna 2001, pp. 59-61), Maruna has concluded that an individual's choice to turn their life around is largely subjective and their narrative identity is fluid, as it can change throughout their life-course (Maruna 2001, pp. 59-61).

Although criminologists nowadays understand desistance not only as a maturational process but also as one that depends on both structural conditions and individual 
agency, there is still a dearth of research about the ways in which socio-economic circumstances interact with - and affect - the agentic aspect of desistance, especially in adolescents. There is also a lack of research into whether institutions that work with behaviourally challenging young people and their parents make different decisions about families of diverse backgrounds and what kind of consequences that has for the beginnings of children's offending pathways as well as their willingness and ability to change.

In this paper, I explore the views of practitioners who work with troubling youths and their parents across a range of agencies on the intersections between deviance, parenting and social class. I consider how their perceptions and decisions might interplay with the identities - and the desistance processes - of the young people they work with. I begin by introducing criminological theories that have become central to UK's youth justice practice and demonstrate why they might be insufficient. I then outline the concept of social class in my study before presenting the study's research design and outcomes. I conclude by suggesting alternative ways of understanding the connections between children's challenging behaviour, parenting and social class and explain how they could affect young people's desistance pathways.

\section{Intersections between youth deviance and parenting: theory, practice and the UK context}

In criminology, there has long been an interest in the impact of family life and parenting on the development of children's troubling behaviour (for example, see Wilson \& Herrnstein 1985, pp. 213-265). Although some authors have argued that delinquency can occur in both broken homes and intact families (for example, see Hirschi 1995, p. 136), Condry has stressed that most contemporary discourses on crime and the family still focus predominantly on the individual offenders and their parents while underestimating the structural factors influencing their everyday lives (for example, see Condry 2007, p. 4).

According to the General Theory of Crime (GTC) by Gottfredson and Hirschi, the development of children's self-control is crucial for minimising their propensity for delinquency (Gottfredson \& Hirschi 1990, p. 97). Furthermore, their inability to delay gratification - and a consequently increased probability that they will become an offender - is, to a great extent, triggered by parental failure to monitor the child, to notice their inappropriate behaviour, and to prevent it (Gotffredson \& Hirschi 1990, p. 97).

Alongside family breakdown and parents' criminal history, poor parenting in early childhood is a strong predictor of youth offending for developmental criminologists (for example, see Farrington 2002, p. 147). Nevertheless, Farrington has acknowledged that the ways in which childrearing affects delinquency remain unclear (Farrington 2002, p. 148). In addition, he has argued that parenting and crime should not 
be studied in a vacuum, so the family's social circumstances - as well as their possible impact on parenting styles and children's misbehaviour - should always be taken into account (Farrington 2002, p. 144).

Some macro theories have addressed structural factors of offending by exploring the relationship between crime and economic conditions in light of class struggles. Back in 1916, Bonger used a neo-Marxist approach to argue that the means of production are concentrated in the hands of the elites due to the capitalist division of labour, which makes the disadvantaged more inclined to criminality (Bonger 2003, p. 60). In addition, Merton drew upon Durkheim by using his anomie theory to explain criminal behaviour. Based on his observation of American culture, he concluded that monetary success is a universal goal, but society fails to acknowledge that the legitimate means to achieve this aim are unequally allocated, which makes the deprived more likely to adapt through crime (Merton 1938, pp. 678-682).

However, despite the socially more conscious developmental theories as well as the challenges of macro- and other critical criminological perspectives, the uneven distribution of capital and poverty have continuously been downplayed, ${ }^{1}$ and insufficient parenting has been decontextualized ${ }^{2}$ in the UK's political and professional discourse on crime and the family. As a consequence, bad parenting is often still perceived as an independent causal risk factor of youth deviance and is symbolically linked to disadvantaged households (Goldson \& Jamieson 2002, p. 85), and their material reality tends to be sidelined. Furthermore, simplified versions of developmental and life-course criminology seem to have anchored themselves in Britain's youth justice practice.

According to McAra and McVie, critical criminology was unable to hamper the appeal developmental accounts of crime had for politicians and practitioners in the UK (McAra \& McVie 2012a, p. 540). Both had good reasons to accept that delinquency was rooted in faulty upbringing and risks in early childhood, so it could be easily predicted and prevented (McAra \& McVie 2012a, p. 540). With calls for youth justice to respond, politicians were seen to be "doing something" about crime in a seemingly neutral way by hiding behind the "risk-factor prevention paradigm" (McAra \& McVie 2012a, p. 540). Practitioners, on the other hand, made sense of the new role they had in addressing troubling youth behaviour through early intervention into the lives of children "at risk" of offending and their families (McAra \& McVie 2007, p. 316).

However, Gillies has exposed that risk-factor analysis retrospectively reveals the association between child delinquency and parenting, but does not explain the causal link between them (Gillies 2000, p. 216). Secondly, it takes socioeconomic factors into account when controlling for their effects statistically (Gillies 2000, p. 217), but

$1 \quad$ As argued, for instance, by Gillies 2005.

2 As argued, for instance, by Burney \& Gelsthorpe 2008 and Hollingsworth 2007. 
does not consider the lived experiences of being disadvantaged or how they impact upbringing. Furthermore, Skardhamar has argued that early intervention could help young people with their immediate concerns, but it is harder to advocate for an intervention that aims to prevent troubled children from becoming chronic offenders and perceives them as such before they have actually offended (Skardhamar 2009, p. 875).

Lastly and most importantly, a simplified developmental attempt to understand youth crime focuses on individual and familial risk factors but disregards the possible "selection effects" (McAra \& McVie 2007, p. 317) of institutions that deal with behaviourally challenging young people before and after they have offended. It thus seems reasonable to follow McAra and McVie's recommendation that criminologists should use alternative theoretical and methodological approaches to explore the functioning of agencies that help troubling youths and their parents, which has been a key aim of my study (McAra \& McVie 2012a, p. 532).

This suggestion seems especially topical in the UK context since the Edinburgh Study of youth transitions to crime has shown that even in the Scottish welfare-oriented juvenile justice system, young people's offending pathways begin before their contact with law-enforcement officials, namely with labelling practices in schools and other agencies (McAra \& McVie 2012b, p. 374). ${ }^{3}$ Moreover, an ongoing "filtering process" (McAra \& McVie 2007, p. 337) continuously propels the same young people into the youth justice system, whereby this does not necessarily depend on the seriousness of their offences but, rather, on prior agency contact per se and conditions that they cannot control, including their family reputation and social disadvantage (McAra \& McVie 2007, p. 338). ${ }^{4}$

Furthermore, Nugent and Schinkel have concluded that relational desistance and the recognition of change in behaviour by other people is hugely important for growing out of crime (Nugent \& Schinkel 2016). However, similarly to Healy, they have stressed that desistance and its acknowledgment by others to a great extent relies on the desister's social capital (Nugent \& Schinkel 2016; see also Healy 2013). It therefore seems reasonable to explore whether the interactions of practitioners with behaviourally challenging young people and their parents from different family environments could play out adversely and how they could impact the onset of young people's delinquent pathways on one side - and their desistance patterns on the other. Nevertheless, in order to attend to these issues, I first provide the understanding of social class I use in my study and consider the different forms of capital in its definition.

3 For an insight into similar experiences of young people with the range of interventions in the youth justice system of Northern Ireland, see McAlister \& Carr 2014.

4 For similar findings in the justice system of Ireland, see also Corr 2014, p. 264. 


\section{Researching the role of social class in institutional responses to youth deviance and parenting}

\subsection{Conceptualising social class}

The above analysis has shown that a "familial-risk-factor" account of youth deviance can be too focused on the individual offender and their parents while de-emphasising the social factors that influence their lives (McAra \& McVie 2012a, p. 555). Likewise, Savage et al. have argued that social class should not be determined only according to resources and employment, so its definition does not sidestep the social and cultural meaning of class for an individual's identity or disregard the ways in which class shapes subjectivities on a symbolic level (Savage et al. 2013, p. 222). I therefore draw on Bourdieu's "multi-dimensional" theory (Bourdieu 2010, pp. 100 103), which understands class as a function of the amount, structure and mobility of economic, social (networks and connections with others) and cultural (benefits of academic and cultural engagement) capital as well as the intersections between them (Bourdieu 2010, p. 261; see also Savage et al. 2013, p. 222).

According to Bourdieu, different sorts of capital do not operate independently, but rely on - and should thus be thought together with - underlying practices. Over time, similar combinations tend to be constant in certain areas of social life, so they constitute patterns (Bourdieu 2010, p. 261). As a consequence, social class plays out in interactions between groups of people with different amounts and forms of capital and manifests itself in symbolic struggles between them. In social reality, only some blends of capital and its accompanying values are perceived as normative (Bourdieu 2010, pp. 241-246) and are sustained through the "inertia [...] of institutions" (especially schools), which reinforces familiarity with the dominant culture (Bourdieu 2010, p. 315).

Bourdieu therefore suggested that the social sciences investigate the origins of "class-making" and the processes that generate social hierarchies (Bourdieu 2010, p. 470). Furthermore, he emphasised that categorising people into classes does not depend on anything inherent in their identities, but, rather, derives from stigmatising processes of seemingly impartial agencies that might be making biased decisions based on the discrepancies between their institutional ethos and a family's cultural capital (Bourdieu 2010, p. 379). Since McAra and McVie have recommended that criminologists explore the working practices of institutions and the ways in which they could be contributing to young people's criminal involvement (McAra \& McVie 2012a, p. 532), Bourdieu's examination of class-reproduction through (amongst other processes) agency contact could be not only sociologically but also criminologically relevant.

Furthermore, desistance scholars have recently proposed that Bourdieu's view on class - and its emphasis on the importance of capital for an individual's agency - is crucial for understanding the ways in which young people grow out of crime (Barry 
2013, p. 49). It therefore seems plausible to adopt the above-described theoretical framework to examine how practitioners who work with troubling young people and their parents perceive institutional responses to delinquency and childrearing according to social class. However, before I outline the findings of my study, I briefly present the research design and explain why it was appropriate for exploring this topic.

\subsection{Research design}

When examining whether institutions and their staff might be treating young people and their parents differently depending on their background, studying both the largescale socio-political and the face-to-face interactional processes of class-reproduction seems important. Nevertheless, since, according to Bourdieu, elites "produce discourse about the social world" (Bourdieu 2010, pp. 398-400) - so that class-division is preserved in any political system -, it is reasonable to move away from societal determinants and to focus on the micro-level. In order to explore the ways in which class distinction within youth justice might be maintained on the ground, I conducted semi-structured interviews with 15 practitioners in a Home Counties local authority. I talked to youth workers, counsellors in education, early intervention specialists, drug - and alcohol - misuse workers, parenting counsellors, Youth Offending Team (YOT) officers, child psychiatrists and clinical psychologists. The reasons why I consulted practitioners in several institutions were threefold.

Firstly, I followed Paternoster and Iovanni's suggestion that within youth justice, class-conditioned labelling effects should be examined across a range of agencies, as choices made about young people at earlier stages might influence the decisions and outcomes later on (Paternoster \& Iovanni 1989, p. 374). Secondly, the UK's YOTs use a multi-agency approach to youth delinquency and coordinate the work of various organisations to help young offenders desist from crime (Muncie 2015, pp. 292-294). It therefore seems sensible to examine the responses of staff in as many of them as possible. Thirdly, interviewing people across different milieus prevents "individual worker or service bias" (Morris 2013, p. 200) and enables the comparison of professional discourses across diverse settings.

Since my study draws on the accounts of a small number of professionals, its findings are not necessarily representative of institutional responses across the UK. However, their generalizability might not be as limited as it appears. I stopped interviewing additional participants in line with the "principle of saturation" (Bachman \& Schutt 2011, p. 275) when the same topics kept emerging and I thought I had a " good enough' understanding" (Noaks \& Wincup 2004, p. 70) of my research question. Although local and structural factors can interplay adversely within particular institutions, interviews with practitioners in their professional capacities across a range of agencies can provide data on institutions as organisational forms per se, regardless of where they are located (Smith 2005, p. 42-43). 


\section{Results}

\subsection{Professional perceptions on the intersections between social class, parenting and youth deviance}

According to Simons, Simons and Hancock, professionals who work with troubling young people mainly draw on social learning perspectives, the GTC and developmental criminology when trying to explain how parents affect their children's conduct (Simons, Simons \& Hancock 2011, pp. 175-194). Similarly the practitioners in my study used developmental psychology and theories on the intergenerational transmission of crime (Besemer 2014, p. 79) so as to interpret the connections between childrearing and youth delinquency. However, they neither followed Farrington's recommendation to avoid focusing only on individual and familial risk factors, nor did they adequately acknowledge the social context of both parenting and offending (Farrington 2002, p. 144-148):

I think social class does make a huge difference. I think it would be crazy to pretend that it didn't. Sometimes, when I see what people are struggling with, I think "God, would I manage to live in that sort of environment or to move house really often or to just never have enough money?" So I think that being comfortable makes everything much easier. There's no doubt about that. But I also think that there are certain things in terms of attitudes ... and I suppose empathy and self-awareness can go a long way in any circumstances. You can go into biological explanations, social explanations, but, ultimately, it's each individual case. Going back to the whole parenting thing. I think that early experiences as an infant are absolutely huge for young people. (YOT worker 3)

Gillies has posited that decontextualized attachment and developmental explanations of delinquency can help perpetuate a deterministic perception of childrearing, namely that parents with less resources and social capital cannot provide their children with secure attachments; so in some predominantly working-class families, both delinquency and bad parenting are passed down from one generation to another ( $\mathrm{Gil}$ lies 2012, pp. 97-100). Similarly, the experts in my research talked about damaged parental bonds in a child's formative years but, unexpectedly, rarely considered the ways in which other events in a young person's life (Besemer 2014, p. 80) and their relationships outside the family might influence their delinquent pathway or, conversely, could contribute to their desistance. In addition, their views usually disregarded possible intervening circumstances that could affect both the child's behaviour and their parents' childrearing, namely parental stress, lack of resources, inappropriate housing, or other indicators of class (Besemer 2014, p. 93).

When I worked within youth offending, I started asking - every time I went to see a parent - "How was your bond when he was a baby?" And I lost count ... I'd say that $99 \%$ of them said "It was really difficult. I didn't really bond in the first place. He cried a lot and she did this ... and I had a really hard time." I know there's a lot of research about the attachment that's not in place in years $0-2$. I mean it's probably 
reversible to some extent, but I'm not sure. It amazed me how many young people that were being really aggressive and violent and were involved in youth offending have had a really rough time with their parents for the first few years. (parenting specialist)

In addition, the interviewees rarely considered other sources of influence such as peers, law-enforcement professionals and youth justice officials (Besemer 2014, p. 79) in the development of deviance, but agreed that most troubled children learn challenging behaviour from their parents (Simons et al. 2011, p. 177). Nevertheless, their narratives were often conflicting since most of them believed that young people from middle-class families who have experienced adequate upbringing also transgress, but their wrongdoings remain invisible:

I think the view that youth crime is limited to the lower classes oversimplifies a complex reality. I think that those who are better off have a better way of keeping bad things beyond the noses of agencies, so it's like white-collar or elite crime in adults. Probably, a lot of it bears a resemblance to burglars from the local council estates, but the scrutiny just isn't there or the state's response to it is more permissive. Or it can be hidden easily. As with offending generally, I think that those with a deprived background are more likely to come to the attention of agencies. For a variety of reasons ... They're going to be picked up and identified. That might be prompted by problematic behaviour on the part of their children, but they don't have the resources to access services that can help without statutory agencies getting involved and imposing help. (YOT worker 1)

Furthermore, while McAra and McVie have found that children from disadvantaged backgrounds get propelled into the youth justice system through continuous system contacts (McAra \& McVie 2007, pp. 337-338), my research participants also believed that police officers and other law-enforcement officials perceive deviance differently in affluent youths, so they treat them more leniently. This helps divert troubling middle-class children away from statutory agencies, predominantly into the private sector and realms other than youth justice:

These first-time entrants are going in who are unable to represent themselves well because they are chaotic, homeless, "looked after" [by the local authority], or they've got mental health issues, so they turn up looking unkempt ... You know because they don't have any smart clothes and mum couldn't be bothered and hasn't fed them that morning, or they've had a massive row at home ... They are stressed about a court appearance, so of course they're not gonna come across well and they're gonna be difficult and belligerent. I think young people who are able to show up in court, dressed smartly, and who are able to answer well in court are also less likely to be punished than young people who don't have the ability or the capacity to do that. There have been cases when we have seen young people walk away with a much lighter sentence because they've been able to do that. Yeah, it feels unfair. (YOT worker 2)

It therefore becomes apparent that the professionals in my study were aware of the structural circumstances that can shape family life on a daily basis and the possibly 
biased decision-making across law-enforcement agencies and the judiciary. In addition, they also believed that parents' social capital could play an important role in the desistance processes of young delinquents:

He could go wrong, and he did go wrong, and his parents were always there to pick him up, and he'd just start again. You wouldn't have that possibility in an economically less developed family. If you're affluent and get it wrong, someone, usually your parents, will rescue you. And that's not emotional support - "You'll be safe" -, because you get that kind of support in disadvantaged families as well. It's a financial and very practical thing ... "If you get into financial or whatever problems, I will help." So it's not the emotional part but the financial one, when you know you can survive ... Even if you have massive problems or just a gap of a couple of months, a year ... (youth worker 1 )

However, despite their social awareness, a number of practitioners focused predominantly on the correlation between parenting styles and the development of a young person's behaviour when they talked about youth deviance. This was not surprising since a complex understanding of the impacts of class - and the forms of capital that determine it - on a youngster's trajectory is currently still absent in their initial assessment within the youth justice system:

In the core Asset [youth justice assessment tool], we do try and capture some information [about the child's class background], but it's mostly related to whether the family is on benefits or not, which isn't necessarily a good indicator. It's not the same as talking about the educational level of parents or their socio-economic status, and, in fact, I think that we, as a routine, don't record that information. There's nowhere in our system that we capture that. We capture other issues about diversity in terms of gender or ethnicity ... But in terms of thinking about deprivation or a parent having aspirations for their children - educationally and occupationally ... I mean, our primary focus is working with individuals. (YOT worker 1)

Secondly, youth justice interventions within which young people are dealt with seem to be designed in socially decontextualised ways, which has also been reported by other researchers in the UK. Gray, for example, has shown that young offenders' difficulties are addressed through individualised cognitive behavioural programmes that intend to help them understand themselves and control their own conduct (Gray 2013, p. 520). As a consequence, practitioners often ascribe young people's challenging behaviour to their disrespectful attitudes, while the problems their families are facing seem to be sidelined (Gray 2013, p. 518). The practitioners I interviewed also spoke about individual-focused programmes:

At the moment, we've received training about sort of psychological skills in working with young people. This has given us quite a good knowledge about attachment and trauma and being able to unpick that with young people. So that's been quite good. We can use CBT and talk to young people and help them understand how other people have affected them to increase their ability to cope ... to get them to regulate their emotions. (YOT worker 3) 
If the overarching aim of youth justice is to encourage young offenders to desist, the above analysis begs the question of whether it is even possible to speak about a unified experience of growing out of crime for children across all backgrounds that are adversely equipped with economic, social and cultural capital. I therefore use the next section to explore the possible classed consequences of both the perceptions of practitioners and the rationale of programmes that are currently in place for young offenders. I examine their likely impacts on young people's identities and on the decisions institutions make about their troubling behaviour. I also consider the effects of these processes on young people's future offending and on their desistance.

\subsection{Professional perceptions, institutional responses and their impacts on offending and desistance pathways}

In his work on distinction, Bourdieu argued that differences in manner are acquired within the household and applied adversely outside the familial setting as well as valued distinctively by others across a range of social contexts (Bourdieu 2010, pp. 58-59). Standards of conduct that are obtained within the family thus become distinctive "markers of class" in institutional settings, depending on whether or not they play out as culturally legitimate in professional interactions (Bourdieu 2010, p. 59). It therefore seems important to contextualise how the above-presented professional perceptions and the working practices within youth justice could impact upon the ways in which practitioners interpret family-rooted but socially conditioned behaviours of challenging young people. In this task, it is also crucial to think about whether similar professional stances and organisational processes might be influencing the same young people throughout their life course, as well as the possible cumulative consequences for their offending and desistance pathways.

In her study of pupils at risk of exclusion, Gillies has found that children's emotional literacy has become hugely important in the UK's educational setting, while at the same time, schools rarely acknowledge that the pupil's levels might be socially and culturally conditioned (Gillies 2011, p. 185). Based on her findings, Gillies has concluded that encouraging young people to express "socially appropriate thoughts" presents another classed exercise and exposes the pupils who cannot articulate their feelings calmly and eloquently (Gillies 2011, pp. 192-197). As a consequence, schools often label young people's poor behaviour as "psychologically immature" and "pathological" (Gillies 2011, pp. 194-195) while largely disregarding the reasons behind their emotional excesses; thus, the social disadvantages of families remain sidelined and become normalized (Gillies 2011, p. 201).

Furthermore, Robinson has criticised a youth justice system that operates mainly on the individual level and sidelines structural circumstances, as well as disregarding the importance of viable relationships between families and the professionals who work with them (Robinson 2016). She has suggested that within such an individualised micro-setting, practitioners' actions and their interactions with young offenders could exacerbate families' vulnerabilities and intensify the criminogenic factors that 
derive from their disadvantage at a macro level, rather than preventing them (Robinson 2016, p. 21). Gillies and Robinson's findings - just like McAra and McVie's work on the onset of offending pathways (McAra \& McVie 2012b, p. 374) - thus suggest that similar class-conditioned labelling practices might derive from the functioning of institutions that deal with troubling youth behaviour at different levels, which could have criminologically significant outcomes.

Back in 1972, Lemert concluded that continuous labelling, even if unintended and repeated in good faith, could have secondary deviance effects and might trigger offending if internalised by the designated individual (Lemert 1972). Furthermore, Matsueda has argued that the reactions of others and their projection to the self as "reflected appraisals" can trigger delinquent behaviour (Matsueda 1992, pp. 16021604). Therefore, not paying enough attention to structural circumstances and frequently attributing the label of "troublemaker" (based on superficial observations of problematic conduct within an institutional setting) could become a stand-alone "cause and consequence" of deviance (Matsueda 1992, p. 1603).

Moreover, (over)reacting to children's challenging behaviour might - even if wellintended - result in exclusionary practices or lesser expectations by troubling youths, both of which could contribute to their offending. In the US, criminologists have exposed school exclusion as one of the processes through which some young people might be criminalised in the web between public schools and the youth justice system (Meiners 2013). Furthermore, Kupchik, Green and Mowen's research has shown that formal differences between punitive disciplinary practices in the US and the UK's needs-focused school-disciplinary discourse play out similarly in practice, as they result in near-equal exclusion rates and an over-representation of disadvantaged pupils therein (Kupchik et al. 2015, pp. 11-16). In addition, Savolainen et al. have argued that exclusions marginalise young people and prepare them for occupations that are not in high demand in post-industrial countries. This could become a contributing lead towards offending pathways either independently (Savolainen et al. 2013, p. 610 ) or, according to Briggs, through young people embracing the "street culture" of similarly vulnerable peers (Briggs 2010).

Since young people of underprivileged backgrounds are over-represented in official exclusion statistics, it is crucial to consider whether and (if so) how prior class-conditioned circumstances in their lives could impact upon their misbehaviour in schools and across other institutions (Williamson \& Cullingford 2003). This seems especially important as children's continuous troubling behaviour within the same institutional milieu might, through time, lead to professionals becoming less tolerant; this decrease in tolerance could, in return, make practitioners less motivated to assist young people attentively with their desistance pathways. I therefore conclude with proposing alternative ways of contextualising the links between parenting, delinquency and class within youth justice. I also touch upon the role of law enforcement and other agencies that deal with young people in trouble in order to highlight their possible effects on growing out of crime. 


\section{Conclusion}

Although social class may seem like a relic of the past, exploring professional perceptions of - and institutional responses to - youth deviance and parenting reveals possible covert mechanisms through which it might play out as a real lived experience. In criminological research, analysing the implications of class in the relationship between parents and their children on one side and the interactions of both with institutions on the other seems relevant to help disentangle the extent to which delinquency could be attributed to poor parenting or, rather, labelling of children's troubles and their parents' childrearing across organisations based on the family's social location. In addition, so as to design viable desistance programmes for young offenders in the future, it is crucial to understand the links between social factors, family life and the development of juvenile offending holistically, especially in the UK context.

According to Walkerdine, a particular public perception of disadvantage in Britain remains, namely that the undeserving stay impoverished due to their intrinsically flawed lifestyles, inclusive of improper parenting, as well as their unconformity, including criminality (Walkerdine 2015, p. 171). Since this notion has provided the "material and discursive conditions under which lives (...) [have been] led" throughout British history, it has resulted in intergenerational insecurity for the families that are classified as unworthy (Walkerdine 2015, pp. 168-169). Based on this reasoning, Walkerdine has concluded that it is not the bad habits of working-class families or their damaged relationships per se that are passed down from generation to generation, but rather their embodied suffering (Walkerdine 2015, pp. 174-175). Therefore, responses to youth deviance and parenting should not focus on behaviour only as it is but a symptom of the lived experience of class (Walkerdine 2015, pp. 171-172).

In addition, Besemer, Farrington and Bijleveld have found that there is no real transmission of criminal behaviour from parents to their children, since criminal justice institutions and law-enforcement officials are biased against children of convicted parents as well as, independently and statistically significantly against those from low-income families (Besemer et al. 2013, pp. 438-448). As criminality is not only transmitted through failed childrearing but also through an intergenerational exposure of some families to official bias (Besemer 2014, p. 79), practitioners' explanations that draw predominantly on a simplified attachment theory and intergenerational transmission of criminal behaviour might be preventing a more nuanced understanding of how the effects of social class are intertwined with the impacts of parenting and how both, jointly, influence the formation and continuation of - as well as the desistance from - deviance in children. 
Although classed institutional practices are not the only significant factor in shaping the pathways to and from delinquency, as social mobility and the diverse personalities of individuals 5 should also be acknowledged, the "bogeymen" (Maruna 2001, p. 5) stigma of offending is persistent, and certain families are repeatedly perceived as “"doomed' to deviance" (Maruna 2001, p. 165). In addition, desistance is not only an internal process of restorying but is also embedded in social relations and thus inevitably interactional (Kirkwood 2015, pp. 233-234). Within education and youth justice, institutional discourses and professional interactions therefore provide significant "formal (...) auspices of storytelling" that restrict some parents and children in constructing the identities they "choose to live by" (Holstein \& Gubrium 2000, p. 105). In addition, class still seems to be a "deep reservoir (...) of self-construction resources" (Holstein \& Gubrium 2000, p. 105) as responsible parenting and suitable behaviour are culturally determined according to middle-class standards (Holstein \& Gubrium 2000, p. 105).

Individualised strategies - within which young people and their parents are encouraged to negotiate new (or to revitalize previous) non-deviant identities or to enhance their self-esteem - could thus be standardizing the ability to be "artfully agentic" (Holstein \& Gubrium 2000, p. 12) based on the experiences of individuals that are equipped with economic, social and cultural capital. As working-class families struggle with numerous day-to-day concerns (Holstein \& Gubrium 2000, p. 105), their willingness and ability to change through socially decontextualized, albeit welfareoriented, programmes could restrain their identity (re)formation. In order to enable more equal pathways to desistance and adulthood, a multi-agency approach to delinquency should not only balance justice and welfare in theory (Muncie 2015, pp. 265299) but also consider how to ensure procedurally and socially fair encounters of young people and their parents with the institutions that address their problems on the ground.

\section{References}

Bachman, R. \& Schutt, R.K. (2011): The Practice of Research in Criminology and Criminal Justice. London.

Barry, M. (2013): Desistance by Design: Offenders' Reflections on Criminal Justice Theory, Policy and Practice. European Journal of Probation 5/2, pp. 47-65.

Besemer, S. (2014): The Impact of Timing and Frequency of Parental Criminal Behaviour and Risk Factors on Offspring Offending. Psychology, Crime and Law 20/1, pp. 78-99. 
Besemer, S., Farrington, D.P. \& Bijleveld, C.C.J.H (2013): Official Bias in Intergenerational Transmission of Criminal Behaviour. British Journal of Criminology 53/3, pp. 438-455.

Bonger, W. (2003): Criminality and Economic Conditions, in: E. McLaughlin, J. Muncie \& G. Hughes (eds.), Criminological Perspectives: Essential Readings. London, pp. 58-65.

Briggs, D. (2010): 'The world is out to get me bruv': life after school 'exclusion'. Safer Communities 9/2, pp. 9-19.

Burney, E. \& Gelsthorpe, L. (2008): Do We Need a 'Naughty Step'? Rethinking the Parenting Order After Ten Years. The Howard Journal 47/5, pp. 470-485.

Condry, R. (2007): Families Shamed. The consequences of crime for relatives of serious offenders. London.

Corr, M. (2014): Young People's Offending Careers and Criminal Justice Contact: A Case for Social Justice. Youth Justice 14/3, pp. 255-268.

Farrington, D.P. (2002): Families and Crime, in: J.Q. Wilson \& J. Petersilia (eds.), Crime: Public Policies for Crime Control. Oakland, pp. 130-157.

Gillies, V. (2012): Personalizing Poverty: Parental Determinism and the "Big Society" Agenda, in: W. Atkinson, S. Roberts \& M. Savage (eds.), Class Inequality and Austerity in Britain: Power, Difference and Suffering. Basingstoke, pp. 90 110 .

Gillies, V. (2011): Social and Emotional Pedagogies: Critiquing the New Orthodoxy of Emotion in Classroom Behaviour Management. British Journal of Sociology of Education 32/2, pp. 185-202.

Gillies, V. (2005): Raising the 'Meritocracy': Parenting and the Individualization of Social Class 39/5, pp. 835-853.

Gillies, V. (2000): Young People and Family Life: Analysing and Comparing Disciplinary Discourses. Journal of Youth Studies 3/2, pp. 211-228.

Goldson, B. \& Jamieson, J. (2002): Youth Crime, the 'Parenting Deficit' and State Intervention: A Contextual Critique. Youth Justice 2/2, pp. 82-99.

Gottfredson, M.R. \& Hirschi, T. (1990): A General Theory of Crime. Stanford, CA.

Gray, P. (2013): Assemblages of Penal Governance, Social Justice and Youth Justice Partnership. Theoretical Criminology 17/4, pp. 517-534.

Healy, D. (2013): Changing Fate? Agency and the Desistance Process. Theoretical Criminology $17 / 4$, pp. 557-574.

Hirschi, T. (1995): The Family, in: J.Q. Wilson \& J. Petersilia (eds.), Crime. San Francisco, CA, pp. 121-140. 
Hollingsworth, K. (2007): Responsibility and Rights: Children and Their Parents in the Youth Justice System. International Journal of Law, Policy and the Family 21/2, pp. 190-219.

Holstein, J.A. \& Gubrium, J.F. (2000): The Self we Live by: Narrative Identity in a Postmodern World. Oxford.

Kirkwood, S. (2015): Desistance in Action: An Interactional Approach to Criminal Justice Practice and Desistance from Offending. Theoretical Criminology 20/2, pp. 220-237.

Kupchik, A., Green, D.A. \& Mowen, T.J. (2015): School Punishment in the US and England: Divergent Frames and Responses. Youth Justice 15/1, pp. 3-22.

Lemert, E.M. (1972): Human Deviance, Social Problems, and Social Control. Englewood Cliffs.

Maruna, S. (2001): Making Good: How Ex-Convicts Reform and Rebuild their Lives. Washington.

Matsueda, R.L. (1992): Reflected Appraisals, Parental Labeling and Delinquency: Specifying a Symbolic Interactionist Theory. American Journal of Sociology 97/6, pp. 1577-1611.

McAlister, S. \& Carr, N. (2014): Experiences of Youth Justice: Youth Justice Discourses and their Multiple Effects. Youth Justice 14/3, pp. 241-254.

McAra, L. \& McVie, S. (2012a): Critical Debates in Developmental and Life-Course Criminology, in: M. Maguire, R. Morgan \& R. Reiner (eds.), Oxford Handbook of Criminology. Oxford, pp. 533-560.

McAra, L. \& McVie, S. (2012b): Negotiated Order: The Groundwork for a Theory of Offending Pathways. Criminology and Criminal Justice 12/4, pp. 347-375.

McAra, L. \& McVie, S. (2007): Youth Justice? The Impact of System Contact on Patterns of Desistance from Offending. European Journal of Criminology 4/3, pp. 315-345.

Meiners, E. (2013): Schooling the Carceral State: Challenging the School-to-Prison Pipeline, in: D. Scott (ed.), Why Prison? Cambridge, pp. 261-277.

Merton, R. (1938): Social Structure and Anomie. American Sociological Review 3/5, pp. $672-682$.

Moffitt, T.E. (1993): Adolescent-Limited and Life-Course-Persistent Antisocial Behaviour: A Developmental Taxonomy. Psychological Review 100/4, pp. 674 701.

Morgan, R. \& Newburn, T. (2012): Youth Crime and Justice: Rediscovering Devolution, Discretion, and Diverison?, in: M. Maguire, R. Morgan \& R. Reiner (eds.), The Oxford Handbook of Criminology. Oxford, pp. 490-530. 
Morris, K. (2013): Troubled Families: Vulnerable Families' Experiences of Multiple Service Use. Child and Family Social Work 18/2, pp. 198-206.

Muncie, J. (2015): Youth and Crime. London.

Noaks, L. \& Wincup, E. (2004): Criminological Research: Understanding Qualitative Methods. London.

Nugent, B. \& Schinkel, M. (2016): The Pains of Desistance. Criminology \& Criminal Justice; http:/crj.sagepub.com/content/early/2016/03/14/1748895816634812.ful 1.pdf + html, pp. 1-17.

Paternoster, R. \& Iovanni, L. (1989): The Labeling Perspective and Delinquency: An Elaboration of the Theory and the Assessment of the Evidence. Justice Quarterly 6/3, pp. 359-394.

Rutherford, A. (1992): Growing out of Crime: The New Era. Winchester.

Savage, M., Devine, F., Cunningham, N., Taylor, M., Li, Y., Hjellbrekke, J., Le Roux, B., Friedman, S. \& Miles, A. (2013): A New Model of Social Class? Findings from the BBC's Great British Class Survey Experiment. Sociology 42/2, pp. 219 250 .

Savolainen, J., Hughes, A.L., Hurtig, T.M., Ebeling, H. \& Taanila, A.M. (2013): Does Vocational Schooling Facilitate Criminal Offending? A Study of Educational Tracking in Finland. European Journal of Criminology 10/5, pp. 606-622.

Simons, L.G., Simons, R.L. \& Hancock, D. (2011): Linking Family Processes and Adolescent Delinquency: Issues, Theories, and Research Findings, in: D.M. Bishop \& B.C. Feld (eds.), The Oxford Handbook of Juvenile Crime and Juvenile Justice. Oxford, pp. 180-181.

Skardhamar, T. (2009): Reconsidering the Theory of Adolescent-Limited and LifeCourse-Persistent Anti-Social Behaviour. British Journal of Criminology 49/6, pp. 863-878.

Smith, D.E. (2005): Institutional Ethnography: A Sociology for People. Lanham.

Walkerdine, V. (2015): Transmitting Class Across Generations. Theory \& Psychology, pp. 167-183.

Williamson, I. \& Cullingford, C. (2003): Everybody's a Nobody in School: Excluded Students' Perceptions of the Threats to Autonomy in the English Secondary School. Young 11/4, pp. 309-321.

Wilson, J.Q. \& Herrnstein, R.J. (1985): Crime and Human Nature. The definitive study of the causes of crime. New York. 


\title{
Focus on New French Schemes and Methods to Support Prison Release and the Desistance Process
}

\author{
Astrid Hirschelmann
}

This proposal looks at the results of an action research project called "Preparing release and preventing recidivism: assessment and support of a new French scheme the Longuenesse Quartier pour peines aménagées (QPA) (2014-2015)" and funded by the French Prison Service in Paris. ${ }^{1}$

Several studies have shown that re-offending often occurs due to people encountering a lack of choice upon leaving prison. ${ }^{2}$ It is therefore in the interest of both the public and their elected representatives to work together on devising and implementing inclusive policies that guarantee public well-being, as well as on facilitating the passage from the closed world of a prison to life in the community.

The French Prison Service is aware of these problems and insists on the fact that detained convicts need to receive help at the right moment - and especially after release - via programs and procedures that are specially designed to support the transition from life in prison to a law-abiding life in the community (Maestracci 2012, pp. 202-212). It has therefore issued a certain number of circulars over the course of several years, stating that release from prison needs to be prepared from the moment the individual enters it. Although these principles are the subject of general consensus, numerous difficulties arise when it comes to implementing them.

\section{Current penal policy and preventing re-offending in France}

Before presenting the action research, we first need to provide a brief overview of French penal policy so as to better understand the context in which QPAs have been introduced.

1 The French Quartiers pour peines aménagées, which translates approximately as "detention centres for adapted sentences", are intended to provide an appropriate response to people convicted to short sentences (and predominantly under 30 years of age) whose remaining sentence is less than one year. The QPA is a small and very flexible centre organized into three units of 30 cells, designed to promote the implementation of rehabilitation projects and to ensure their success. Longuenesse is a town close to Lille in the north of France.

2 European Forum for Urban Security: innovative strategies for the prevention of re-offending: practice and recommendation for local players. 
Since the early 1980 s, the principle of rehabilitative justice ${ }^{3}$ has been at least partially called into question by the emergence, especially since the early 2000 s, of the idea of dangerousness in the French penal code. In the wake of the law of 12/12/2005, the attempt to tackle recidivism has produced realms of legislation emphasizing increased severity of repression as the key way to prevent recidivism by force of dissuasion. Thus, as the consensus conference panel has observed on numerous occasions, imprisonment is now the standard sentence for re-offenders. ${ }^{4}$ They have a significantly lower likelihood of receiving an aménagement de peine (that is to say, conditional release, suspended sentence for medical reasons, placement in an open prison, or electronic monitoring) and are subject to more stringent surveillance measures on release. The law has introduced mechanisms targeting re-offenders that encourage their imprisonment and/or increase the quantum of punishment.

In parallel to these changes and relating to the number of people placed under judicial surveillance each year, the length of time spent in detention has also increased. The panel of the consensus conference on preventing recidivism noted in 2013 that as things stand, the security mission of protecting society by temporarily neutralizing those found guilty of offences prevails over any other sentencing objectives, in particular rehabilitation and reintegration.

It is clear that the French policy to tackle recidivism has yielded far from glorious results. Figures published by the French Ministry of Justice in its April 2014 Bulletin d'information statistique paint a stark picture. Between 2004 and 2013, 63\% of all people with a criminal record prior to 2004 re-offended. Furthermore, certain offences showed even higher levels of re-offending. Thus, nearly three quarters of those found guilty of driving under the influence of alcohol resulting in homicide or assault re-offended (74.2\%).

And it would appear that the situation is not getting any better. One of the all-toorare studies by the French Prison Service examining re-offending rates in France on 1 January 2009 and 1 January 2014 shows that the situation is getting worse. While in $2009,31.3 \%$ of detainees were being held for an offence recorded as legal recidivism, this figure increased to $41 \%$ until January 2014 , amounting to a $25 \%$ increase over the period, which cannot be attributed solely to changes in the law (Bruyn \& Kensey 2014, p. 6).

The failure of the policy to tackle recidivism is one of the reasons for prison overcrowding in France, an endemic problem that continues to get worse (Farrington \&

3 Rehabilitative justice emphasises the re-socializing and re-educating purpose of the sanction. The idea of the sentence is to encourage the individual to think about their act via which they have excluded themselves from society, and to change in a way to be able to reintegrate themselves.

4 Consensus conference (2013). Pour une nouvelle politique publique de prévention de la récidive. Principes d'actions et méthodes. Consensus panel report presented to the French prime minister. 
Nuttall 1980, pp. 221-231). While there were 47,837 detainees in France in 2001, this figure rose to a record level of 76,075 detainees in 2014, representing an increase of over 40\% (Ministry of Justice 2016). On 1 April 2016, prison overcrowding was still on the rise, with 14,243 prisoners too many, a level not seen since 1 July 2008 (Tournier 2016). This is all the sadder when bearing in mind that prison overcrowding is on a downwards trend across Europe. In its annual penal statistics published in March 2016, the Council of Europe once again singled out French prisons which have 114.5 prisoners per 100 available places, making them the seventh-most overpopulated ones in Europe, after Hungary, Belgium, Macedonia, Greece, Albania, and Spain (Aebi et al. 2014). An equally depressing figure is the suicide rate in French prisons, which stands notably higher than the average Council of Europe country, with 12.4 suicides per 10,000 prisoners, as against an average of 7.6.

For that matter, re-offending and chronic prison overcrowding have been one of the reasons for the continual increase in the justice budget over the past decade and more. Between 2005 and 2015, it rose from $€ 5.461$ billion to $€ 7.98$ billion, an increase of $46 \%$. Despite this, the French judicial system is "in a state of absolute emergency" according to the current Keeper of the Seals, Jean-Jacques Urvoas, who is alarmed at a justice system that "no longer has the means to pay its bills" (Urvoas 2016).

Smith, Gendreau and Goggin (2002) have examined more than 115 studies published between 1958 and 2002 in order to look at the link between prison and re-offending; they have arrived at the conclusion that prison leads to an increase in recidivism rates of between $7 \%$ and 11\% (Smith et al. 2002). Revealingly, the most rigorous studies tended to show even a higher rate of re-offending. Based on 57 studies, a second meta-analysis conducted by Jonson in 2010 led to the same observation: a prison sentence increases recidivism by $14 \%$ in comparison to a sentence that does not involve incarceration (Jonson 2010). Increasing prison sentences thus makes society less safe - and does so in numerous ways. For that matter, public opinion is aware of this fact. In France in 2009, 77\% of those interviewed thought that prison did not succeed in playing a dissuasive role, and 33\% thought it even encouraged re-offending (Belmokhtar \& Benzakri 2013, p. 1).

\section{The turning point - a new policy to favor desistance}

Since the turn of the 2000 s, preventing recidivism has been central to a flurry of compulsive lawmaking with at times broadly contradictory injunctions. The process has been intense given the ten laws passed and 28 regulatory provisions introduced since 1999 - all relating to re-offending -, and compulsive given that this flurry of legislation has all too often been in response to public opinion (such as the Francis Evrard affair in 2007, the Hodeau affair in 2009, and the Pornic affair in 2011). And it has had contradictory injunctions given that these legislative and regulatory provisions respond to principles which whilst not antagonistic are nevertheless broadly contradictory. 
The legislator has encouraged aménagements de peine so as to reduce recidivism, whilst in a mutually incompatible movement introducing simplified aménagement de peine procedures to reduce prison overcrowding and to curb re-offending amongst people with short sentences, as is the case, for instance, with the prison law of 24 November 2009 and the third paragraph of article 707 of the Criminal Procedure Code (CPP) it introduced: "[T] he individualization of sentences must whenever possible make it possible for the convict to return progressively to liberty and avoid their release without any form of supervision" (Prison law no. 2009-1436 of 24 November 2009, Journal Officiel no. 0273 of 25 November 2009, p. 20192).

The approach adopted by penal policy over the past 15 years has taken the prevention of re-offending as its prime objective, as set out in a circular no. 113 of 19 March 2008 issued by the French Prison Service. This has been accompanied by various types of action, such as ensuring that various obligations towards inmates are indeed met, work on the criminal act itself, the meaning of the sentence, social reintegration, and so on. Probation underwent a major shift in France when it was rebaptized "Preventing Re-offending" in 2005. This new terminology is indicative of the polarization of penal policy responses around the principles of risk assessment and dealing with dangerousness (Harcourt 2007).

Preventing recidivism brings together various actors and is confronted with the specific demands of the new penology rooted in two objectives. Firstly, it is a matter of defending society (by avoiding re-offending), and secondly of rationalizing the penal system (by optimizing flow management) (Milburn \& Jamet 2014, pp. 1-15). In other words, this shift, which started in the period 2005-2007, stems from the political will to establish new means of action combining social defense and social protection, which, as observed above, is the guiding principle behind current penal policy (Garapon 2010). Preventing re-offending thus becomes the principal task of Probation and Integration Officers (Conseillers Pénitentiaire d'Insertion et de Probation, CPIP) and thereby the end-purpose of their actions (Milburn \& Jamet 2013).

Thus, the European Probation Rules (EPR) were set up to regulate various practices tending towards the same objective. However, they also apply to other organizations carrying out tasks covered by these rules, including other public bodies and nongovernmental organizations. These European Probation Rules set out the principles that should guide the setting up of probation services and their proper functioning. That is why the first of these rules clearly defines the importance of probation and reintegration agencies:

$[\mathrm{P}]$ robation agencies shall aim to reduce re-offending by establishing positive relationships with offenders in order to supervise (including control when necessary), guide and assist them to promote their successful social inclusion. Probation thus contributes to community safety and the administration of justice (European Probation Rules 2010, rule 1, p. 19). 
The re-offending rates indicated in the introduction show that the strategy to prevent re-offending is patently failing, being inconsistent and a matter of media impact. The poor results explain the pitiful image of the justice system in France, with $77 \%$ of French people reckoning in February 2014 that it functions "fairly badly" or "very badly", the highest level of distrust ever recorded since the barometer began in 1966 (Institut CSA for the Institut pour la Justice, February 2014). The incoherent nature of French policy to prevent re-offending, which privileges a blanket prison response combined with aménagements de peine, has also made the justice system even harder to understand for the public, and in February 2014, 91\% of French people thought it was very opaque. This loss of meaning is a major challenge for all judicial actors especially as detainees are directly affected by these representations. The lack of faith in the justice system means that it is very difficult to mobilize vulnerable people to change and engage on a path towards desistance.

The prison system is often accused of working against the reintegration of detainees. But prison is not the only cause at work here, rather being part of a continuum that in turn reinforces it. Thus, whilst it is not wrong to suggest that prison works against social reintegration and triggers re-offending, it needs to be added that it is not the only factor. This is because many convicts were already in a position of pronounced social exclusion and precariousness prior to being sentenced and sent to prison.

Thus, Denis Salas argues that the initial premise needs to be inverted, suggesting that the risk of re-offending is linked to a poor capacity for reintegration rather than to the offence perpetrated. Current French legislation reduces penal policy to short-term management without any regard for its content. The only people to be preoccupied by this state of affairs are those working in the penal system who witness the damage it causes on a daily basis. Denis Salas thus states that "any sentence which loses view of rehabilitation is an instance of unjustified violence" (Salas 2013, p. 310).

\section{The introduction of Quartiers pour Peines Aménagées as a mechanism to foster desistance}

Although the theories of desistance have only recently emerged in France, they look more and more applicable to what is happening in the field and therefore seem to be increasingly taken up outside academic circles. Thus, desistance is one of the explicit objectives of probation which, as seen earlier, responds to the twin principles of social protection and public security. French practice now tends towards the definition adopted by the Council of Europe for whom probation includes a range of activities and interventions which involve supervision, guidance and assistance aiming at the social inclusion of an offender, as well as contributing to community safety. The aims of these interventions are rehabilitation and desistance, and they should thus be constructive and proportionate to the imposed sanction or measure (Internal note relative to definition no. 76 of the European Prison Rules 2010). 
Adopting and applying the concept of desistance could thus open up the French probation system to another vision of the probation period. In general, the support for desistance provided by probation ought to underpin an approach that is based on encouraging change but without imposing it. It ought to encourage the individual to adopt a law-abiding way of living and aim at questioning their continuation along a path of delinquency by working on their strengths and weaknesses and by maintaining their motivation. These principles are the same as those promoted by Quartiers pour peines aménagées.

\subsection{What is a QPA?}

Quartiers pour peines aménagées are generally geographically dependent upon the local prison and have emerged within this political context. They have lesser security measures and count on being able to motivate the detainee to take part in a program to support them on their way towards release and ideally away from offending. There are currently less than a dozen QPAs in France.

The purpose of QPAs is to take in detainees with less than a year left to serve and who are working towards an aménagement de peine as they prepare for their release from prison.

QPAs have three principal missions: 1) preventing re-offending; 2) reintegration via "support based on working on the criminal act and support based on preparing for release by an aménagement de la peine"; and 3) providing access to independence and responsibility.

In order to meet these objectives, the detainees are provided with support that seeks to prepare them for their release by encouraging them to develop a career or training project and by putting together an aménagement de peine project. This all underpins the principle of preventing detainees from re-offending through the quality and solidity of their reintegration project. The instruments and techniques used for this purpose reveal the determination of the prison authorities (both wardens and the probation service) to place detainees in an active position at the center of their release project. One notable way in which these instruments and techniques take concrete form is the wide range of workshops run by partners in the socio-professional field, focusing on developing job-hunting skills as well as various other aspects of daily life (relating to money, health, and so on). The joint running of discussion workshops to prevent re-offending strengthens the dynamics between the various professions working in the prison system - and more generally helps reinforce the ties and discussions between them.

Such a perspective presupposes according the detainee a capacity for "desistance" (Laub \& Sampson 2003), whether this is a "second chance" or part of a "reparation 
scheme" (Goffman 1968), 5 with the goal of "social reintegration and preparing prisoners for release" (decree 2002 - CPA). Reference to the individualization of support is also associated with a set of values the predominant factor of which is the importance attached to the irreducible singularity and dignity of the individual. It is the opposite of mass treatment, based on taking the specific past history and project of each person into account in order to help them achieve autonomy. As explicitly indicated in the following meeting minutes, intensive support for detainees to help them build an aménagement de peine project is only coherent if it is progressively reduced parallel to the person acquiring increasing autonomy (QSO meeting minutes - 19/09/2013).

This idea of autonomy, paired to that of individualization, is another cardinal value of the project behind the QPA mechanism. It designates access to independence and to responsibility - viewed as the basic conditions for "self-fulfillment". The relative nature of these values with regard to the social milieu in which they transpire is a matter of debate, and there may be a gap between the institution's intent to help the detainee achieve them as part of their individual reconstruction project and the way in which they are experienced within the detainee's milieu of belonging. But for the moment, the essential point is to note that the project behind the QPAs is grounded in its reference to individualization and autonomy, irrespective of how these are apprehended by detainees given their social belonging and the conditions in which they exist.

\subsection{Research design and first impressions}

Our action research chose to focus on three aspects of the support provided by the Longuenesse QPA:

1. The ways of implementing support for detainees;

2. The manner in which detainees appropriated the support provided;

3. The effects the support had on the detainees' ability to respect self-imposed limits or on enabling them to adopt a legal form of life in society.

To this end, we adopted a methodology that triangulated sociological, psychological and legal assessments, based on observations of the various activities provided and on interviews with professionals (19 wardens, 2 prison directors, 9 probation officers, 1 psychologist, 6 professionals from the partner agencies) and 22 detainees. The

5 It is worth noting that the "second chance" and "reparation scheme" perspectives have different ideological and paradigmatic underpinnings. The idea of a "second chance" is rooted in a liberal interpretation of social relationships where an individual's place in society depends on their willingness to seize opportunities in a market of goods and services. The "reparation scheme", on the other hand, is based on social re-adaptation constituting the heart of a service relationship between a professional with the recognized technical skills to repair a "defective object" and a user who places his faith in this professional. Thus, the service relationship is not reducible to an exchange of wills but stems from the social determinants (social belonging, the position and role of the actors, institutional setups, and social norms), giving it content. 
latter were interviewed at various phases of the program (before, during and after) and were observed during the different activities proposed by the QPA professional team.

It is worth noting here that the values of prevention and reintegration targeted by QPAs are broadly supported by the CPIPs and wardens, even though some of them remain attached to a disciplinary conception of sentencing and detention. They thus consider the QPA mission to be central to their job and that it gives new meaning to supporting detainees:

For a warden, security is a matter of seeing that the internal rules and security are respected. And I'm for dialogue and reintegration, otherwise I wouldn't have come here. (a warden)

For me, in any case, our mission is to prevent re-offending, and for me, that involves above all preparing the detainee for release and reintegration. (a CPIP)

Wardens and CPIPs thus work together in the QPA to serve a joint purpose. They view the QPA as being of genuine benefit to what they do, giving additional "meaning" to the exercise of their functions:

For me, the QPA really corresponds to the missions of a CPIP. For me, it is really the reason why there is a prison sentence, so that you can trigger an external reintegration mechanism, so there ought to be places like QPAs everywhere, it ought to be the norm. Having something that enables people to do all they can to get ready for release. (a CPIP)

The work is the same, we still carry out our tasks doing (umm) cell searches, body searches after the cells, checking the inmates are there and so on, but it is the way we do it that has changed, it is mainly talking with the inmates. (a warden)

The QPA takes groups of up to 12 detainees per session. Five groups of detainees were observed during our action research between March 2014 and May 2015 as they interacted with the professionals and partners working with them, and then during interviews three months after they were released.

\subsection{The typical phases in a QPA}

There are typically three phases in a QPA:

\section{1) A reception phase lasting two weeks:}

Individual interviews in the first week with the probation and reintegration service and senior staff (during which an agreement is signed, the program presented and a supervision booklet given to the detainee) as well as individual interviews with the state employment agency and Sodexo. 
The second week is spent attending workshops on health education, access to rights, accommodation, budgeting, and a presentation of training courses.

2) A career guidance and job-search program which lasts eight weeks:

The purpose of the guidance module is to draw up or to validate a professional project.

The training or job-search module is based on workshops on how to write a CV and covering letters. It works on self-image, prepares for job interviews, identifies job openings, and so on.

3) An exit phase:

A four-week exit phase may be added after time spent in the QPA, during which the individual may do final preparations for starting a job or training course, with help from partners supporting their return to work.

The external partners who intervene in the QPA are:

- the Sodexo company which provides detainees with career support (career guidance, job-hunting techniques and increasing their awareness of the world of work);

- the state employment agency and the Mission Locale (the local agency for the social and professional integration of young people) which provide help with job-hunting;

- other local partner associations which focus on access to rights, accommodation, budgeting, and preventative measures relating to care, hygiene, addiction, high-risk sexuality, and so on.

\section{Results and observations of the QPA during the action research}

This type of interdisciplinary approach is necessary given that reintegration needs to address not only social, economic and professional practice but also individual factors, notably the individual's predisposition to change.

We looked at three areas or vectors to see if the hoped-for change came into sight:

1. The social dimension, looking at the relationship between differentiation and support, which we shall call the "re-socialization process";

2. The moral dynamic proceeding resulting from a relationship between regulation and enablement, which we shall call the "desire remobilization process"; 
3. The dynamic of the psycho-legal dimension proceeding resulting from a relationship between resources and renunciation, which we shall refer to in accordance with the models examined above as being crucial within the desistance process.

\subsection{A new social contract}

The interviews with detainees brought out the radically different nature of the relationships they had at the main prison where a state of permanent tension reigned and at the QPA where relations were calm and incidences of violence were very rare. Equally, the detainees stated that at the QPA, they encountered respectful attitudes and relationships based on parity, whereas they had hitherto been confronted with intimidating and dominating behavior. The solidarity within the groups also contrasted with the general atmosphere of suspicion at the main prison.

The detainees' relationship with the law also changed, for whilst various infractions and forms of trafficking were prevalent at the main prison - something the staff knew about but tolerated -, the QPA applied stricter rules seen as fair and the slightest infraction was punished.

Nobody has any respect in the main prison, it's not the same here, everybody has respect, everybody says hello. Everyone looks at each other distrustfully at the main prison. If you look down, then people say you're a poofter and things like that. Here, nobody pays any attention, we're all the same. (a detainee)

It's different, it's completely different to the main prison. At the main prison, everybody is shouting the whole time - you see fights, drug trafficking the whole time, and on the other hand, that doesn't happen here. (a detainee)

QPA Staff tended to share this representation of the inmates' lives in comparison to the main prison. They viewed their mission as being to re-establish and rehabilitate a common law and to reconstitute a framework within which the detainees could then establish other structural points of reference and find new ways of relating to others:

For me, [the QPA] is a place where you really talk about what is useful, about the meaning you are going to give to the prison sentence so as to try to build something, to set something in motion. (a CPIP)

So it is a matter of transforming social relationships within the prison milieu in order to establish favorable conditions for re-socializing and re-mobilizing the detainees.

Notions of respect, trust and listening are an indication that the detainees count for other people, that is to say they are not reduced to the single dimension of their stigmata, even though the prison framework is not dissipated thereby.

We know the warden/inmate role but we talk to each other ... in the context of the prison. We know not to overstep the boundary, and I mean things go really well ... 
Yes, you feel like someone. You know, we're aware that we're not just prisoners, we know that we've done something bad, something wrong, otherwise we wouldn't be here, but I mean people listen far more here. (a detainee)

\subsection{Reintegrating detainees}

The job/vocational training reintegration support consists of helping the inmate rediscover a role and a sense of belonging to society, in short to once more become "a citizen amongst other citizens".

But their desire of belonging to society still needs to be mobilized, that is to say work has to be done on pursuing a sense of satisfaction linked to the restrictions rendering it possible.

To this end, the GPA organizes discussion groups about preventing re-offending (PPR groups). These groups are jointly run by a CPIP and a warden. They are composed of six sessions and focus on "citizenship" - respecting rules, respecting oneself and respecting others. It was decided not to work on themes specifically related to the criminal act in order to emphasize the projection into the future rather than going back over the past.

What I liked best was the PPR, where we talked, I thought it was good. Even if it was hard at first. But we all talked together, at least we knew what the others had once done, and that way, we won't do the same thing. Then it was the only moment when we talked about things like that, as we talk about other things when we're together. (a detainee)

We talk together. When something isn't right, we tell each other. If there weren't any PPRs, nobody would go and see the wardens and all that. And what's good with the PPRs is that there is a warden and that he joins us, he talks to us, not many of them would do that. (a detainee)

The PPR groups were a particularly beneficial experience for the inmates, and for prison staff, too; indeed, they made it possible to experiment with a new way of interacting with others, something that was just as true for staff as it was for inmates. In addition to this, the rules in force at the QPA strengthen the social ties based on respect and reciprocity. This was described by staff and inmates as something wholly new and progressively contributed to the person shaking off their label as a lawless detainee who inspired nothing but distrust. This effect would appear to be essential for engaging in the process of desistance. In the approach adopted by Braithwaite (1989), the labeling of detainees acts as a means to exploit shame and has the potential to destroy integration. But here, the first thing inmates mentioned was an experience of "self" in which the other took part in this "integrative listening".

It is nevertheless essential that detainees talk about their aspirations and the paths they hope to follow. By building up new meaning and values, they are setting themselves concrete goals and the virtues needed to carry them towards these goals (Cot- 
traux 2007). They also share the potential for longer-term goals within a better controlled timeframe as they anticipate and organize things better, thereby placing change within their reach (The Hofstede Centre 2012).

\section{Conclusions and perspectives}

This paper has examined the results obtained in terms of how the QPA is a novel experience for both staff and inmates, as well as embodying a new method based on a new social contract that involves seeing detainees as individuals endowed with rights. This new contract emerges in the reaffirmation and reconfiguration of professional roles for a common purpose, the aim of which is to remobilize and re-socialize detainees, not only by giving their sentence new meaning, but still more ambitiously by giving new meaning to their life - and thereby, it is to be hoped, making it pointless to resort to delinquency in the future.

The QPA seeks to make the "interns" on the program more mature by guiding them towards the future. The participation of external partners such as Sodexo, the state employment agency etc. actively contributes to planning for their release and to organizing their social and professional reintegration. The PPR group and the rules governing discussion within the QPA reinforce respect for others and help foster self-control (in order to suppress the use of violence). All of these aspects have been mentioned as essential preconditions for supporting successful change towards desistance (cf. Mc Neill \& Weaver 2010).

The success of QPAs and their survival in the future nevertheless depends on taking several prerequisites into account:

1) Placement in a peine aménagée unit or a Quartier pour peines aménagées requires the agreement of the detainee. The QPA therefore significantly alters the relationship which is traditionally based on constraint, and this implies establishing a regulatory framework specific to this sort of prison establishment.

2) Recognition of the work carried out by the multidisciplinary team and a shift away from a "surveillance" mission:

- It is essential that the different professionals choose to work at a QPA on a voluntary basis.

- It is important to provide training about the new multidisciplinary approach for all staff working in the Quartiers pour peines aménagées.

- It is essential to put together a group of care professionals who can give their medical opinion on whether or not it is appropriate to recruit a given trainee and whether it is the right moment, as well as on the conditions in which to do so. 
3) Partners have to make specific, solid commitments.

- It is important that actors agree to adhere to the local project, which requires the involvement of magistrates in particular.

- It is preferable to appoint a single local interlocutor.

- It is necessary to have a firm grasp of the objectives of the QPA and to anticipate and provide support for any problems that may be encountered on release.

- Good coordination with the QPA team is essential.

4) The commitment of detainees is based on a genuine contractual process in which they assume responsibility.

- The agreement of the detainee: a contract is signed on the basis of an interview.

5) Selection criteria must be drawn up, based on:

- an open approach, encouraging as many people as feasible to apply;

- the local QPA project (capacity, group size, and so on);

- trying to maintain stability within the groups;

- expanding the scheme to inmates held in other prison establishments;

- volunteers;

- flexibility regarding the length of the session and the composition of the group;

- a strong alliance between staff and inmates.

6) Preparing for release must be based on:

- the composition and stability of the teams:

- Solidarity within the multidisciplinary team;

- Progressively building up cohesion between team members and their reciprocal recognition.

- organizing post-QPA supervision:

- Appointing a designated person who gets in touch with the detainee prior to release and provides support for a few weeks after release;

- Presentation modules for jobs and training courses.

But is the future of such schemes assured? Despite all the work preparing for release and the investment of professionals in establishing human relationships with the detainees, support stops at the QPA gates. We observed that the human factor has a very significant impact to such an extent that the detainees asserted with entirely new candor that they wanted to leave delinquency behind them, for simple reasons of recognition of the work the professionals had put in and what they had experienced with them, especially their designated CPIP. But the survey carried out with former QPA inmates revealed that real prison starts on release from prison. After having 
encountered respect and hope, often for the first time, they find it even harder to bear the judgmental and disparaging way they are looked at by the world outside. This should alert us to the fact that the QPA is not the final stage in serving a sentence but rather a point of departure for the individual to set their (new) life on a different course.

\section{References}

Aebi, M., Tiago, M.M. \& Burkhar, C. (2015): Council of Europe annual penal statistics: SPACE 1 (2014). Lausanne, 23 December 2015; http://wp.unil.ch/space/ files/2017/04/SPACE_I_2015_FinalReport_161215_REV170425.pdf/Notizie/2 016/03/carceri-report-consiglio-ue.pdf.

Belmokhtar, Z. \& Benzakri, A. (2013): Les Français et la prison. Infostat Justice 122, pp. 1-6.

Braithwaite, J. (1989): Crime, Shame and Reintegration. Cambridge.

Bulletin d'information statistique. April 2014. French Ministry of Justice; www.justice.gouv.fr/budget-et-statistiques-10054/infostats-justice-10057/une-approchestatistique-de-la-recidive-des-personnes-condamnees-27086.html [16/02/2017].

Cottraux, J. (2007): La Force avec soi: pour une psychologie positive. Paris.

De Bruyn, F. \& Kensey, A. (2014): Durées de détention plus longues, personnes détenues en plus grand nombre (2007-2013). Cahiers d'études pénitentiaires et criminologiques 9/40, pp. 1-12.

Farrington, D.P. \& Nuttall, C.P. (1980): Prison size, overcrowding, prison violence, and recidivism. Journal of Criminal Justice 8/4, pp. 221-231.

Garapon, A. (2010): La raison du moindre État: Le néolibéralisme et la justice. Paris.

Goffman, E. (1968): Asiles. Études sur al condition sociale des malades mentaux. Présentation de Robert Castel, traduction française. Paris.

Harcourt, B. (2007): Critique du champ pénal à l'âge actuariel. Cahiers parisiens 3. University of Chicago, Center of Paris, pp. 785-808.

Jonson, C.L. (2010): The impact of imprisonment on re-offending: A meta-analysis. $\mathrm{PhD}$ thesis, University of Cincinnati; https://etd.ohiolink.edu/pg_10?0::NO:10:P1 0_ACCESSION_NUM:ucin1285687754 [16/02/2017].

McNeill, F. \& Weaver, B. (2010): Changing Lives? Desistance Research and Offender Management. The Scottish Centre for Crime and Justice Research (SCCJR), Report 3/2010.

Milburn, Ph. \& Jamet, L. (2014): Prévention de la récidive: les services de probation et d'insertion français dans la tourmente. Champ Pénal 9/1, pp. 1-15. 
Milburn, Ph. \& Jamet, L. (2013): La prévention de la récidive comme secteur de l'action institutionnelle: processus d'ajustements entre acteurs, normes et pratiques. Research report, Paris, GIP Mission de Droit et Justice.

Ministry of Justice (2016): Les chiffres clefs de l'administration pénitentiaire au 1er janvier 2016; www.justice.gouv.fr/prison-et-reinsertion-10036/les-chiffres-clefs$10041 /[11 / 04 / 2016]$.

Salas, D. (2013): Vers une politique pénale de gauche? Études 10/419, pp. 307-316.

Sampson, R.J. \& Laub, J.H. (2003): Desistance from Crime over the Life Course, in: J.T. Mortimer \& M. Shanahan (eds.), Handbook of the Life Course. New York, pp. 295-310.

Smith, P., Gendreau, P. \& Goggin, C. (2002): The Effects of Prison Sentences and Intermediate Sanctions on Recidivism: General effects and individual differences. Ottawa.

The Hofstede Centre (2012): Long-Term Orientation versus Short-Term Normative Orientation (LTO); http://research-methodology.net/hofstedes-cultural-dimensio ns-2/ [16/02/2017].

Tournier, P.-V. (2016): État de la population sous écrou au 1er avril 2016 et évolution sur un an. Statistics communicated by the Observatoire de la privation de liberté et des sanctions et mesures appliquées dans la communauté, March 2016.

Urvoas, J.-J. (2016): Le ministère de la Justice n'a plus les moyens de payer ses factures. Le Journal du Dimanche, 2 April 2016; www.lejdd.fr/Societe/Justice/ Urvoas-Le-ministere-de-la-Justice-n-a-plus-lesmoyens-de-payer-ses-factures-77 9427 [16/02/2017]. 



\title{
Epilogue
}

\author{
Hans-Jörg Albrecht, Maria Walsh and Elke Wienhausen-Knezevic
}

The aim of this book and the workshop organized by the Max Planck Institute for Foreign and International Criminal Law (MPICC) was to provide some insight into the different ways young offenders experience judicial interventions as well as into their life transitions towards desistance. Discontinuities in the biographies of young repeat offenders typically start at an early age, contain contacts with the youth welfare centres and later on continue with constant interactions with the justice system. The disadvantages these young people experience before and further on during their criminal careers might still influence their lives after they have desisted from crime - even more so the more frequent and the harsher the interactions with the justice system were.

The authors took different methodological and theoretical approaches in examining young offenders' desistance from crime. Yet, they all agree that both internal and external factors are crucial for a person to desist from crime. However, some devote more meaning to internal, others to external factors. We want to summarize the main points and conclusions of each contribution.

Stephen Farrall outlined macro-level structures of desistance from crime. Hence, he emphasized that gender, ethnicity, age, the point in time, the economic system in the country one lives in, as well as the criminal justice system play key roles when it comes to desistance and persistence from crime. Moreover, Farrall argued that the criminal career itself structures a person's way into a concurrent lifestyle. He concluded that the wider context in which an individual operates shapes possibilities for desistance to occur.

Joanna Shapland and Anthony Bottoms stressed the influence friends have on one's lifestyle. They argued that desistance is a matter of temptation. Persistence can be the more exciting path. Hence, they pointed out the importance of social support given by concurrent individuals. As Diana Willems and Jana Meier elaborated, windows for desistance can be found in the biographies of delinquent youth. Yet they can be perishable. Furthermore, the same factors can either open or close these windows. The authors also attached great importance to the stabilization of supportive relationships for young delinquents.

The fourth contribution draws on a more internal approach to desistance. Mechthild Bereswill's paper dealt with the biographical discontinuity and conflicts incarceration has especially on young individuals. She argued that the unresolved conflicts 
and psychological stress both inside prison and in unstructured situations after prison release can hinder desistance.

Elke Wienhausen-Knezevic argued that "resources of recognition", as she calls it like an employment or a caring partnership, but also self-acknowledgement -, are able to initiate a process of desisting from crime. Her results show that the dynamic interplay of primarily five core categories, such as goals (in life), agency, resources, identity, and recognition is crucial for turning oneself around and for building up blocks for a crime-free life. Finally, she develops an interaction model for analysing trajectories of desistance and persistence in the same way after prison release.

Anke Neuber then took a gender-related perspective on desistance, reflecting on women's fragile transitions into desistance from a methodological stance. She argued that conflict-theoretical aspects and biographical analysis have a lot of potential for explaining desistance from crime. Hence, she stressed the importance of considering gender norms and differences in the analysis of narratives. Taking a biographical perspective in analysing desistance from crime was also the approach taken in Franz Zahradnik's paper. His case example emphasized the influence of generativity on desistance from crime, as well as the struggles and challenges in establishing a concurrent lifestyle. Based on two case examples, Walsh argued that apparent turning points are no guarantee for desistance to occur or to succeed. She stressed the importance of inner changes to arise as well. Furthermore, both external and internal factors might be reciprocally reliant to keep up the process of desistance from crime.

Jasmina Arnez' analysis on the professional perceptions of youth deviance and parenting style showed that views on social class might still play an important role. As the author argued, delinquency might not be a result of poor parenting but an institutional labelling based on a family's social backgrounds. Therefore, she demanded reasonable encounters in addressing problems of young delinquents and their parents.

Finally, a new French method in supporting prison release and desistance was introduced by Astrid Hirschelmann. The Quartiers pour peines aménagées (QPAs) obtain maturation and guidance for the detainees. They were implemented considering indispensable requirements for the promotion of desistance from crime. Still, there is the challenge of institutional release which terminates the professional relationship between detainees and wardens. As Hirschelmann argued, the human relationship with the detainee plays an essential role in promoting desistance.

We want to close these remarks by reiterating Stephen Farrall's demand that more studies from different countries would enrich the current research on desistance from crime. The differences between the justice systems, welfare systems, and cultures certainly influence the biographies of individuals and therefore also criminal desistance and persistence. In this book, the authors reported provided accounts of their research from Germany, Great Britain, France, and Switzerland and therefore lay ground for future research in the demanded direction. Yet there is still more to come. 


\section{Annex}

\section{Index of authors}

Professor em. Dr. Dr. h.c. mult. Hans-Jörg Albrecht was Director at the Max Planck Institute for Foreign and International Criminal Law in Freiburg/Germany. He teaches criminal law, criminal justice and criminology at the University of Freiburg. $\mathrm{He}$ is guest professor at the Center for Criminal Law and Criminal Justice of the China University of Political Science and Law, Beijing, at the Law Faculty of Hainan University, at the Law Faculty of Renmin University of China, Beijing, at the Law Faculty of Wuhan University, and at the Law Faculty of Beijing Normal University. He also holds a Life membership at the Clare Hall College at Cambridge University UK, a professorship and permanent faculty membership at the Faculty of Law of Qom High Education Center, Teheran/Iran, and is Honorary Member of the Serbian Section of Criminology at the University of Belgrade/Serbia. The research interests of Professor Albrecht are various legal, criminological and policy topics such as sentencing theory, juvenile crime, drug policies, environmental crime and organized crime, evaluation research, systems of criminal sanctions, empirical criminal procedure and security research. He has published, co-published and edited various books, among them on sentencing, day-fine systems, recidivism, child abuse and neglect, drug policies, research on victimisation, white-collar crime, etc. Professor Albrecht is editor-in-chief of the journal Monatsschrift für Kriminologie und Strafrechtsreform, co-editor of Déviance \& Société and Recht der Jugend und des Bildungswesens, and he is a member of Advisory Boards of numerous international journals. Professor Albrecht is also deputy spokesperson of the International Max Planck Research School on Retaliation, Mediation and Punishment (REMEP).

Jasmina Arnez is a doctoral researcher at the Centre for Criminology, Oxford, and an Economic and Social Research Council (ESRC) scholar. Her research interests include the intersections between social class, youth crime and the family and desistance processes in young offenders. Her thesis focuses on class-conditioned labeling effects of institutional responses to youth deviance and the experience of young offenders and their parents with transitions to desistance. It is supervised by Dr. Rachel Condry. Ms. Arnez completed a BA in Law, University of Ljubljana (2009) cum laude and an MPhil in Criminology and Criminal Justice, University of Oxford (2015) with distinction. Before commencing her doctorate, she worked as a judicial assistant at the District and Appellate Courts in Ljubljana. Her publications include articles on various topics linked to criminology. She is the founder and convenor of the Criminology Working Group at Green Templeton College, Oxford. Her research is funded by the ESRC. 
Dr. Mechthild Bereswill has been Professor for Sociology at Kassel University (Institute for Social Work and Social Welfare) since 2007. Her research interest and empirical projects are focused on gender studies (e.g. gender and violence), social problems and social control (e.g. prisonisation, juvenile detention centres) and qualitative methodologies (e.g. longitudinal studies and biographical approaches). After having studied sociology, social psychology and political sciences at Hanover University, she finished her $\mathrm{PhD}$ in gender studies and did her habilitation in sociology, also at Hanover University. From 1998 to 2006, Dr. Bereswill worked as a senior researcher at the Criminological Research Institute of Lower Saxony (KFN). There, she conducted two qualitative longitudinal studies on the effects of incarceration on biographical processes of young male offenders. She is a co-editor of the journal Soziale Probleme and a member of the board of the section Soziale Probleme und soziale Kontrolle of the German Association of Sociology (DGS).

Professor Sir Anthony Bottoms is Emeritus Wolfson Professor of Criminology, University of Cambridge, Life Fellow of Fitzwilliam College, Cambridge, and Honorary Professor of Criminology, University of Sheffield. He is Director of the Centre for Penal Theory and Penal Ethics in the Institute of Criminology, Cambridge. In 2007, he was presented with the European Criminology Award by the European Society of Criminology, for lifetime contributions to European Criminology, and in 1996, he was presented with the Sellin-Glueck Award by the American Society of Criminology, for international contributions to criminology. In 2001, Professor Bottoms was appointed Knight Bachelor for services to the British criminal justice system. Since 1997, he has been Fellow of the British Academy and Honorary Fellow of Corpus Christi College, Oxford, and recipient of honorary degrees from Sheffield University (LL.D.), Queen's University Belfast (LL.D.), and Malmö University (Ph.D.).

Stephen Farrall is Research Professor in Criminology at the University of Derby and Honorary Professor of Criminology at the University of Sheffield. He has been studying desistance from crime since the early 1990s, running a prospective longitudinal study of this topic since 1996. His other research interests include the fear of crime, middle-class crimes, and crime histories. Professor Farrall is on the editorial boards of the British Journal of Criminology and the European Journal of Criminology.

Dr. Astrid Hirschelmann is a professor for clinical psychology and psychopathology at the University of Caen (Normandy). She was senior lecturer at the University of Rennes 2 for 18 years, co-director of the CIAPHS (Interdisciplinary Centre for the Analysis of Human and Social Processes) for four years and a member of the Institute of Criminology and Human Sciences. Recently she has concentrated on criminal 
processes, the prevention of recidivism and restorative justice. In her thesis, she assigns a central role to the notion of conflict so as to better understand criminal behaviour and offender-victim relationships. Astrid Hirschelmann is mainly interested in issues related to offenders' feelings of responsibility as well as the difficulties and defence mechanisms both offenders and victims develop after criminal acts. From 2012 to 2014, she has coordinated the lifelong-learning intensive Erasmus programme "Violence and Entrapment: Practice and Ethic" at the University of Rennes. For several years, she has been working for the French Penitentiary Administration and has elaborated a national training programme on risk assessment and management that is currently developed by probation officers in France.

Jana Meier (Dipl.-Soz., M.A. International Criminology) has been working for the Criminological Institute at the University of Cologne since 2015. She is involved in the research project "Illegal drug markets within and outside of prisons". From 2011 to 2014, she worked as a researcher for the German Youth Institute (DJI) in the project "Careers of young multiple offenders between youth services and the justice system". Prior to that, she had worked as a researcher for the Association of Public Transport Companies Berlin-Brandenburg from 2009 to 2011 on people's sense of security within public transportation.

Professor Dr. Anke Neuber has a diploma in social science and a $\mathrm{PhD}$ in sociology. She wrote her $\mathrm{PhD}$ about the relation between violence and masculinity in young men in prison from a biographical and a gender-theory perspective. This work was associated at the Criminological Research Institute of Lower Saxony and is based on interviews conducted in the qualitative part of the project "The consequences of incarceration". Currently, Dr. Neuber is a professor for sociology at the Faculty of Social Work at the Ostfalia University of Applied Sciences Braunschweig/Wolfenbüttel and also teaches criminology in master courses. Her research areas are deviance, adolescence and gender, transition processes, methods and methodologies of qualitative research, youth offenders' institutions, (youth) violence, gender theories, and masculinity studies.

Professor Joanna Shapland is Edward Bramley Professor of Criminal Justice at the University of Sheffield, UK, and Director of the Centre for Criminological Research. The Sheffield Desistance Study was directed by Professor Anthony Bottoms and herself and funded by the Economic and Social Research Council. Professor Shapland's research interests cover a number of areas of criminology and criminal justice, including victimology, restorative justice and the informal economy, as well as desistance. In 2013, she won the Outstanding Achievement Award of the British Society of Criminology. Following this award, she has been named an Honorary Member 
at the BSC in 2016. She is Executive Editor of the International Review of Victimology.

Dr. Maria Walsh has a Magister Artium in educational sciences, criminology and psychology and a $\mathrm{PhD}$ in educational sciences and criminology. She worked as a researcher at the Max Planck Institute for Foreign and International Criminal Law from 2011 to 2013. From 2013 to 2015, Maria Walsh was a PhD candidate of the International Max Planck Research School on Retaliation Mediation and Punishment (IMPRS REMEP). Since 2016, she has been a researcher at the National Center for Crime Prevention where she was named deputy head in 2017.

Elke Wienhausen-Knezevic (Dipl.-Soz., LL.M. Crim.) majored in sociology, psychology, criminology and criminal justice. She worked as a researcher within the project "Juvenile Sexual Offenders in the Correctional Treatment Facilities of the Free State of Saxony" at the Max Planck Institute for Foreign and International Criminal Law from 2009 until 2017 and completed her PhD under the supervision of Prof. Hans-Jörg Albrecht. Wienhausen-Knezevic studied in Munich, Greifswald and Freiburg and received her $\mathrm{PhD}$ in sociology and criminology at the Albert Ludwig University Freiburg in 2016. Since October 2017, she has been working as a researcher at the University of Bern (Switzerland), Institute for Penal Law and Criminology.

Dr. Diana Willems (Dipl.-Soz., M.A. Sociology of Law) has been working at the Centre for the Prevention of Youth Crime, German Youth Institute (DJI), as a senior researcher since 2011. From 2007 to 2011, she worked at the Department of Criminology, Criminal Policy and Police Science at Ruhr University Bochum and between 2004 and 2007 as a researcher at the Department of Criminology and Criminal Law, Martin Luther University of Halle-Wittenberg. Dr. Willems studied in Regensburg, Munich and Oñati (Spain) and received her PhD at the Martin Luther University of Halle-Wittenberg.

Dr. Franz Zahradnik (Dipl.-Soz.) worked from 2008 to 2014 at the Institute for Employment Research in Nuremberg where his main research topic was "Welfare Sanctions against Young Unemployed". This is also the subject of his doctoral thesis which is supervised at the University of Kassel. Since April 2014, Dr. Zahradnik has been working at the University of Zurich (Institute of Educational Science) and is part of the research project "Ways out of Delinquency - Reintegration of Young Convicted Offenders" which is funded by the Swiss National Science Foundation. 


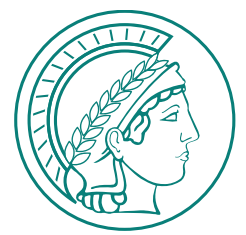

\title{
Programme of the Workshop
}

\section{Desistance Processes among Young Offenders following Judicial Interventions}

\author{
31 March - 01 April 2016 \\ Freiburg i. Br./Germany
}

Thursday, 31 March 2016

\begin{tabular}{|c|c|}
\hline 9:00 & $\begin{array}{l}\text { Introduction to the topic and research overview } \\
\text { Prof. Hans-Jörg Albrecht, MPICC }\end{array}$ \\
\hline \multirow[t]{2}{*}{$9: 15$} & Chair: Maria Walsh \\
\hline & $\begin{array}{l}\text { Theorizing structural and individual-level processes in de- } \\
\text { sistance and persistence } \\
\text { Prof. Stephen Farrall, University of Sheffield (via Skype) }\end{array}$ \\
\hline $9: 45$ & $\begin{array}{l}\text { Interactions between agency and social structures in early } \\
\text { desistance in young adults: Findings from the Sheffield } \\
\text { Desistance Study } \\
\text { Prof. Joanna Shapland, University of Sheffield }\end{array}$ \\
\hline 10:15-10:45 & Coffee Break \\
\hline \multirow[t]{2}{*}{$10: 45$} & Chair: Prof. Joanna Shapland \\
\hline & $\begin{array}{l}\text { In and out - Young multiple offenders in between youth } \\
\text { services and the justice system } \\
\text { Dr. Diana Willems, German Youth Institute }\end{array}$ \\
\hline
\end{tabular}




\begin{tabular}{|c|c|}
\hline $11: 15$ & $\begin{array}{l}\text { Desistance as psycho-social process in the context of bio- } \\
\text { graphical discontinuity } \\
\text { Prof. Mechthild Bereswill, University of Kassel }\end{array}$ \\
\hline $11: 45$ & $\begin{array}{l}\text { Life-course dynamics among young prison releasees. An } \\
\text { empirical interaction model (ZARIA Scheme) for analys- } \\
\text { ing trajectories after prison release } \\
\text { Elke Wienhausen-Knezevic, MPICC }\end{array}$ \\
\hline $12: 15-13: 30$ & Lunch Break \\
\hline $13: 30$ & Chair: Prof. Mechthild Bereswill \\
\hline & $\begin{array}{l}\text { Early desistance from crime: prisoners' pre-release expec- } \\
\text { tations and their post-release criminal behavior } \\
\text { Jennifer Doekhie, University of Leiden }\end{array}$ \\
\hline $14: 00$ & $\begin{array}{l}\text { Fragile transitions - methodological considerations on } \\
\text { young women's processes of desistance } \\
\text { Dr. Anke Neuber, University of Kassel }\end{array}$ \\
\hline $14: 30-15: 00$ & Coffee Break \\
\hline $15: 00$ & $\begin{array}{l}\text { Young offenders in Russia: research in a detention center } \\
\text { Prof. Oksana Ilchenko, Far Eastern Federal University }\end{array}$ \\
\hline $15: 30-16: 15$ & Discussion \\
\hline
\end{tabular}

Friday, 1 April 2016

\begin{tabular}{|l|l|}
\hline 9:00 & Chair: Elke Wienhausen-Knezevic \\
\cline { 2 - 3 } & $\begin{array}{l}\text { Generativity and the struggle of young offenders for desistance } \\
- \text { theoretical considerations and empirical explorations } \\
\text { Franz Zahradnik, University of Zurich }\end{array}$ \\
\hline $9: 30$ & $\begin{array}{l}\text { Judicial interventions as turning points? The potential of judi- } \\
\text { cial interventions in promoting desistance from crime } \\
\text { Maria Walsh, MPICC }\end{array}$ \\
\hline
\end{tabular}




\begin{tabular}{|l|l|}
\hline 10:00 & $\begin{array}{l}\text { How restorative justice practices in prison can promote de- } \\
\text { sistance from crime. Or does it? } \\
\text { Dr. Bart Claes, University of Sheffield }\end{array}$ \\
\hline $\mathbf{1 0 : 3 0 - 1 0 : 4 5}$ & Short Coffee Break \\
\hline 10:45 & $\begin{array}{l}\text { Chair: Maria Walsh } \\
\text { Youth deviance and parenting styles: exploring the role of so- } \\
\text { sistance from crime through the perceptions of professionals } \\
\text { working with young offenders and their families } \\
\text { Jasmina Arnez, University of Oxford }\end{array}$ \\
\hline $11: 15$ & $\begin{array}{l}\text { Focus on new French devices and methods to support the re- } \\
\text { lease from prison and the desistance process } \\
\text { Dr. Astrid Hirschelmann, University of Rennes }\end{array}$ \\
\hline $11: 45$ & $\begin{array}{l}\text { Sex offenders' life course after release. Preliminary results of } \\
\text { a qualitative approach to re-entry processes and pathways to } \\
\text { desistance and/or recidivism } \\
\text { Kira Gauder, MPICC }\end{array}$ \\
\hline $\mathbf{1 3 : 0 0}$ & $\begin{array}{l}\text { Discussion } \\
\text { Departure }\end{array}$ \\
\hline $13: 00$ & \\
\hline 15
\end{tabular}



Schriftenreihe des Max-Planck-Instituts für ausländisches und internationales Strafrecht

Die zentralen Veröffentlichungen des Max-Planck-Instituts für ausländisches und internationales Strafrecht werden in Zusammenarbeit mit dem Verlag Duncker \& Humblot in den folgenden fünf Unterreihen der „Schriftenreihe des Max-Planck-Instituts für ausländisches und internationales Strafrecht" vertrieben:

- „Strafrechtliche Forschungsberichte“,

- „Kriminologische Forschungsberichte“,

- „Interdisziplinäre Forschungen aus Strafrecht und Kriminologie“

- „Publications of the Max Planck Partner Group for Balkan Criminology“ sowie

- „Sammlung ausländischer Strafgesetzbücher in deutscher Übersetzung“.

Diese Publikationen können direkt über das Max-Planck-Institut unter www.mpicc.de oder über den Verlag Duncker \& Humblot unter www.duncker-humblot.de erworben werden.

Darüber hinaus erscheinen im Hausverlag des Max-Planck-Instituts in der Unterreihe „research in brief" zusammenfassende Kurzbeschreibungen von Forschungsergebnissen und in der Unterreihe „Arbeitsberichte“ Veröffentlichungen vorläufiger Forschungsergebnisse. Diese Veröffentlichungen können über das Max-Planck-Institut bezogen werden.

Detaillierte Informationen zu den einzelnen Publikationen sind unter www.mpicc.de abrufbar.

Research Series of the Max Planck Institute for Foreign and International Criminal Law

The main research activities of the Max Planck Institute for Foreign and International Criminal Law are published in the following five subseries of the "Schriftenreihe des MaxPlanck-Instituts für ausländisches und internationales Strafrecht/Research Series of the Max Planck Institute for Foreign and International Criminal Law", which are distributed in cooperation with the publisher Duncker \& Humblot:

- "Strafrechtliche Forschungsberichte" (Reports on Research in Criminal Law),

- "Kriminologische Forschungsberichte" (Reports on Research in Criminology),

- "Interdisziplinäre Forschungen aus Strafrecht und Kriminologie" (Reports on Interdisciplinary Research in Criminal Law and Criminology),

- "Publications of the Max Planck Partner Group for Balkan Criminology", and

- "Sammlung ausländischer Strafgesetzbücher in deutscher Übersetzung" (Collection of Foreign Criminal Laws in German Translation).

These publications can be ordered from the Max Planck Institute at www.mpicc.de or from Duncker \& Humblot at www.duncker-humblot.de.

Two additional subseries are published directly by the Max Planck Institute for Foreign and International Criminal Law: "research in brief" contains short reports on results of research activities, and "Arbeitsberichte" (working materials) present preliminary results of research projects. These publications are available at the Max Planck Institute.

Detailed information on all publications can be found at www.mpicc.de. 
Auswahl aktueller Publikationen aus der kriminologischen Veröffentlichungsreihe $\mathrm{K}$ :

K 181 Maria Walsh

Intensive Bewährungshilfe und junge Intensivtäter

Eine empirische Analyse des Einflusses von Intensivbewährungshilfe auf die kriminelle Karriere junger Mehrfachauffälliger in Bayern

Berlin 2018 • 210 Seiten • ISBN 978-3-86113-269-1

K 180 Linn Katharina Döring

Sozialarbeiter vor Gericht?

Grund und Grenzen einer Kriminalisierung unterlassener staatlicher

Schutzmaßnahmen in tödlichen Kinderschutzfällen in Deutschland und England

Berlin 2018 • 442 Seiten • ISBN 978-3-86113-268-4

$€ 42$,-

K 179 Michael Kilchling

Opferschutz innerhalb und außerhalb des Strafrechts

Perspektiven zur Übertragung opferschützender Normen aus dem

Strafverfahrensrecht in andere Verfahrensordnungen

Berlin 2018 • 165 Seiten • ISBN 978-3-86113-267-7

$€ 32,-$

K 177 Tillmann Bartsch, Martin Brandenstein, Volker Grundies, Dieter

Hermann, Jens Puschke, Matthias Rau (Hrsg.)

50 Jahre Südwestdeutsche und Schweizerische Kriminologische

Kolloquien

Berlin 2017 • 312 Seiten • ISBN 978-3-86113-265-3

K 175 Michael Kilchling

Täter-Opfer-Ausgleich im Strafvollzug

Wissenschaftliche Begleitung des Modellprojekts Täter-Opfer-

Ausgleich im baden-württembergischen Justizvollzug

Berlin 2017 • 218 Seiten • ISBN 978-3-86113-262-2

$€ 35$,-

K 174 Min Kyung Han

The Effectiveness of Electronic Monitoring in Korea

Berlin 2017 • 210 Seiten • ISBN 978-3-86113-261-5

$€ 35$,-

K 173 Jing Lin

Compliance and Money Laundering Control by Banking Institutions

in China

Self-Control, Administrative Control, and Penal Control

Berlin 2016 • 222 Seiten • ISBN 978-3-86113-260-8

$€ 35$,-

K 172 Julia Kasselt

Die Ehre im Spiegel der Justiz

Eine Untersuchung zur Praxis deutscher Schwurgerichte

im Umgang mit dem Phänomen der Ehrenmorde

Berlin 2016 • 495 Seiten • ISBN 978-3-86113-255-4

$€ 42,-$ 
Auswahl aktueller Publikationen aus der kriminologischen Reihe BC und der interdisziplinären Reihe I:

BC 2 Sunčana Roksandić Vidlička

Prosecuting Serious Economic Crimes as International Crimes

A New Mandate for the ICC?

Berlin 2017 • 530 Seiten • ISBN 978-3-86113-264-6

$€ 44$,-

BC 1 Anna-Maria Getoš Kalac, Hans-Jörg Albrecht, Michael Kilchling (eds.)

Mapping the Criminological Landscape of the Balkans

A Survey on Criminology and Crime

with an Expedition into the Criminal Landscape of the Balkans

Berlin 2014 • 540 Seiten • ISBN 978-3-86113-248-6

$€ 44,-$

I 25 Chenguang Zhao

The ICC and China

The Principle of Complementarity and National

Implementation of International Criminal Law

Berlin 2017 • 245 Seiten • ISBN 978-3-86113-266-0

$€ 35$,-

I 24 Ulrich Sieber (Hrsg.)

Strafrecht in einer globalen Welt

Internationales Kolloquium zum Gedenken an Professor Dr.

Hans-Heinrich Jescheck vom 7. bis 8. Januar 2011

Berlin 2016 • 200 Seiten • ISBN 978-3-86113-259-2

$€ 30,-$

I 23 Hans-Jörg Albrecht (Hrsg.)

Kriminalität, Kriminalitätskontrolle, Strafvollzug und Menschenrechte

Internationales Kolloquium zum Gedenken an Professor Dr.

Günther Kaiser am 23. Januar 2009

Berlin 2016 • 176 Seiten • ISBN 978-3-86113-258-5

$€ 30,-$

I 22 Claudia Carolin Klüpfel

Die Vollzugspraxis des Umweltstraf- und Umweltordnungswidrigkeitenrechts

Eine empirische Untersuchung zur aktuellen Anwendungspraxis sowie Entwicklung des Fallspektrums und des Verfahrensgangs seit den 1980er Jahren

Berlin 2016 • 278 Seiten • ISBN 978-3-86113-257-8

$€ 35,-$

\section{21 Tanja Leibold}

Der Deal im Steuerstrafrecht

Die Verständigung gemäß $§ 257$ c StPO in der Systematik des formellen und materiellen Rechts

Berlin 2016 • 254 Seiten • ISBN 978-3-86113-256-1

$€ 35$,- 
